\title{
ESTIMABILIDADE EM DELINEAMENTOS DESCONEXOS
}

OMARUDON FEROLDABNOD OAEDUONA YOLCA

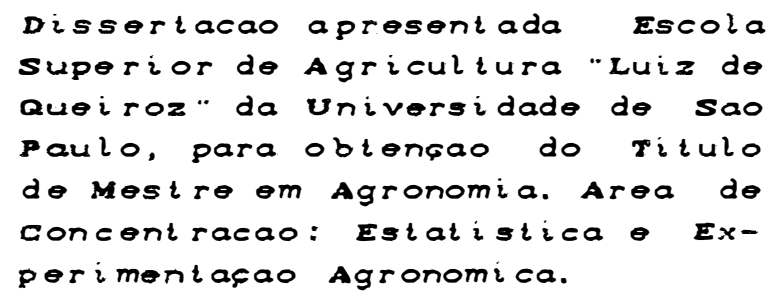

P I R A C I C A B A

Estado de São Paulo - Brasil

Novembro - 1990 


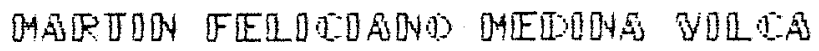

Orientador: PROF. DR. ANTONIO FRANCISCO IEMMA

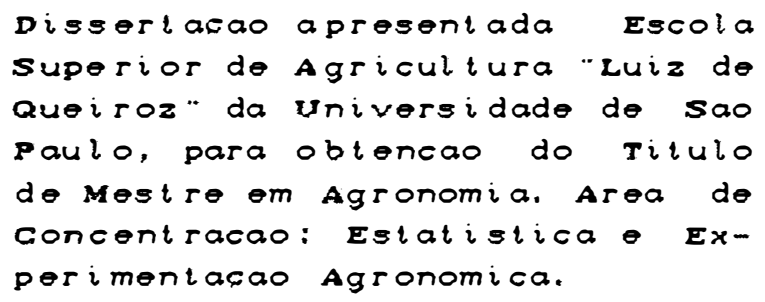

$P$ I R A C I C A B A

Estado de São Paulo - Brasil

Noyembro - 1990 
Ficha catalográfica preparada pela Seção de Livros da Divisão de Biblioteca e Documentação - PCAP/USP

Medina Vilca, Martin Feliciano

M49le Estimabilidade em delineamentos desconexos. Piracicaba, 199.

$125 \mathrm{p}$.

Diss. (Mestre) - ESALQ

Bibliografia.

1. Delineamento de experimento - Estimativa 2. Estatística agrícola 3. Modelo matemático I. Escola Superior de Agricultura Luiz de Queiroz, Piracicaba.

CDD $\quad 630.219$ 


\section{ESTIMABILIDADE EM DELINEAMENTOS DESCONEXOS}

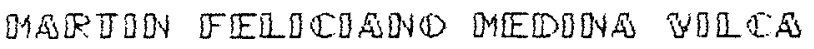

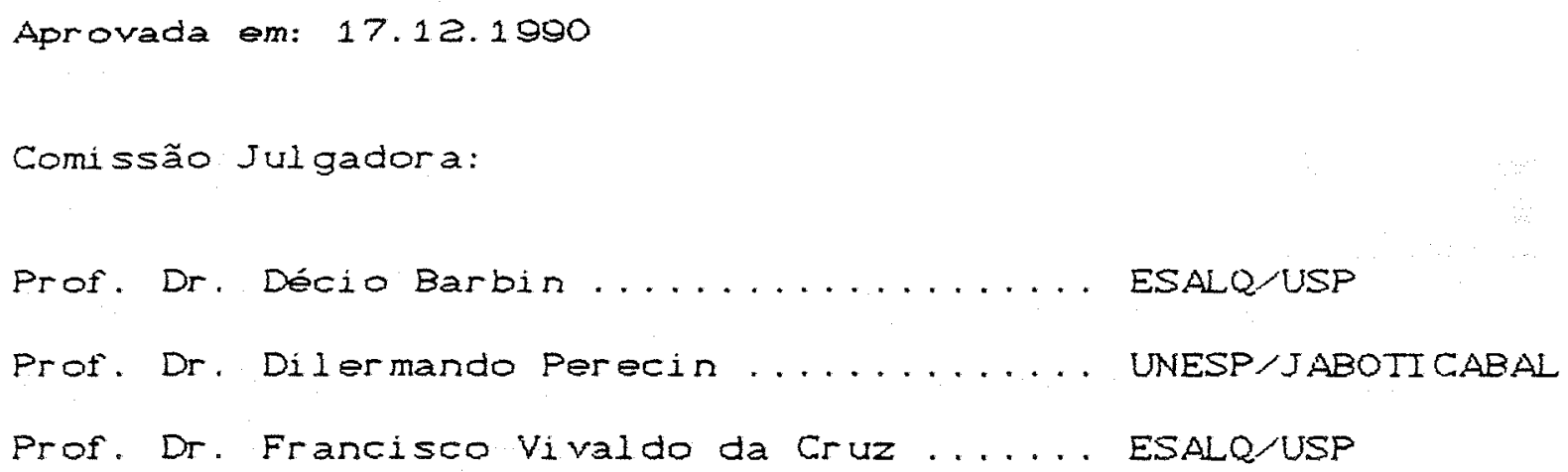


í.

Ao Altissimo por conceder-me

uma vida abundante

DEDICO

A minha măe (in memorian)

A mou Pai e Irmãos

OFEREÇO 


\section{AGRADECI MENTOS}

Ao Dr. Antonio Francisco Iemma, Professor Associado do Departamento de Matemática e Estatística da ESALQUSP, pela gentileza sensibilidade na sugestäo do assunto, orientacăo e apoio no decorrer dos estudos, para elaboracão deste trabal ho.

So Dr. Humberto de Gampos Diretor da ESALQ Prof. Iitular do Departamento de Matemática e Estatistica, pelo incondicional apoio e constante estimulo na minha permanência neste centro de estudos.

Aos professores do curso de Pós-Graduacão em Estatística E Experimentacão Agrônomica da ESALQ/USP, na pessoa de seu coordenador e muito amigo pessoal Prof. Dr. Décio Barbin pela compreensăo, receptividade e estímulos nos ensinamentos.

Ao Dr. Manuel Zeballos Vera, Ex-rector da Universidade Nacional Săo Agostinho, pelo valioso apoio incomensurável e oportunidade concedida para a realizacăo do curso.

Ao Departamento de Matemática Estatística e faculdade de Ciências Naturais e Formais pela licenca concedida.

Ao Consel ho Nacional de Desenvolvimento Científico e Tecnológico (CNPq) pela bolsa concedida.

A Gabriel Andrian' Sarries pelo apoio incondicional na elaboracão deste trabalho. 
A Maria Izalina Ferreira Alves pela amizade e constante estimulo na continuidade destes estudos.

Ao Prof. José Nivaldo Garcia do Departamento de Engenharia de Ciências Florestais pela amizade e estínulo na realizacăo deste trabalho, assim também a Luiz Eduardo Facăo, funcionário do mesmo Departamento.

Ao Prof. Sergio Duarto do Mascimento do Departamento de Irrigabà e Drengem pelag sugestós na redaço do trabalho.

Aos funcionários do Departamento de Matemática - Estatística da ESALQUSP, por sua simpatia e copperarăo oferecidas, nas pessoas de Luciane Bajăo e Rosa Maria Alves. Aos colegas do curso de Pós-Graduacão, pela vi vência, amizade o colaboracăo incondicionais.

Aos funcionários do Departamento de Economia em particular a Alice da Silva Gipriano, Luciane Gristina Martineli e Maria Angélica Amador Funaro.

A todos aqueles que contribuiram na realizacão deste trabal ho. 


\section{INDI CE}

Página

RESUMO

visi

SUMMARY

xi

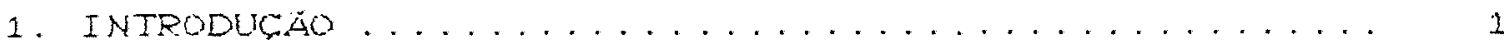

2. REVTSAO DE LITERATURA .................

Z.1. Introdurazo ..................

ə. E. Blocos Gasualizados .................. g

2. ᄅ. 1. Garacterizară ................ g

2. 2. 2. Equacŏes normais ............... 10

2. 3. Blocos Incompletos .................... 11

2. 3.1. G. assificacăo dos BIB ............ 13

2. 3. 2. o Modelo Linear ................... 15

2. 3. 3. Eficiència ................. 17

2. 4. Delineamentos em Blocos Incompletos Parcialmente Balanceados ................... 20

2.5. Equações Normais Reduzidas ............... 23

2. B. Estimabilidade ................... 27

2. 6. 1. Caracterizacão ............... 27

2. 6. 2. O Método dos Mínimos Quadrados ....... 28

2. 6. 3. BLUE CMelhor Estimador Linear Não Vie-

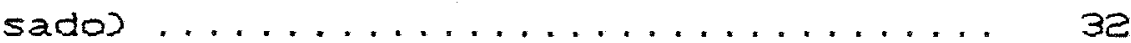

2.7. Influência dos Efeitos Fixos @ Aleatórios na Estimação de Parcelas ................. 33

2.7.1. Conceituasăo ................. 33

2.7.2. Caso em que os dois fatores são fixos. 34 
2.7. 3. Blocos Aleatórios e Tratamentos Fixos. 36

2.7.4. Caso em que Ambos fatores săo Aleató$r i o s \ldots \ldots \ldots \ldots \ldots$

3. METODOLOEIA ........................... 41

3.1. Conectividade ....................... 41

3.1.1. Conceito de conectividade ......... 41

3.1.2. Detinigoes e teoremas ............. 4己

3. 2. Modelos de Médias ................... 44

3.2.1. Conectividade em modelo de médias ..... 44

3.2.2. Exemplo do modelo de Graybill ........ 46

3. 2. 3. Modelo de médias simplificado . . . . . . 47

3.2. 4. Testes de hipóteses .............. s1

3. 2.5. Modelos conectados ............... 53

3. 2.5.1. Conceituacăo ............ 53

3. 2.5.2. Exemplo aplicativo ....... 54

3.2.6. Modelo de médias e algoritmo geométrico apresentado por Searle .......... 55

3. 2.6.1. Conceituaçăo ............ 56

3. 2. 6. 2. Um exemplo gráfico ........ 56

3.2.7. Modelo de médias de efeitos fixos de Hocking .................... 59

3.2.7.1. Modelo reduzi do .......... 61

3.2.7.2. Modelo efetivo........... 63

3.2.7.3. Exemplo de modelo reduzido de médias de HOCKING ......... 65 
vi i.

Página

3. 3. O Modelo Aditivo de Classificacăo de Dois Fatores de Efeitos Fixos Sem Inteirasăo ou Mode10 de DODGE (1985) .....................

3. 3.1. Conceituzçăo . . . . . . . . . . . . . 73

3. 3.2. o prosesso f .............. 79

3. 3. . Un processo alternativo .......... 81

3. 3. 4. Exemplo modelo ................. se

3. 3.5. Análise de variància ............. 87

3. 3.6. Cálculo da soma de quadrados de regressão ajustados para as diferentes fontes de variarăo ................. 88

3. 3. 6.1. Exemplo 2............. 90

4. EXEMPLOS APLICATI VOS EM DELINEAMENTOS DE DOIS FATO-

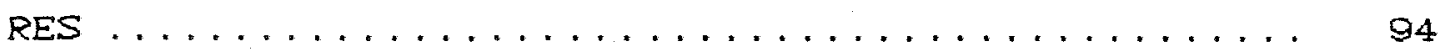

4.1. Delineamento em Blocos Incompletos .......... 94

4. 2. Modelo de Médias ..................... 94

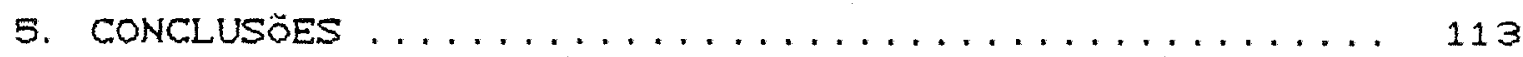

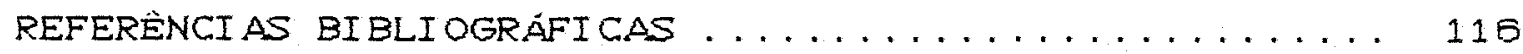


vi i i.

\section{ESTIMABILIDADE EM DELINEAMENTOS DESCONEXOS}

Autor: MARTIN FELICIANO MEDINA YILCA

Orientador: PROF. DR. ANTONIO FRANCISCO IEMMA

RESISMO

o presente trabal ho aborda estudos desenvolvidos sobre o tema de desconexão, como uma forma de determinar funçöes paramétricas estimáveis, mediante a obtencăo de contrastes em delineamentos de dois fatores, quando acontece perda de observacốes.

Com esse objetivo, apresentam-se os critérios mais importantes desenvolvidos na teoria de conectividade, bem como três dos mais usados algoritmos na deteccão de conecti vi dade.

0 modelo efetivo de médias apresentado por HOCKING (1985), o qual restringe o número dos parâmetros, é dado pela combinaçăo das suas médias. Neste modelo as médias das parcelas perdidas são dadas por $\mu_{m}$ e $\mu_{0}$, respectivamente. Através de um processo de reducão de linhas e reordenamento respectivo na matriz de restricão G, no modelo reduzido, são eliminadas do modelo as médias das parcelas perdidas $\mu_{m}$. Estas parcelas são representadas mediante contrastes em 
funcăo das parcelas conheridas, determinando-se deste modo, a conexăo ou desconexão do deli neamento.

- uso do algoritmo apresentado por DODGE (1985), conheci do como "Processo R", na situacăo de perda de parcelas considera-se a matriz de "Incidencia $N "$ a qual permite, por um processo iterativo, a obtencăo da matriz final $M$ que determina que parcelas săo estimáveis.

$$
\text { Medianto a doterminaro do triangulo contador }
$$

sao obtidos os contrastos estimaveis, tanto para o fator a, como o fator $\beta$. Obtidas as dimensoues dos fatores $\alpha=\beta$, determina-se as bases dos contrastes estimáveis, obtendo-se - "posto da matriz $x "$, e por conseguinte, os graus de liberdade para cada fator. Deste modo, ó estruturado o quadro de Análise de Variància.

Englobando estes dois procedimentos, utiliza-se alternativamente o método gráfico, como um instrumento de verificacão dos resultados obtidos pelos dois algoritmos citados. Como corolário, săo apresentados dois casos de delineamentos desconexos, analisados pelos dois algoritmos, obtendo-se resul tados semel hantes.

Tendo em vista os estudos realizados, estabeleceram-se dentre outras as seguintes conclusões:

- ostabelecimento de contrastes ortogonais entre os niveis de cada fator é uma alternativa eficiente para se estimar a perda de parcelas, prestando uma valiosa contribuicão na análise de variância e proporcionando os graus de liberdade para cada efeito. 
- o modelo efetivo de médias determina as estimativas dos contrastes das parcelas năo observadas em funcăo das parcelas observadas, que são vistas na particão final da matriz de restricăo $G$.

- o modelo efetivo de médias permite observar a estrutura de conexăo do delineamento de forma transparente, contribuindo na compreensăo dos problemas de conexäo estimabilidade de funcöes estimáveis. Essa metodologia poderia ser utilizada com finalidade didática.

- O processo $R$ é mais operante e funcional, atuando com sucesso nos casos de grande quantidade de dados, em relacăo ao modelo efetivo de médias, que emprega maior número de passos e tempo de operacão. 


\title{
ESTIMABILITY IN DISCONECTEDNESS DESIGNS
}

\author{
Author: MARTIN FELICIANO MEDINA VILCA \\ Adviser: PROF. DR. ANTONIO FRANCISCO IEMMA
}

SUMMARY

In the present work current literature about. the theory of desconnection is shown as mean to determine parametric functions estimability by contrasts in two factors design, with missing data.

Whith this purpose, the main facts abound desconection theory were studied as well as three of the most used algorithmy for detect connectedness.

The means effective model presented by HOCKING (1985), that restrained the numbers of parameters, is given by combinations of their respective means. In this model the means of parcels missing and of the parcels present are given for $\mu_{m}$ e $\mu_{0}$, respectively. The means of the missing parcels $\mu_{m}$ are eliminated from the model by a reduction rows process and reorganized respectively in the $G$ restric matrix in the reduced model. These parcels are represented by contrast in function of know parcels, determinating by this way the connectivity or desconnectedness of the design. 
The use of the algorithmy presented by DODGE (1985), namely the "R Process", in case of missing cells, considerate the incident "matrix $N$ " which enables the obtainment of the matrix M by a iterative process. This $13 s t$ matrix determinate which parcels are estimable.

The estimable contrasts are obtained, as for factor $\alpha$ as for factor $\beta$, by the determination of the triangle counter. After obtaining factors o and l? dimensicns, contrasts bases estimability are determined and the rank of the design matrix $2 x$ is obtained, wich lead to the determination of the grees of freedom for each factor. From this mode, the variance analise "Tableu" is conformed.

Inoluding these two proceedings, the grafic method is used alternatively as a instrument of verification of the results obtained by the two cited algorithmy. To check the proceeding two cases of desconnected design are presented and analised by each algorithmy, obtaining the same result.

The analysis of the results lead to the following conclusions:

- Ortogonal contrasts establishment between each fator level is a eficient alternative for missing parcels estimative, leading to a valuable contribution to the variance analise and giving the grees of freedom needed for each factor. 
- The effect model in means determinate the contrasts estimabilities of no the observed parcels in function of the observed parcels, which are obtained in the final G restric matrix partition.

- The efiect model in means permit obtainning the connectedness design structure in a transparent form, contributting to the connectedness problems comprehension and to the estimate functions estimability. This methodology can be used with didact purpose.

- The "R Process" is easier to opperate, working very well in cases of great number of data, in comparison with the effective model in means, which needs a great. number of passes and time of operation. 
A perda de parcelas nos delineamentos em blocos, especialmente nos blocos incompletos cbalanceados ou parcialmente balanceados acarreta, em determinadas situacões, há imposibilidade de se estimar certas combinacöes lineares dos parâmetros do modelo correspondente. Essa situacão caracteriza um delineamento desconexo, ou não conectado.

Dentre as funcóos lineares paramétricas, as de maior interesse prático são, em geral, os contrastes entre efeitos de tratamentos. Assim torna-se importante a disponibilidade de algoritmos eficientes que permitam evidenciar, num delineamento experimental desconexo, quais dessas funcões lineares são estimáveis e quais são os grupos de conexão do delineamento.

Um outro inconveniente em caso de perda de conexão é a dificuldade de se identificar o número de graus de liberdade de tratamentos ajustados para blocos e para a média, que em geral não são calculados substraindo-se uma unidade do número de tratamnetos, como é usual nos delineamentos conexos (bal anceados ou não).

Existem algoritmos que permitem estudar a estimabilidade de funcões lineares paramétricas baseados em 
processos matriciais, em geral muito onerosos em termos de memória e tempo de computacão.

Por outro lado a revisăo bibliográfica evidencià a ausência de publicacões sobre o tema, direcionadas para os verdadeiros e reais interessados, isto é, direcionadas aos usuários das ciências aplicadas.

Nesse contexto, aflora como um dos objetivos deste trabalho, dissertar sobre o problema da desconexáo de modo prático e direto, possibilitando, tanto quanto possivel a fixacăo a divulgacăo dos conceitos envolvidos entre os leitores das ciências aplicadas.

Para tanto, optou-se por abordar os delineamentos de classificąão dupla, por considerar-se que eles constituem um excelente recurso didático e por entender-se que a partir daí as generalizacões são muitas vezes imediatas. Sob essa filosofia são abordados vários modelos lineares como os superparametrizados as de médias de caselas, dentre outros, naturalmente são exaustivamente exemplificados. 


\section{REVISAO DA LITERATURA}

\subsection{Introduçâo}

E frequente, mesmo em bons planejamentos expe-

rimentais a perda de observacóes por diversas causas tais como acidentes, pestes, ausência do paciente, morte dentre outras, determinando desbalanceamento dos dados, especialmente em casos de delineamentos em blocos incompletos.

O estudo dos delineamentos com perda de parcelas têm sido considerado a várias décadas. Segundo Allan \& Wishart citado por YATES (1933) foram os primeiros em abordar este problema no ano de 1930 (ver também Tocher, 1952 . Eles fornecem duas fórmulas para estimar o valor de uma observacão perdida em delineamentos em blocos casualizados e quadrados latinos. Assim, considerando $y$ como o rendimento dependendo do fator bloco b do fator tratamento t pode-se expressar esta relacão funcional como $y=b_{i}+t_{j}+k$ onde $k$ é uma constante, e representa a producão de uma parcela perdida minimizando:

$$
\sum_{i j}^{n s-1}\left(y-b_{i}-t_{j}-k\right)^{2}
$$

sob $b_{i}, t_{j} e k$, tem-se 
4.

$$
k=\frac{(n+s-1) s-s s_{t}-n s_{b}}{(n-1)(s-1)}
$$

onde:

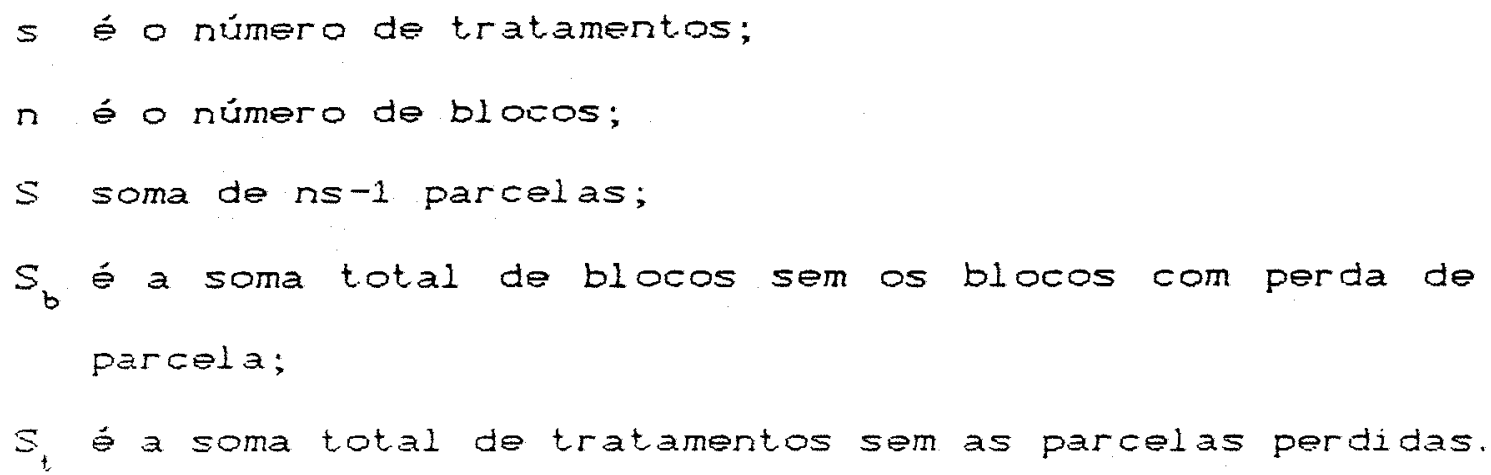

YATES (1933) aplica o critério de estimativas de observacões perdidas mediante a minimizacão de Soma de Quadrados dos residuos. Esse critério é recomendado posteriormente por TEDERCY (1955), COCHRAN \& COX (1957), JOHN (1971), TAYLOR (1948), NELDER (1954), NORTON (1955) THOMPSON (1958).

Se existir mais de uma observacão perdida YATES (1933) recomendou o uso da fórmula para o valor perdido iterativamente, comecando com um valor suposto para a parcela perdida, as iteracões continuam até que os residuos nas parcelas sejam despresíveis.

É importante ressaltar o fato que YATES (1933) apresenta um modelo linear

$$
Y=\mathscr{R} \theta+\varepsilon
$$

onde:

$$
\begin{aligned}
& y \text { é o vetor de } n \neq 1 \text { observacõos; } \\
& Y \text { é a matriz do delineamento } n \times p \text { de posto } r \text {, }
\end{aligned}
$$


$\theta$ é o vetor dos parâmetros desconhecidos $\theta$

- é o vetor dos elementos não observáveis e distribuídos independentemente com média zero e variância $\alpha^{2}$.

Com o objetivo de minimizar as observacöes perdidas, yATES (1933) particiona a expressăo inicial do modelo.

$$
\left[\begin{array}{l}
y_{1} \\
y_{2}
\end{array}\right]=\left[\begin{array}{l}
Z \\
Z \\
Z
\end{array}\right] \theta+\left[\begin{array}{l}
s_{1} \\
\varepsilon_{2}
\end{array}\right]
$$

considerando $m$ como o número de observacōes perdidas $e n$ total de observacões, de modo que $y_{z}$ Cde dimensão $m \times 1$ lé o vetor de observacões perdidas é $y_{1}$ Cde dimensão $\left.n \times 1\right)$ o vetor de observacóes presentes. Assim a soma de quadrados dos residuos fica:

$$
\begin{aligned}
\left.\operatorname{se} \theta, y_{2}\right) & =(y-2 R \theta) \cdot(y-Z R \theta) \\
& =\left\|y_{1}-R_{1} \theta\right\|^{2}+\left\|y_{2}-\not R_{2} \theta\right\|^{2} \\
& =S_{1}(\theta)+S_{2}\left(y_{2} \theta\right)
\end{aligned}
$$

então é possivel minimizar a soma de quadrados do resíduo com respeito aos parâmetros $\theta \theta y_{z}$ obtendo-se primeiramente a sol ucão para $\theta$ como se não existissem observacóos perdidas - dizer tanto, no processo de obter o estimador $\hat{\theta}$ como na solucão de mínimos quadrados do residuo são funcões de $y$.

$$
\text { CORNISH (1940) extendeu o método de yATES }
$$

(1933) para cobrir um amplo espectro de delineamentos experimentais.

HEALY \& WESTMACOTT (1956) propuseram um método iterativo para estimativas de observacões perdidas. 
6.

HARTLEY (1956) apresentou uma técnica para estimar quando existir apenas uma observacão perdida.

BARTHELL (1937) apontou um procedimento não iterativo, alternativo no caso de observacóes perdidas, completando os dados com o valor zero nas $m$ observacóes perdidas e contírmou que seu método era similar ao método de YATES $(1933)$

TOCHER (1952) proposs um modelo de análise padrá baseado no uso da notacăo matricial a partir da qual as observacbes perdidas săo est.imadas e corrigidas.

WILKINSON (1958) baseado no modelo particionado de YATES (1933) o qual admite perdas de observacôes apresenta uma fórmula explicita para delineamentos padróos e prova que a expressão $y_{z}=Z_{z} \theta$ é esti mável sendo que $y_{z}$ corresponde as observacões perdidas, fato que indica $\hat{y}_{2}=Z_{2} \hat{\theta}$, esta expressão é chamada sol ução de minimos quadrados para $\hat{y}_{2}$. É importante ressaltar que se o posto de $Z_{1}$ é igual ao posto de $\not R$ então a restricão imposta a $\theta$ é suficiente para garantir a unicidade de $\hat{\theta}$ unicamente no caso em que o delineamento da matriz $Z R$ é de posto máximo. Assim por mi nimizacão da soma de quadrados do resíduo com respeito aos parâmetros não conhecidos $\theta e$ os valores não conhecidos $y_{2}$, após o. processo se tem

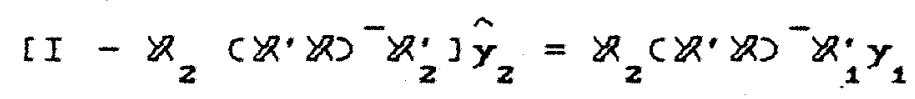

- que implica que a esperanca dos valores perdidos é

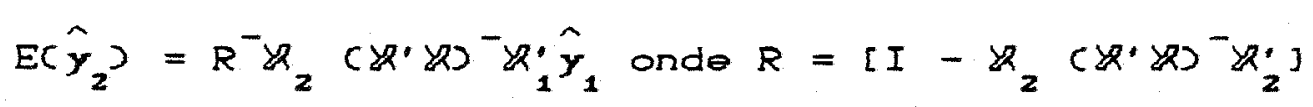


O citado autor observa que a coluna de ordem I da matriz do lado esquerdo [de 2.1$]$ chamada matriz $R$ é um vetor dos resíduos obtidos pela análise de um vetor de dados simulados com 1 na i-ésima observacão perdida (de ordem 1 ) e zero nas outras parcelas; e do lado direito de [2.1 ] consiste nos menores residuos p nas parcelas perdidas quando o dado observado $y_{1}$ é aumentado pelos valores ficticios, ou seja, zeros nas parcelas perdidas. Assim se m observacŏes săo perdidas em um delineamento experimental, pode-se proceder a uma série de $m+1$ análises padräo com vetores de dados inscrevendo os residuos nas parcelas perdidas e resol vendo as equacõos

$$
\begin{gathered}
{\left[R \hat{\mathbf{Y}}_{2}=-\rho\right]} \\
\text { RUBIN (1972) apresentou um algoritmo simples }
\end{gathered}
$$
baseado na análise de covariância o qual obtem-se a matriz $R_{m \times m}$ e o vetor $\rho_{m \times 1}$, onde $m$ são as observacões perdidas.

Assim mediante uma subrotina do algoritmo é possivel encontrar-se uma matriz simétrica $R_{m \times m}$. Entretanto se a matriz $R$ for singular o método de Rubin não tem solucão. Rubin acrescenta algumas ideias nas quais a matriz singular $R$ corresponde a uma solucão onde se tenta estimar um parâmetro para o qual não existem dados.

HASSEMAN \& GAYLOR (1973) apresentaram um procedimento simples não iterativo para a obtencão de valores perdidos, resol vendo um conjunto de equacóes i ineares simultâneas onde a matriz de delineamento deve ser "conectada". No caso de ausência de dados a matriz de coeficientes "R" é 
singular onde $R$ é a matriz dos residuos; neste caso os valores perdidos podem ser estimados por aplicacão de algoritmos dentro dos grupos de dados desconectados, levando-se em consideracăo o numero de 1 i rihas e colunas. Os mesmos autores apresentaram um procedimento similar para o caso de estimacão de valores perdidos numa classificacão cruzada de p fatores.

JOHN (1980), ARTHANARE \& DODGE (1981) estudaram as diterencas dos delineamentos em blocos incompletos utilizando a matriz de incidència "N", obtendo-se nesse trabalho uma contribuição importante no desenvolvimento de algoritmos para deteção de conectividade.

Posteriormente LI (1982) apresentou um estudo de aproximacão para conduzir a análise experimental de classificacăo dupla com dados não balanceados, através da solucão de equacóes lineares simultâneas. Os métodos descritos de estimacão de valores perdidos são somente uma solucão parcial do probiema, pois todos requerem a inclusão de uma matriz singular, quando o delineamentos da matriz original $\backslash$ não é de posto máximo.

\subsection{Blocos Casualizados}

Trata-se de um modelo linear para experimentos com um fator e uma restricăo na casualizacão. Em múltiplos experimentos quando a natureza do material experimental é heterogênea, é recomendável a formacão de blocos com o obje- 
tivo de reduzir a variacăo residual, agrupando o material experimental em blocos homogèneos.

2.2.1. Caracterizaçăo

- modelo linear que representa esse delineamento experimental apresentado por IEMMA (1987) é o seguinte:

$$
y=z x e+\varepsilon
$$

Gauss Markov Normal

onde ${ }_{b} y_{1}$ é o vetor de realizacóes de variáveis aleatórias $y^{\prime}=\left[y_{11}, \ldots, y_{1 v} ; y_{z_{1}}, \ldots, y_{2 v} ; \ldots ; y_{b_{1}}, \ldots, y_{b v}\right]$ e $b v_{1+b+v}$ é a matriz conhecida do delineamento de posto $b+v-1$

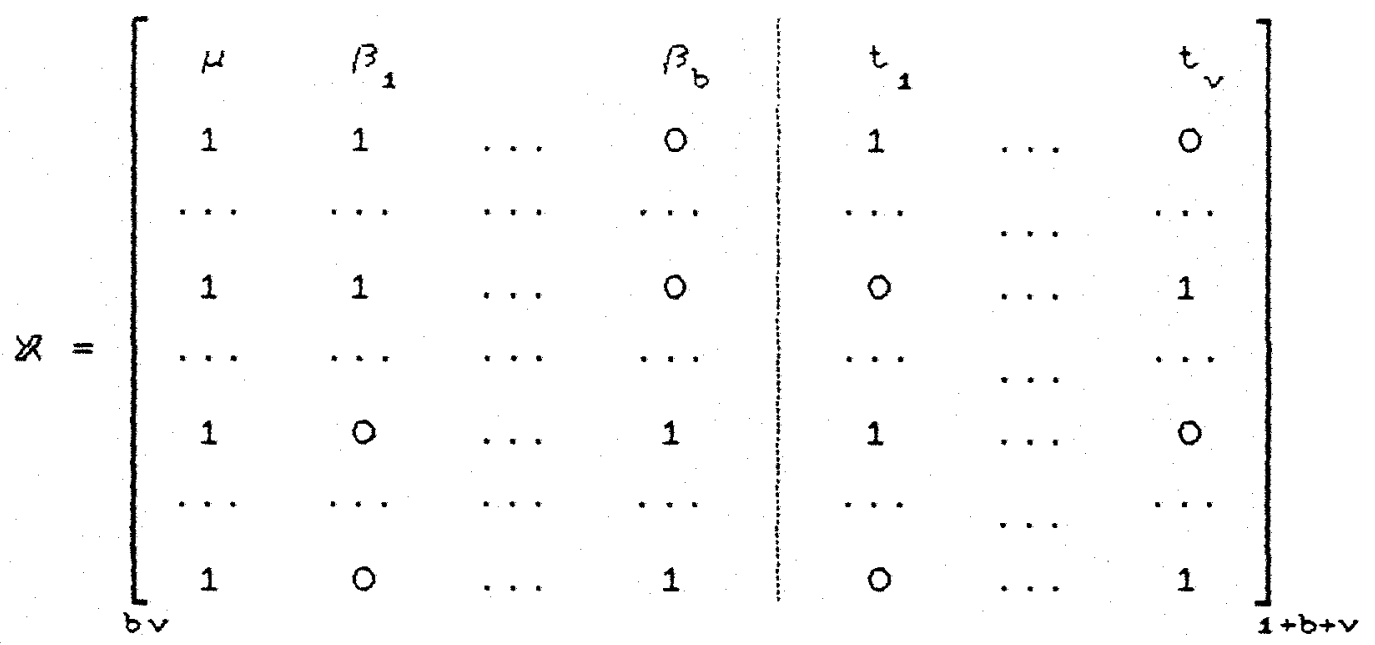

$$
\begin{aligned}
& =\left[Z_{1}: Z_{3}: Z_{0}\right]
\end{aligned}
$$

$1+b+v_{1}$ é um vetor de parâmetros desconhecidos

$$
\theta=\left[\begin{array}{l}
\beta \\
\beta \\
\tau
\end{array}\right] \quad \beta=\left[\begin{array}{l}
\beta_{1} \\
\cdots \\
\beta_{b}
\end{array}\right] ; \quad \tau=\left[\begin{array}{c}
\tau_{1} \\
\cdots \\
\tau_{v}
\end{array}\right]
$$

$b^{\varepsilon}{ }_{1}$ é um vetor de variáveis aleatórias não observáveis, tal que 


$$
e \sim N\left(\phi, I \alpha^{2}\right)
$$

e cuja caracterizacão é $y_{i j}=\mu+\beta_{i}+\tau_{j}+e_{i j}$, onde $i=1$, $2, \ldots, b$ blocos $e j=1,2, \ldots, v$ tratamentos

$$
\begin{aligned}
& y_{i j} \text { o valor observado na parcela do bloco i que recebeu } \\
& \text { - tratamento j } \\
& \text { H é uma constante inerente a todas as observacões; } \\
& \beta_{i} \text { é o efeito do bloco i } \\
& \tau_{j} \text { é o efeito do tratamento } j \\
& \theta_{i j} \text { é o erro aleatório atribuido a observacăo } y_{i, j} \text { tal } \\
& \text { que } \theta_{i j} \sim N\left(0, \alpha^{2}\right) \text { posto }(Q)=b+v-1
\end{aligned}
$$

\subsubsection{Equaçởes normais}

Em geral o sistema de equacões normais em blocos casualizados dado por $\mathscr{R} R \theta^{\circ}=\ell^{\prime} y$, tem a forma:

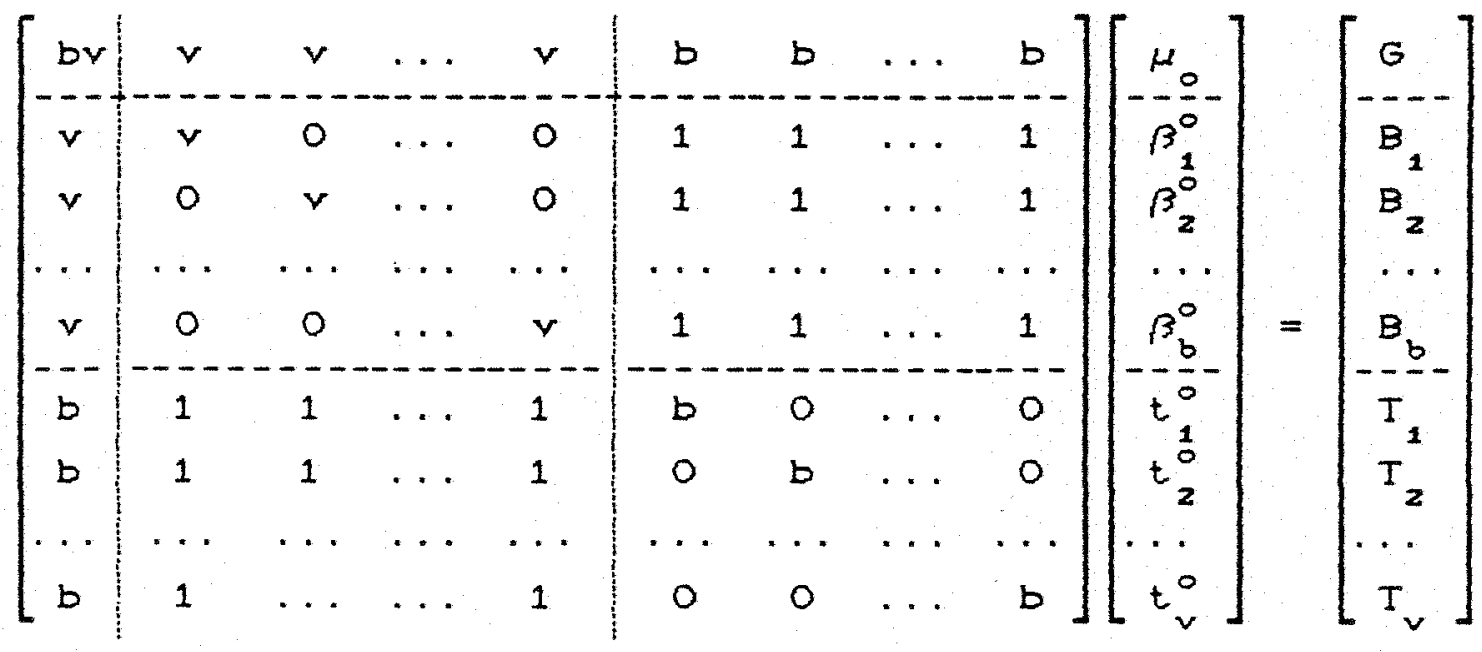

onde:

$G$ é o total geral, $B_{i}$ é o total observado no bloco i e $I_{j}$ é o total observado no tratamento $j$. 
Deste modo é possivel obter as solucóos para as equacõos normais. Em geral, para o sistema sem restricões - vetor solucão dado por

$$
e^{0}=\left(R^{\prime} 2 R\right)^{0} Z^{\prime} y
$$

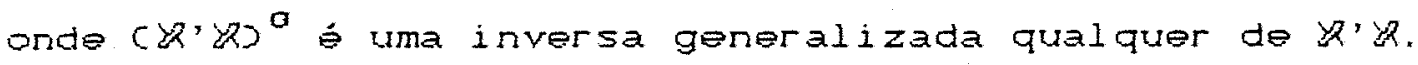

$$
\text { Sabendo-se que } \hat{y}=P y=y \theta^{\circ} \text { é invariante } \forall \theta^{\circ}
$$

solucăo das equacóes normais, obtem-se de maneira simples as somas de quadrados dos tratamentos; assim

$$
\text { SQT }=\text { SQPar }+ \text { SQR }
$$

onde:

$$
\begin{aligned}
& \text { SQT é a soma de Quadrados devida à variacão total; } \\
& \text { SQPar é a soma de quadrados dos efeitos métodos os parâ- } \\
& \text { metros; } \\
& \text { SQRes é a soma de quadrados devida ao efeito dos fatores } \\
& \text { não controlados. }
\end{aligned}
$$

\section{3. Blocos Incompletos}

Por razões econômicas e de homogeneidade do material experimental muitas vezes não é possivel a utilizacão de blocos que permitam a locacão de todos os tratamentos co número de unidades experimentais num bloco é menor que o número de tratamentoss. Essa situacăo identifica os Delineamentos em Blocos Incompletos.

Esses delineamentos foram introduzidos por

YATES (1936) quem generalizou o conceito dos ensaios em blocos e apresentou técnicas para análise de experimentos em blocos incompletos. 
12.

Autores como SCHEFFÉ (1959), CHAKRABARTI (1962), JOHN (1971), RAGHAYARAO (1971), GRAYBILL (1976), JOHN \& QUENOUILLE (1977) E DAS \& GHOSH (1985) consideram os ensaios em blooos incompletos balanceados (BIB) como aqueles obtidos por arranjos de $v$ tratamentos aplicados nas parcelas dos b blocos de tamanhos

$$
k_{1}, K_{2}, \ldots, K_{v}
$$

onde $C K<w e$ sendo que o i-esimo tratamento ocorre em $r_{i}$ blocos, os tratamentos i, $i$, ocorrem juntos em $\lambda_{i i}$ blocos onde

$$
\begin{aligned}
& (\lambda<b),(i, i=1,2, \ldots, v ; i \neq i> \\
& \text { Considere-se } T_{i} \text { como o rendimento total para o }
\end{aligned}
$$
i-ésimo tratamento $\mathrm{B}_{j}$ como o total produzido no j-ésimo bloco $\left.c_{i}=1,2, \ldots, v ; j=1,2, \ldots, b\right)$ eseja

$$
T^{\prime}=C T_{1}+T_{2}+\ldots+T_{V} e^{\prime}=\left(B_{1}+B_{2}+\ldots+B_{b}{ }^{\prime} .\right.
$$

Define-se a matriz de Incidência $N=\left(n_{i j}{ }^{2}\right.$ de ordem $v \times b$ onde $n_{i j}$ e número de vezes que o $i$-esimo tratamento ocorre no j-ésimo bloco.

Nos BIB observam-se as seguintes propriedades:

i) o experimento consta de $\left[\begin{array}{l}v \\ 2\end{array}\right]$ pares de tratamentos e cada par ocorre em $\lambda$ blocos;

iis Cada bloco tem $\left[\begin{array}{l}k \\ 2\end{array}\right]$ pares de tratamentos, assim em b blocos tem-se b $\left[\begin{array}{l}k \\ 2\end{array}\right]$ pares de tratamentos. Desse modo

$$
\lambda\left[\begin{array}{l}
v \\
z
\end{array}\right]=b\left[\begin{array}{l}
k \\
2
\end{array}\right]
$$

e então $v \lambda(v-1)=b k(k-1)$. 
Além disso o número total de parcelas (n) pode ser obtido por bk ou $r v$. Assim a última expressão transforma-se em

$$
\lambda(v-1)=r(k-1)
$$

o que fornece uma condicão de balanceamento e permite isolar $\lambda$,

$$
\lambda=\left[\begin{array}{l}
v-2 \\
k-2
\end{array}\right]
$$

Os BIB satisfazem a desigualdade de FISHER (1940) $b \geq v$, consequentemente $r=k$ e por isso săo chamados delineamentos simétricos.

\section{3.1. Classificaça dos BIB}

Com o objetivo de apresentar os métodos de cálculo mais viáveis e aplicar um melhor controle reduzindo os erros exprimentais, COCHRAN \& COX (1957) IEMMA (1987) classificam os ensaios de BIB em 5 tipos:

i) BIB tipo I: Quando os blocos podem ser arranjados em repeticões de tratamentos,

- sendo que o números de repeticões é dada por

$$
r=\frac{\lambda(v-1)}{k-1}
$$

e o número necessário de blocos obtidos é

$$
\begin{gathered}
v \lambda(v-1)=b k(k-1) \\
b=\frac{v \lambda(v-1)}{k=!}
\end{gathered}
$$

- se b* o número de blocos por repeticão, então

$$
b^{*}=\frac{b}{r}
$$


ii) BIB tipo II: Quando os blocos năo podem ser arranjados em repeticöes, mas podem ser arranjados em grupos de repeticões, neste caso o número de blocos é

$$
\lambda=\left[\begin{array}{l}
r-2 \\
k-2
\end{array}\right]
$$

isto é verificado previamente ao se obter $\lambda$ o número de blocos para cada par de tratamentos, e a partir deste valor obter-se as repeticöes dos tratamentos; se este valor é comparado como total dos blocos, para obter-se b* bloros por repeticăo, entăo

$$
b^{*}=\frac{b}{r}
$$

se o valor resultante é fracionário; adota-se o tipo II.

iiis BIB III: Quando os blocos não podem ser arranjados en repeticões e nem mesmo em grupos de repeticões de tratamentos; o número de blocos para cada par de tratamentos será:

$$
\lambda=\frac{r(k-1)}{(2-1)}
$$

neste ensaio não é possível obter-se b* ao não cumprir a condição do tipo I, que consiste em que todos os tratamentos fossem repetidos o mesmo número de vezes em cada repeticão. Por outro lado năo é possivel obter um BIB tipo II $r^{*}=\frac{r}{g}$ onde g representa o número de grupos por bloco, portanto $\Rightarrow g$ $\in \mathbb{N}$ Cnão existe um $g$ pertencente a $\mathbb{N}$, tal que $r^{*}$ seja inteiro; nota-se que of é o conjunto de números naturais. 
iv) BIB IV: Quando o número de tratamentos é igual ao número de blocos. O número de blocos para cada par de tratamentos será

$$
\lambda=\left[\begin{array}{l}
x-2 \\
x-2
\end{array}\right]
$$

e o número de repetiqôes

$$
r=\lambda \frac{(v-1)}{x-1}
$$

Este esquema é um caso particular de um BIB do tipo III, no qual $b=V$. Acontece do mesmo modo para os casos $I$ \& II.

v) BIB tipo V: Quando o número total de parcelas é pequeno em relacăo ao número de tratamentos e de blocos, acarretando em pequeno número de graus de liberdade para o resíduo.

A esse respeito é importante notar, que qualquer dos tipos abordados anteriormente pode ser entendido como um BIB tipo V. Na verdade a grande maioria dos autores, com excecão daqueles que seguem COCHRAN e COX (1957) adota os três primeiros tipos.

\subsubsection{O Modelo Linear}

$$
\begin{gathered}
\text { De acordo com IEMMA (1987) se tem } \\
y=\not R \theta+e \quad \text { (GMN) }
\end{gathered}
$$

onde:

$$
\begin{gathered}
b_{v} \mathbf{y}_{1} \text { é um vetor de realizacóes de variáveis aleatórias } \\
\qquad y=\left[y_{11} \ldots y_{1 v}, y_{21} \ldots y_{z v}, y_{b 1} \ldots y_{b v}\right]
\end{gathered}
$$


$b R_{1+b+v}$ é a matriz conhecida do delineamento de posto col una $b+v-1$

\begin{tabular}{|c|c|c|c|c|c|c|}
\hline 1 & 1 & $\ldots$ & 0 & 1 & $\ldots$ & 0 \\
\hline$\cdots$ & $\cdots$ & $\cdots$ & $\cdots$ & $\cdots$ & $\cdots$ & $\cdots$ \\
\hline 1 & 1 & $\cdots$ & 0 & 0 & $\cdots$ & 1 \\
\hline$\cdots$ & $\ldots$ & $\cdots$ & 1 & 1 & $\cdots$ & 0 \\
\hline 1 & 0 & $\ldots$ & 1 & 1 & $\cdots$ & 0 \\
\hline$\cdots$ & $\cdots$ & $\cdots$ & $\cdots$ & . & $\cdots$ & $\cdots$ \\
\hline 1 & 0 & $\ldots$ & 1 & 8 & $\ldots$ & 0013 \\
\hline
\end{tabular}

sendo

$$
\begin{aligned}
& \theta=\left[\begin{array}{l}
\mu \\
\beta \\
\tau
\end{array}\right] \\
& \beta=\left[\begin{array}{l}
\beta_{i} \\
\cdots \\
\beta_{b}
\end{array}\right] \\
& \tau=\left[\begin{array}{l}
t_{j} \\
\cdots_{v} \\
t_{v}
\end{array}\right]
\end{aligned}
$$

A notacão o(1) na última componente da matriz do delineamento indica que o ull timo tratamento poderão estar presente no último bloco crefere-se aqui aos blocos incompletoss.

$b_{v}{ }_{1}$ é um vetor de variáveis aleatórias não observáveis, tal que e $N\left(\phi, I \sigma^{2}\right)$

- o-modelo apresenta a seguinte caracterizacão

$$
\begin{gathered}
y_{i j}=\mu+\beta_{i}+\tau_{j}+e_{i j} \\
i=1, \ldots, b \quad j=1, \ldots, v
\end{gathered}
$$




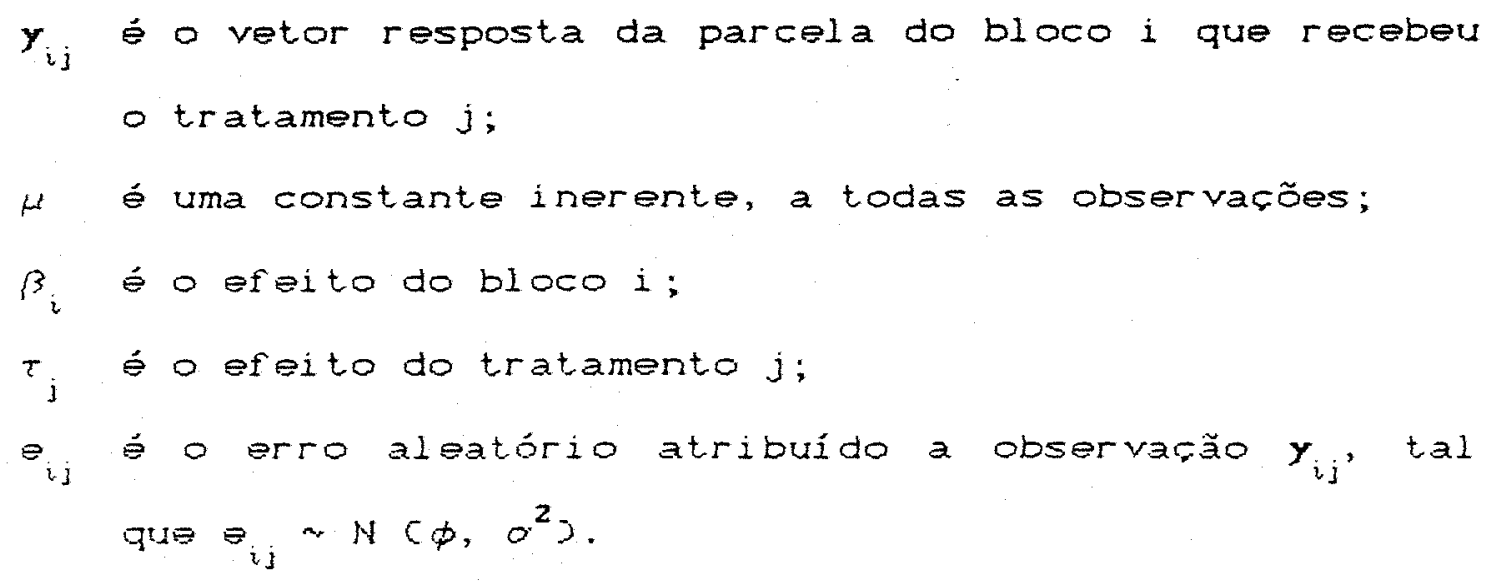

\subsubsection{Eficiencia}

De acordo com RAGHAVARAO (1971), uma caracteristica dos delineamentos em blocos incompletos é a sua eficiência, definida pela razão

$$
E=\frac{\bar{V}_{r}}{\bar{V}}
$$

onde $\bar{V}$ é a variància média das estimativas intrablocos dos contrastes elementares entre tratamentos, para o delineamento de BIB considerado, $e \bar{V}_{r}$ representa o mesmo, para blocos casualizados, usando o mesmo número de unidades experimentais; tanto $V_{r}$ e $\bar{V}$ são calculados com a suposicão de que a variancia residual intrablocos seja a mesma em ambos casos.

De acordo com KEMPTHORNE (1976), a variância média nos delineamentos conexos vem dado por

onde

$$
\bar{v}=\frac{1}{v(v-1)} \sum_{i \neq i} v\left(\hat{t}_{i}-\hat{t}_{i}\right)=\frac{2 \sigma^{2}}{H}
$$

$$
H=\frac{V-1}{\frac{1}{\theta_{1}}+\frac{1}{\theta_{2}}+\ldots+\frac{1}{\theta_{v}-1}}=\frac{V-1}{\sum_{i=1}^{v-1} \frac{1}{\theta_{i}}}
$$


18.

$\bar{V}$ é a variância média para estimar os contrastes elementares $\hat{t}_{i}-\hat{t}_{i}$

$H \dot{\theta}$ a média harmònica dos autovalores $\theta_{i}$ da matriz $C$, onde $i=1,2, \ldots, v-1$, sendo um autovalor de C nulo pois seu postóé $V-1$ e. Por outro lado

$$
\bar{V}_{r}=\frac{2 \sigma^{2}}{\bar{r}}
$$

onde:

$$
\begin{aligned}
& \bar{r}=\frac{r}{v} n \doteq \text { o total das parcelas, } \bar{F} \text { o número módio de } \\
& \text { repeticbes dos tratamentos, entăo } \\
& E=\frac{\bar{V}_{\bar{r}}}{\bar{V}}=\frac{2 \sigma^{2} / \bar{r}}{2 \sigma^{2} / H}=H / \bar{r}
\end{aligned}
$$

Sendo que a média harmônica de um conjunto de quantidades positivas não pode exceder a média aritmética desta quantidades, $\theta$ como $\operatorname{Ir}[\mathrm{C}]=\sum_{i=1}^{V-1} \theta_{i}$, onde $\operatorname{Ir}[\mathrm{C}]$ representa o traco da matriz $c$, tem-se:

$$
H \leq \sum_{i=1}^{V-1} \theta_{i} / V-1=\operatorname{Tr}[C] / V-1=\frac{V \bar{T}-b}{V-1}
$$

e então

$$
E \leq \frac{\vec{r}-b}{\bar{r}(r-1)}
$$

para os delineamentos de igual repeticão $\bar{r}=r$ à eficiência será

$$
E \leq \frac{v r-b}{r(r-1)}
$$

A igualdade é válida somente quando os autovalores não nulos de C são iguais, isto é, quando

$$
\theta_{1}=\theta_{2}=\ldots=\theta_{r-1}=\theta
$$


nesse caso a média harmônica $H$ desses autovalores é igual a média aritmética

$$
H=\sum_{i=1}^{v-1} \theta_{i}(v-1)=(v-1) \theta(v-1)=\theta
$$

se os autovalores de C são iguais o delineamento é dito balanceado e conexo, como será visto no capitulo 3 de conectividade. Segundo RAGHAVARAO (1971) o delineamento bal anceado é sempre mais eficiente dado que a igualdade para a expressalo de E se verifica.

Partindo da condicão de balanceamento

$$
E=V_{\bar{r}} \rho \bar{V}=\frac{2 \alpha^{2} / r}{2 \lambda \sigma^{2} / \lambda v}=\frac{\lambda v}{\tau k}
$$

$\lambda(v-1)=\gamma(k-1)$, se tem

$$
\frac{\lambda}{r}=\frac{(k-1)}{r-b}
$$

então

$$
E=\frac{\lambda v}{r k}=\frac{v(k-1)}{k(v-1)}=\frac{k-1 / k}{v-1 / v}=\frac{1-\frac{1}{k}}{1-\frac{1}{v}}
$$

nos blocos incompletos tem-se $k<v$, e então

$$
\frac{1}{k}>\frac{1}{v} \text { ou }-\frac{1}{k}-\frac{1}{v}
$$

Logo se tem,

$$
1-\frac{1}{k}<1-\frac{1}{v}
$$

de modo que

$$
E=\frac{\lambda V}{\Gamma k}=\frac{1-\frac{1}{k}}{1-\frac{1}{V}}<1
$$

Assim nos BIB a eficiência é sempre menor de que 1, por isso deve-se dar preferencia aos delineamentos experimentais cuja eficiência $E$ seja a mais próxima possivel de 1 . 
20 .

2. 4. Delineamentos em Blocos Incompletos Parcialmente BaI anceados

Os BIB nem sempre podem ser aplicados em problemas práticos, já que exigem um número elevado de repeticöes, o que se faz necessário a utilizacăo de outros delineamentos.

BOSE \& NAIR (1939) introduziram os delineamentos em blocos incompletos farcialmente balanceados (FEIBS que requerem um menor número de parcelas que os BIB. Segundo os autores um delineamento em blocos incompletos é parcialmente bal anceado se satisfaz as seguintes condicões:

i) Os tratamentos săo agrupados em b blocos de $k$ parcelas com diferentes tratamentos alocados em cada uma delas.

ii) Existem $v$ tratamentos que ocorrem em $r$ blocos.

iiis Em relacão a qualquer dos $v$ tratamento, os demais podem ser divididos em $m$ grupos contendo, respectivamente $n_{1}, n_{2}, \ldots, n_{m}$ tratamentos, tal que os tratamentos do i-ésimo grupo ocorram juntos com um determinado tratamento em $\lambda_{i}$ blocos. Os tratamentos do i-ésimo grupo são chamados de i-ésimos associados do tratamento em questão e os valores de $n_{1}, n_{2}, \ldots$, $n_{m} \odot$ de $\lambda_{1}, \lambda_{2}, \ldots, \lambda_{m}$ săo independentes do tratamento considerado. 
iv Dados quaisquer dos tratamentos que săo i-ésimo associados, o número de tratamentos que são j-ésimo associados do segundo tratamento, e o mesmo sem importar com que par de i-ésimo associado se inicia. Este número se representa pelo simbolo $p_{i k}^{i}$ ademais $P_{j k}^{i}=P_{k j}^{i}$.

No conceito de BOSE \& NAIR (1939), os pares de tratamentos que ocorrem juntos num mesmo bloco, chamam-se de primeiras associados, o número de primeiros associados é dado por $\lambda_{1}$. Os pares de tratamentos que näo ocorrem juntos num mesmo bloco, chamam-se de segundos associados, o número de segundos associados é dado por $\lambda_{2}$.

Considere-se o seguinte modelo

$$
\begin{gathered}
y_{i j}=\mu+\beta_{i}+\tau_{j}+e_{i j} \\
i=1,2, \ldots, v \\
j=1,2, \ldots, b
\end{gathered}
$$

onde:

$y_{i j}$ é a observacão do i-ésimo tratamento no j-ésimo bloco;

$\mu$ é uma constante inerente a todas as observacões;

$\tau_{i}$ é o efeito do i-ésimo tratamento;

$e_{i j}$ é o erro experimental associado a observacão $\boldsymbol{y}_{i j}$. Supõe-se $e_{i j} \sim N\left(0, \alpha^{2}\right.$ ) são independentes.

o modelo tem em consideracão a restricão paramétrica

$$
\sum_{i=1} t_{i}=0
$$

e efetuando a conveniente particão da matriz ${ }_{R}$ 


$$
Z=\left[\begin{array}{l:l:l}
x_{1} & x_{2} & x_{3}
\end{array}\right]
$$

onde:

$$
\begin{aligned}
& r V R_{1} \text { é o vetor de coeficiente associados a média; } \\
& r V R_{2} \text { é a matriz dos coeficientes associados aos tratamen- } \\
& \text { tos; } \\
& V V_{3} \text { é a matriz dos coeficiente associados aos blocos. }
\end{aligned}
$$

$$
\text { O vetor é particionado conforme a particão }
$$

da matriz 2 como segue

$$
\theta=\left[\begin{array}{l}
\mu \\
t \\
\beta
\end{array}\right]
$$

$$
v_{1}^{t}=\left[\begin{array}{c}
t_{1} \\
t_{2} \\
\cdots \\
t_{v}
\end{array}\right] \quad b_{1}^{\beta_{1}}=\left[\begin{array}{c}
\beta_{1} \\
\beta_{2} \\
\cdots \\
\beta_{b}
\end{array}\right]
$$

O sistema de equaçós normais é

$$
\begin{aligned}
& \mathscr{R} R=2 R \cdot Y
\end{aligned}
$$

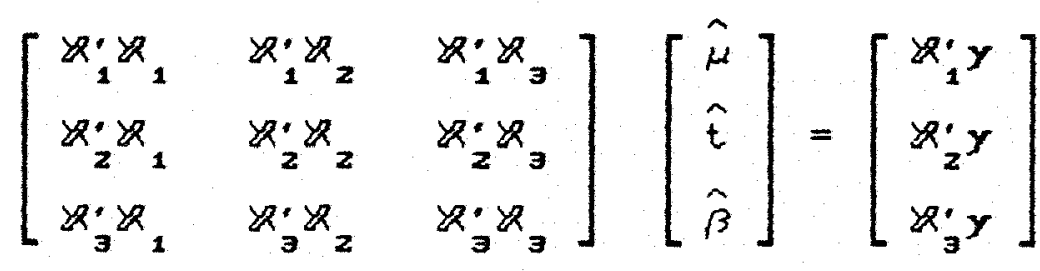

$$
\begin{aligned}
& Z_{1}: R_{1}=b k=r V=n \text { é o número total de unidades experimen- } \\
& \text { tais ou parcelas }
\end{aligned}
$$




\subsection{Equaçôes Normais Reduzidas}

Segundo IEMMA (1987), considera-se a expressão vetorial das observacões como $y=2 R \theta+e$ Neste modelo linear a coluna correspondente à média na matriz de delineamento $k$ é dependente das demais colunas.

Com o objetivo de se obter o sistema de equacöes normais reduzidas a col una correspondente à média será suprimida de modo que a matriz de delineamento terá a seguinte forma particionada.

onde:

$$
X=\left[X_{1}: X_{2}\right]
$$

$$
\begin{aligned}
& X_{1} \text { é a matriz dos coeficientes associados aos blocos; } \\
& x_{2} \text { é a matriz dos coeficientes associados aos tratamen- } \\
& \text { tos. Assim o modelo pode ser escrito da forma }
\end{aligned}
$$

$$
\begin{gathered}
y=\left[Z_{1}\left[Z_{2}\right]\left[\begin{array}{c}
\beta \\
\tau \\
\tau
\end{array}\right]+e\right. \\
y=Z_{2} \beta+Z_{2} \tau+e
\end{gathered}
$$

A expressão no sistema de equacõos normais na forma matricial é

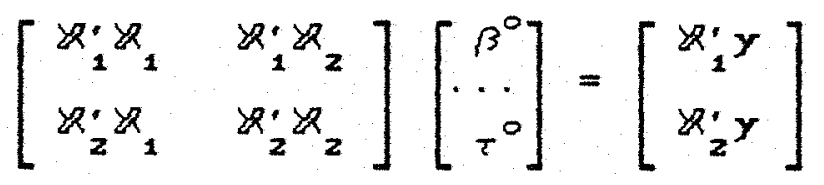

ous

$$
\begin{aligned}
& R_{1} R_{1} \beta^{\circ}+2 R_{1}^{\prime} R_{2} T^{0}=Z_{1}^{\prime} Y \\
& X_{2} X_{1} \beta^{\circ}+X_{2} X_{2} \tau^{\circ}=X_{2}^{\prime} Y
\end{aligned}
$$

multiplicando $[2.5 .1]$ por $Z_{2} Z R_{1}^{\prime}$ vem 


$$
\begin{aligned}
& Z_{2}^{\prime} R_{1}^{\prime}{ }^{+} R_{1}^{\prime} Z_{1} \beta^{\circ}+Z_{2}^{\prime} R_{1}^{\prime}{ }^{+} R_{1}^{\prime} Z_{2} \tau^{\circ}=Z_{2}^{\prime} R_{1}^{\prime}{ }^{+} R_{1}^{\prime} Y \\
& \Rightarrow Z_{2}^{\prime}\left(Z R_{1} R_{1}^{+}\right) \cdot Z R_{1} \beta^{0}+Z_{2}^{\prime}\left(Z R_{1} Z_{1}^{+}\right) \cdot Z_{2} T^{0}=Z R_{2}^{\prime}\left(Z_{1} Z_{1}^{+}\right)^{\prime} y
\end{aligned}
$$

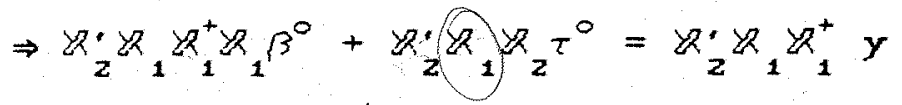

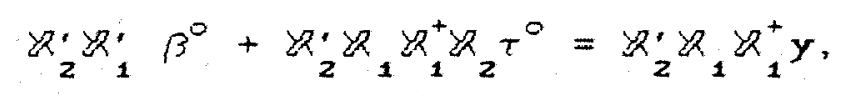

esta expressăo é subtraida de 2.5.2 obtendo-se

$$
\begin{aligned}
& X_{2}^{\prime} Z_{1} P^{0}-X_{2}^{\prime} X_{1} Z_{1}^{+} Z_{2}{ }^{0}=Z_{2}^{\prime} Y-R_{2}^{\prime} R_{1} Z_{1}^{+} Y \\
& R_{z} Z_{z} \tau^{0}-X_{z} P_{1} R_{2} \tau^{0}=R_{z}^{\prime} Y-R_{z} P_{1} Y \\
& R_{2}^{\prime}\left(I-P_{1} Z_{2} R^{0}=X_{2}^{\prime}\left(I-P_{1}\right) Y\right.
\end{aligned}
$$

Que a expressão do sistema de equacões normais reduzidas para efeitos de tratamentos eliminando-se desse modo o efeito da média e blocos.

Muitos autores adotam a forma

$$
C \tau^{\circ}=Q
$$

onde

$$
C=X_{2} C I-P_{1} V_{2}
$$

e

$$
Q=R_{2}\left(I-P_{1}\right)^{Y}
$$

então

$$
C=R_{2} R_{2}-X_{2} P_{1} X_{2}
$$

sabe-se que $R_{2} Z_{2}=R=V I_{(v)}$ é a chamada matriz de repeticões dos tratamentos $e Z_{1}: X_{1}=K=K I_{(b)}$ é a chamada matriz dos tamanhos dos blocos dado que $P_{1}=V_{1}\left(R_{1} \cdot R_{1}\right)^{-1} X_{1}$ e 0 projetor correspondente aos blocos.

Substituindo estes valor em $[2.5 .7]$ se tem a matriz 
25.

$$
\begin{aligned}
& C=R-R_{2}^{\prime} Z_{1}\left(R_{1} \cdot Z_{1}\right)^{-1} R_{1}^{\prime} Z_{2} \\
& C=R-\frac{1}{k} R_{2}^{\prime} Z_{1} R_{1}^{\prime} Z_{2}
\end{aligned}
$$

pois

$$
\left(2 R_{1}^{\prime} \geq R_{1}^{-1}=\frac{1}{k} I_{(b)}\right.
$$

sendo $Z R_{1}: Z_{2}=N^{\prime}$

$$
\sigma=R-\frac{1}{k} N N^{\prime}
$$

onde $N$ é a matriz de incidencia dos tratamentos nos blocos; entăo os valores das parcelas para

$$
N=\cos _{i j}=\left\{\begin{array}{l}
1 \text { se o tratamerto } j \text { está no bloco i } \\
0 \text { caso contrário }
\end{array}\right.
$$

no caso dos delineamentos em BIB a estrutura matricial será

onde:

$$
\mathrm{NN}^{*}=\left[\begin{array}{cccc}
v & \ell & \cdots & \ell \\
\ell & v & \cdots & \ell \\
\cdots & \cdots & \cdots & \cdots \\
\ell & \ell & \cdots & v
\end{array}\right]
$$

\footnotetext{
$r=e ́$ o número de repeticões por tratamento;

$\ell=$ = o número de vezes que se repetem os pares de tratamentos no número de blocos.
}

Deste modo, a matriz C é facilmente obtida por quanto

$$
\begin{aligned}
C=\left(C_{i j}^{\prime}\right) & \left\{\begin{array}{l}
\frac{r(k-1)}{k} \text { se } j=j \text { para } j=1,2 \ldots \\
-\frac{l}{k} \text { se } j=j
\end{array}\right. \\
& \text { De modo semel hante procede-se para se obter a }
\end{aligned}
$$

matrizQ

$$
Q=Z_{z}^{\prime} C I-P_{1}{ }^{\prime} y=Z R_{2}^{\prime} y-\frac{1}{k} N R_{1}^{\prime} y
$$


26.

dado que $R_{2}: Y=T$ é o vetor dos totais dos tratamentos igualmente $Z_{1}{ }_{1}=B$ é o vetor dos totais dos blocos; a qual permi te se expressá-10 como

$$
Q=T-\frac{1}{K} N B
$$

CHAKBARARII (1963) apresenta a matriz C mediante a expressão:

$$
C=\left(A^{\prime} A\right)-N\left(B^{\prime} B\right)^{-1} N^{\prime}
$$

onde A é a matriz de coeficientes dos tratamentos, B ́a matriz de coeficientes dos bloose $N$ é a matriz de incidencia; Cé a chamada matriz reduzida intrablocos.

Uma outra forma de obtencão do sistema de equaçós normais reduzidas nos delineamentos de blocos incompletos é apresentado por RIBOLDI (1988), no desenvolvimento teórico para análise de experimentos em blocos incompletos parcialmente balanceados (PBIB).

Observa-se nesta secão a relacão existente entre as propriedades dos delineamentos em blocos incompletos e o conceito de estimação expressado no sistema de Equaç̃es Normais Reduzidas eliminando-se o efeito de blocos. o estudo de estimacão por sua vez, leva á mencão de funções Iineares paramétricas estimáveis da forma $\lambda^{\prime} \theta$, com

$$
\lambda \cdot I=\sum_{i}^{V}=\sum_{i=1}^{v} \lambda_{i}=0
$$

denominados contrastes elementares do $t_{i p o} t_{i}-t_{i}$ o que permite estabelecer a continuidade ou desconexão entre os parâmetros.

Esse procedimento de obtencão do sistema de equacões normais reduzidas é apresentado por IEMMA ( 1987 ). 


\subsection{Estimabilidade}

DEFINIGÃO 2.6.1. - De acordo com RAO (1945). Dado o modelo linear $y=\not R \theta+e$ GG.M.O.2. Então uma funcão paramétrica $\lambda^{\prime} \theta$ é dita estimável se existir ao menos uma combinacão das observacões dada por $a^{\prime} y$, tal que $E\left[a^{\prime} y\right]=\lambda^{\prime} \theta$.

\subsubsection{Caracterizaçăo}

$$
\text { Sejam } y_{1}, y_{2}, \ldots, y_{n} \text { os valores que assumem }
$$
as variáveis aleatórias $y$, sendo sua esperanca matemática, uma combinacăo 1 inear de parâmetros desconhecidos. O vetor

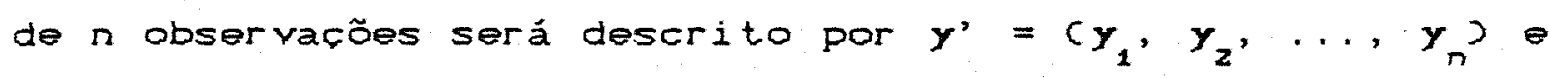
o vetor de parâmetros por $\theta^{\prime}=\left(\theta_{1}, \theta_{2}, \ldots, \theta_{n}\right)$.

A esperanca da variável y pode ser expressada matricialmente como:

$E(y)=E\left[\begin{array}{c}y_{1} \\ y_{2} \\ \vdots \\ y_{n}\end{array}\right]=\left[\begin{array}{cccc}Z_{11} & Z_{12} & \cdots & Z_{1 m} \\ Z_{21} & Z_{22} & \cdots & Z_{2 m} \\ \cdots & \cdots & \cdots & \cdots \\ Z_{n 1} & Z_{n 2} & \cdots & Z_{n m}\end{array}\right]\left[\begin{array}{c}\theta_{1} \\ \theta_{2} \\ \vdots \\ \theta_{m}\end{array}\right]=V_{\theta} \quad[2.0 .1 \mathrm{a}]$

onde $X=\left(\Omega_{i j}\right)$ é uma matriz $\Omega \times n$ de constantes conhecidas. A variância de $y$ é $\operatorname{VAR}(y)=\sigma^{z} I$.

Uma função paramétrica linear

$$
\ell^{\prime} \theta=\ell_{1} \theta_{1}+\ell_{2} \theta_{2}+\ldots+\ell_{m} \theta_{m}
$$

é dita estimável se existir $a^{\prime}=\left(a_{1}, a_{2}, \ldots, a_{n}\right)^{\prime}$ tal que

$$
E\left(a^{\prime} y\right)=1^{\prime} \theta
$$

como $E\left(a^{\prime} y\right)=a^{\prime} \not \theta$ então

$$
x \cdot a=l
$$


Uma condicão necessária e suficiente para a existência da sol ucăo de a para [2.6.1c] é

$$
\text { posto }(X)=\text { posto } C X: D \quad[2.6 .10]
$$

Teorema [2.6.1] Uma condicá necessaria e suficiente para que uma funcăo paramétrica $\ell^{\prime} \theta$ seja estimável e que cumpra a condição $[2.6 .10]$.

2.6.2. O Método dos Mínimos Quadrados

É um dos mais antigos métodos de Estimacão;

foi desenvolvido independentemente por Gauss no ano 1809 e Legendre ano de 1900 segundo: SCHEFFÉ (1959). Posteriores melhoramentos na teoria de mínimos quadrados tem sido registrados após o trabalho de Markov no ano de 1900 de acordo com SCHEFFÉ (1959) \& PLACKETI (1949), AITKEN (1935), BOSE (1949), NEYMAN \& DAVID (1938), PARSEN (1961), RAO (1945a 1962), ZYSKIND \& MARTIN (1969).

a) Mínimos Quadrados Ordinários

Quando a matriz de covariâncias dos erros é do tipo $V=I \alpha^{2}$, tem-se o método dos mínimos quadrados ordinários.

$$
\begin{gathered}
\text { Nesse caso, o sistema de equacões normais fica } \\
\qquad R^{\prime} \mathscr{R} \theta=R^{\prime} y
\end{gathered}
$$

Se a matriz de delineamento 2 tem posto coluna completo, então $Z R^{\prime} \backslash \mathscr{R}$ é positiva e portanto não singualr neste caso o sistema tem sol ucão única dada por 


$$
\hat{\theta}=\left(Z R^{\prime} \cdot R\right)^{-1} \mathscr{R} \cdot Y
$$

Se a matriz de delineamento $2 \mathcal{R}$ não tem posto coluna completo, então o sistema não apresenta solucão úni ca. Săo solucões dentre outras:

$$
\theta^{\circ}=(X \cdot X)^{-} X R^{\prime} y ; \quad \theta^{0}=X^{2} y ; \quad \theta^{\circ}=x^{+} y
$$

b) Método de Mínimo Quadrados Ponderados CGM

$$
\begin{aligned}
& \text { Quando a matriz de covariâncias dos erros é do } \\
& \text { tipo } V=D o^{2} \text { com } D \neq I \text { e } D \text { é matriz diagonal, não singular, } \\
& \text { então o sistema de equacões normais é do tipo. }
\end{aligned}
$$

$$
\mathscr{X} \cdot D^{-1} \not R \theta=Z X^{\prime} D^{-1} Y
$$

De modo análogo ao anterior, se lK posto coluna completo, a sol ução única é dada por

$$
\begin{gathered}
\theta^{0}=C K^{1} D^{-1} X J^{a} X R^{\prime} D^{-1} Y, \\
E \text { se } \backslash \text { não tem posto coluna completa, uma so- }
\end{gathered}
$$

1 ucão é, por exemplo.

$$
\theta^{0}=\left(R^{\prime} D^{-1} X\right)^{9} R^{\prime} D^{-1} y, \forall G \text { - inversa de } R \cdot X
$$

c) O Método dos Mínimos Quadrados Generalizados

Em muitas situacões experimentais, os dados pela própria natureza do experimento, não podem ser analisados através do modelo Gauss Markov Ordinário, nada se pode garantir sobre condicões como homogeneidade de variâncias e independência dos erros. Na prática, as condicões de homogeneidade de variâncias e de independência não são sempre possiveis de cumprir, dai a importancia de se utilizar o modelo de minimos quadrados generalizados. 
30.

Segundo a conceituacão de KSHIRSAGAR (1983) e IEMMA (1987), considere-se o modelo Generalizado Gauss Markov Normal CG.M.N.J.

$$
\mathbf{y}=2 R+\varepsilon
$$

[2.6.2a]

Neste modelo a matriz de variancias e covariâncias dos erros assume a forma $\Omega \sigma^{2}$, onde $\alpha^{2}$ não é conhecida e a matriz $\Omega$ é conhecida é positiva definida e tem estrutura mais geral que as formas diagonais anteriores.

$$
\text { o método de obtencáo dos BLUES das funcöes }
$$

lineares estimáveis de $\theta$ neste modelo é conhecido como o Método de Mínimos Quadrados Generalizados CEquacões de Aitkens.

- problema de se estimar e pode ser reduzido quando o modelo tem residuos não correlacionados, ao se transformar y em outras variáveis. Assim considere-se $\Omega$ como uma matriz positiva definida, isto implica que $\Rightarrow \Delta$ matriz não singular, tal que

$$
\begin{aligned}
\Delta^{\prime} \Delta=\Omega^{-1} & \Longleftrightarrow c \Delta^{\prime} \Delta^{-1}=\Omega \\
& \Leftrightarrow \Delta^{-1} \Delta^{-1}=\Omega \\
& \Rightarrow \Delta \Omega \Delta^{\prime}=I
\end{aligned}
$$

considerando a expressão do modelo linear dado por [2.6.2a] e pré-multiplicando ambos lados por a matriz $\Delta$ tem-se

$$
\Delta \mathbf{y}=\Delta \mathscr{R} \boldsymbol{\theta}+\Delta \varepsilon
$$

fazendo o seguinte câmbio de variáveis

$$
Z=\Delta y ; \quad \text { L }=\Delta Y R \quad e \quad e=\Delta \varepsilon
$$

obtem-se $Z=w e+e[2,6,2 b]$ que é a expressão do sistema de equacóes normais transformadas a partir do qual obtém-se 


$$
\begin{gathered}
E(\theta)=E(\Delta \varepsilon)=\Delta E(\varepsilon)=\Delta(O)=0 \\
V(\theta)=V(\Delta \varepsilon)=\Delta V\left(\varepsilon \Delta^{\prime}=\Delta \Omega \sigma^{2} \Delta^{\prime}=\Delta \Omega \Delta^{\prime} \sigma^{2}=\Delta \Delta^{-1} \Delta^{-1} \Delta^{1} \sigma^{2}\right. \\
V(\theta)=I \sigma^{2} \\
\text { [2. } 6.4 c] \\
\text { Que nos leva de volta aos mínimos quadrados }
\end{gathered}
$$

or di nários.

$$
\begin{aligned}
& \text { Então o sistema de equacóos fica: } \\
& \text { W. WO }=W \cdot \mathbb{Z} \\
& \text { Ou, recuperando } \forall \geqslant y \\
& (\Delta R) \cdot \Delta Y \theta=C \Delta Y)^{\prime} \cdot \Delta Y \\
& Z^{\prime} \Delta^{\prime} \Delta Z R \theta=Z^{\prime} \Delta^{\prime} \Delta y \\
& R^{\prime} \Omega^{-1} \not R \theta=R^{\prime} \Omega y
\end{aligned}
$$

Que é o sistema de equacões normais generalizadas, também conhecidas como sistema de equacões de AI TKEN.

De modo análogo aos anteriores, se $2 k$ tem posto coluna completo a solucão única é dada por

$$
\hat{\theta}=\left(Q^{\prime} \Omega^{-1} Y \Omega^{-1} \mathscr{Q ^ { \prime }} \Omega^{-1} Y\right. \text {. }
$$

Se $\Varangle$ não tem posto coluna completa uma sol ucão é

$$
\theta^{0}=\left(X R^{\prime} \Omega^{-1} X\right)^{0} X: \Omega^{-1} y
$$

$\forall G$ - inversa de $R \cdot \Omega^{-1} X$.

$$
\text { Nesse caso, tem-se o modelo }
$$

$$
y=x \hat{\theta}+\varepsilon
$$

onde:

$$
\begin{aligned}
& { }_{n} \mathbf{Y}_{\mathbf{1}} \text { é un vetor de realizacões de variáveis aleatórias; } \\
& n^{2} p \text { é uma matriz conhecida de posto } k \leq \min \{n, p\} \\
& p_{1}^{\ominus} \text { é um vetor de parâmetros desconhecidos; } \\
& n_{1} \varepsilon_{1} \text { é um vetor de variáveis aleatórias não observáveis } \\
& \text { tais que } \varepsilon \sim N\left(\phi ; \Omega \sigma^{2}\right) \text {. }
\end{aligned}
$$


32.

\subsection{BLUE (Melhor Estimador Linear Năo Viesado)}

Segundo SCHEFFÉ (1959), SEARLE (1971), RAGHAVAFAO (I975), IEMMA (1997), tem-se as seguintes definiroese teoremas que caracterizam o BLUE CBest Linear Umbiased Estimators.

DEFINIGAO 2.6.3.1. - Dado $y=k \theta+e$ CGMO), então se $\lambda$ ' $\theta$ é estimável o sistema consisterte zp'ypo $=\lambda$ é dito sistema de equacöes normais associadas.

Teorema [2.6.3.1] [RAO (1945)] - Uma condicão necessária e suficiente para que $\lambda^{\prime} \theta$ seja estimável no (GMO) e que $\lambda \varepsilon$ $C(X),(p e r t e n c e$ ao espaco col una $2 D$.

Teorema [2.6.3.2] - Se $\lambda$ " $\theta$ é estimável, entăo seu "BLUE" pode ser obtido de: $\lambda^{\prime} \theta=\rho R^{\prime} y$ único, onde $\rho \dot{\theta}$ qualquer sol ucão das equacões normais associadas.

Teorema [2.6.3.3] - Uma condicão necessária e suficiente para que $\lambda^{\prime} \theta$ seja estimável é que a posto $\left(R^{\prime} \cdot R\right)=$ posto $\left(R^{\prime}(R) \lambda\right)$.

DEFINIGÃO 2.6.3.2 - Dado o modelo CGM, sejam todas as combinacões possiveis a'y tais que $E\left[a^{\prime} y\right]=\lambda$ ' $a^{\prime}$. Dentre elas, seja $a^{*} \cdot y$. Então $a^{*}$ 'y é definido como o melhor estimador não viesado de $\lambda^{\prime} O$ se e somente se:

$\operatorname{var}\left[a^{*}, y\right]=\min \operatorname{var}\left[a^{\prime} y\right], \forall a^{*} y: E\left[a^{\prime} y\right]=\lambda^{*} \theta$ 
$a^{*} \cdot y$ é conhecido como BLUE de $\lambda^{\prime} \theta$ cBest linear Umbiased Estimators e denotado

$$
\begin{gathered}
\text { "BLUE" de } \lambda \text { ' } \theta=\lambda \hat{\imath} \theta \\
\text { Pode-se testar se He é estimável partindo do }
\end{gathered}
$$
fato que $\lambda^{\prime} \ominus$ é estimável então $\exists a$ : $\chi^{\prime} a=\lambda \Rightarrow \lambda^{\prime}=a R^{\prime}$; pós-multiplicando-se por $H$, temos

$$
\lambda H=a^{\prime} Y\left(Y R^{\prime} Y\right)^{-} Y \cdot Y R=a^{\prime} \cdot Y=\lambda^{\prime}
$$

onde $\lambda^{\prime} \theta$ é estimável entäo $\lambda^{\prime} H=\lambda^{\prime}$, o que implica que $\lambda$ é combiracão linear dos paràmetros do SEN e está incluindo em $\lambda^{\prime}$ estimável. Deste modo é confi'mada a hipótese testada.

E importante salientar que no caso de Estimacão de delineamentos de Blocos Incompletos não balanceados são válidos as conceituacões de estimabilidade em geral.

\subsection{Influencia dos Efeitos Fixos e Aleatórios na Estima- çăo de Parcelas}

\subsubsection{Conceituaçăo}

Existem fórmulas apresentadas por YATES (1933) para estimacão de parcelas perdidas no delineamento em blocos casualizados (DBC), assim como nos quadrados latinos. - procedimento utilizado o de Minimização da soma de quadrados dos erros, onde as equacões resultantes são resolvidas para os valores estimados das parcelas perdidas.

Nos DBC é aplicada uma fórmula para obtencão de uma estimativa de parcela perdida, no caso de mais de uma 
parcela perdida a fórmula é utilizada interativamente. A suposicão básica de muitos autores é que dita fórmula adequa-se a modelos fixos, aleatórios ou mistos. A continuacão mostrar-se-a que efetivamente a estimativa clássica de perda de parcelas é imparcial independentemente do modelo adotado, porém não tendo variância mínima em todos os casos. Existe variància mínima unicamente quando os efeitos dos fatores são fixos.

De acordo com MURRAY (1989), utiliza-se o modelo de médias apresentado por HOCKING C1985. Dado um delineamento em (Blocos casualizados) (DBC) com t tratamentos e b blocos a parcela perdida na posicão (p, q) a fórmula usual para obter uma estimativa da parcela perdida é:

$$
\hat{y}_{p q}=\left\{t y_{p .}+b y . q-y . \gamma / c t-1\right)(b-1) \quad[2.7 .1 a]
$$

ou

$$
\hat{y}_{p q}=\left\{(t-1) y_{p .}+(b-1) y_{q}-\sum_{\substack{i \neq p \\ j \neq q}} y_{i j /(t-1)(b-1)}\right\}^{\prime} \quad[2 \cdot 7 \cdot 1 b]
$$

\subsubsection{Caso em que os dois fatores săo fixos}

- modelo de médias do DBC de efeitos fixos e

$$
Y_{i j}=\mu_{i j}+e_{i j}
$$

Sendo os erros independentes e identicamente distribuidos com

$$
e_{i j} \sim N\left(O, I \sigma^{2}\right)
$$

sob o suposto de não interacão entre bloco e tratamento, então o modelo toma a forma 
35.

$$
\mu_{i j}-\bar{\mu}_{i,}-\bar{\mu}_{. j}+\bar{\mu}_{.}=0 \forall_{i j}
$$

$[2.7 \cdot 2 b]$

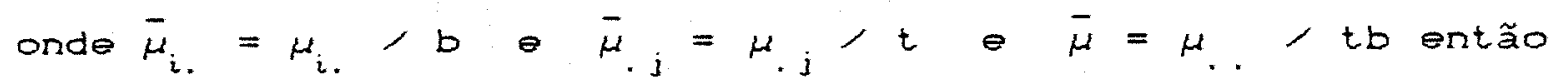
$E\left(y_{i j}\right)=\mu_{i j}$ com a restricão $[2.7 .2 b]$ vem

$$
\begin{gathered}
\operatorname{cov}\left[y_{i j}, y_{i, j}\right]=\alpha_{\theta}^{2} \text { para } i=i \cdot e j=j \cdot \\
\operatorname{cov}\left[y_{i j}, y_{i-j}\right]=0
\end{gathered}
$$

em outros casos. Então a estimativa da parcela perdida tem esperanca

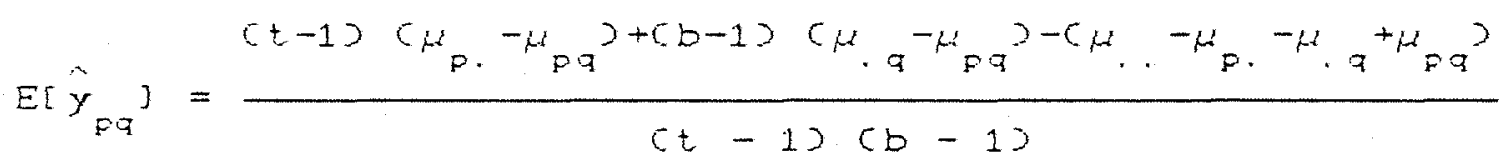

Desenvolvendo a expressão no $2^{0}$ membro e expressando as médias em termos dos seus equi valentes se tem

$$
t \mu_{p .}-t \mu_{p q}+b \mu_{q}-b \mu_{p q}+\mu_{p q}-\mu .
$$

somando subtraindo tb $\mu_{p q}$ no segundo membro se tem

$$
\begin{aligned}
& =\frac{(t-1)(b-1) \mu_{p q}-t b\left(\mu_{p q}-\bar{\mu}_{p}-\bar{\mu}_{q}+\bar{\mu}_{2}\right)}{(t-1)(b-1)} \\
& =\frac{(t-1)(b-1) \mu_{p q}}{(t-1)(b-1)}=\mu_{p q}
\end{aligned}
$$$$
E\left[\hat{y}_{p q}\right]=\mu_{p q}
$$

Sua variância será

$$
\left.\left.v\left[\hat{y}_{i j}\right]=\sigma_{\theta}^{2}(t+b-1)<c t-1\right) c b-1\right)
$$

$[2.7 .2 d]$

e todas suas covariâncias são zero, pois

$$
\begin{aligned}
& E\left(y_{p .}\right)=E \sigma_{p} .-y_{p q}{ }^{2}=\mu_{p .}-\mu_{p q} \\
& E<y \cdot q^{3}=E\left(y \cdot q-y_{p q}\right)=\mu_{\cdot q}-\mu_{p q} \\
& \sum_{\substack{j \neq z_{p} \\
j \neq q}}\left(y_{i j}\right)=E\left[\sum_{i j} y_{i j}-y_{p .}-y_{. q}+y_{p q}\right] \\
& =E\left[\sum_{i j} y_{i j}-y_{p .}-y_{. q}+y_{p q}\right] \\
& =\mu_{.}-\mu_{p .}-\mu_{. q}-\mu_{p q}
\end{aligned}
$$


e sendo que

$$
\begin{aligned}
& \mu_{p .}=b \bar{\mu}_{p .} \\
& \mu_{a}=t \bar{\mu} \cdot q \\
& \mu_{.}=t b \bar{\mu} . .
\end{aligned}
$$

Assim, sob a suposicão de năo interacăo, entre

os fatores fixos. $\hat{\mathrm{Y}}_{i j}$ é imparcial para $\mu_{\mathrm{fr}}$, Assim no caso de um ou ambos fatores serem aleatóriaos năo adota esta forma. o delineamento de blocos casualizados pode ser considerado um caso especial do modelo misto de dois fatores, com interacăo de componente zero.

\subsubsection{Blocos Aleatórios e Tratamentos Fixos}

o modelo é dado por

$$
\boldsymbol{y}_{i j}=\mu_{i}+b_{j}+e_{i j}
$$

onde $\mu_{i} e$ uma constante $e b_{j} \geqslant e_{i j}$ ambos são aleatórios $\theta$ independentes. A suposicão de não interacão bloco por tratamento, e que não existe efeito aleatório no bloco por tratamento, assim $\sigma_{b t}^{2}=0$, então

$$
E\left(y_{i j}\right)=\mu_{i}
$$

e

$$
\begin{aligned}
\operatorname{cov}\left[y_{i j}, y_{i \cdot j}\right] & =\sigma^{2}+\sigma_{b}^{2} \\
& =\sigma_{b}^{2} \\
& =0
\end{aligned}
$$

$$
\begin{aligned}
& \operatorname{para} i=i^{\prime}, j=j^{\prime} \quad i \neq i, j=j^{\prime} \text { outros casos. } \\
& \operatorname{cov}\left(y_{i j}, y_{i \cdot j}\right)=E\left[y_{i j}-E\left(y_{i j}\right)\left[y_{i j}-E\left(y_{i \cdot j}\right)\right]\right.
\end{aligned}
$$


se

$$
\begin{aligned}
& =E\left[\left(y_{i j} y_{i \cdot j}\right)-y_{i j} E\left(y_{i \cdot j}\right)-\right. \\
& \left.-E\left(y_{i j}\right) y_{i \cdot j}+E\left(y_{i j}\right) E\left(y_{i \cdot j}\right)\right]
\end{aligned}
$$

$$
\begin{array}{r}
i=i, \quad j=j, \\
\operatorname{cov}\left[y_{i j}, y_{i j}\right)=v\left(y_{i, j}\right)
\end{array}
$$

Substituindo [2.7.3b] pelos seus componentes, e considerando que tratamento e fixo blocos são aleatórios, tem-se

$$
\begin{aligned}
& \operatorname{cov}\left(y_{i j} y_{i j} j=E\left[t+c e_{i j}^{2}\right]=\right. \\
& \operatorname{cov}\left(y_{i j} y_{i j}\right\rangle=\sigma_{b}^{2}+\sigma_{e}^{2}
\end{aligned}
$$

Seguindo o procedimento anterior tem-se $\operatorname{cov}\left(y_{i j}, y_{i-j}\right)=\alpha_{b}^{2}$, quando $i \neq i \cdot e j=j$ '

Assim a estimativa da parcela perdida pode ser

expressada

$$
\begin{aligned}
E\left(\hat{y}_{p q}\right) & =\frac{(t-1)(b-1) \mu_{p}+(b-1)\left(\mu-\mu_{p}\right)-(b-1)\left(\mu-\mu_{p}\right)}{(t-1)(b-1)} \\
& =\frac{(b-1) \mu_{p}(t-1)}{(b-1)(t-1)} \\
E\left(\hat{y}_{p q}\right) & =\mu_{p}
\end{aligned}
$$$$
[2.7 .3 c]
$$

\section{E a sua variância será}

$$
\begin{aligned}
& \left.V\left(\hat{y}_{p q}\right)=\left(c o_{o}^{2}+o_{b}^{2}\right)(t+b-1)+\sigma_{e}^{2}(t b-2 t-2 b+2)\right) /(t-1)(b-1) \text { [2.7.3d] } \\
& \mathrm{V}\left(\hat{y}_{\mathrm{pq}}\right)=\alpha^{2}(t+b-1) /(t-1)(b-1)+\sigma_{b}^{2}
\end{aligned}
$$
vém da $V\left(y_{i j}\right)$ o segundo termo de $\operatorname{cov} y_{i j}, y_{i \cdot j}{ }^{2}$ e também existe semelhanca da variância $v \hat{y}_{\mathrm{pq}^{2}}$ entre $[2.7 .2 d]$ e [2.7.3e] e ademais as esperancas dos termos: 


$$
c b-12 y . q \quad \theta \quad \sum_{\substack{i \neq p \\ j \neq q}} Y_{i j}
$$

em [2.7.3c] se cancelam pelo que não contribuem para E(y ${ }^{2}$. A esperanca restante e do termo do tratamento $(t-1) y$. entăo uma candidata para estimar a parcela perdida e a média dos tratamentos

$$
\bar{y}_{p j}=\sum_{j \neq q} y_{p j}-c b-12 .
$$

A estimativa de mínimos quadrados não ponderado que é claramente imparcial para $\mu_{p}$ tom variancia

$$
\begin{aligned}
& v c \bar{y}_{p}{ }^{2}=c \sigma_{\theta}^{2}+o_{b}^{2}, b-1 \text {. } \\
& \text { Sendo } \sigma_{0}^{2} \text { e } \sigma_{b}^{2} \text { positivos, se tem que } \\
& v\left(\hat{y}_{p q}\right)>V\left(\bar{y}_{p}\right) \text {. }
\end{aligned}
$$

assim a condição do componentes de variância positiva e restritiva.

Como, por hipótese, a matriz de covariâncias das $y_{i j}$ é positiva definida então os autovalores de $Y$ são todos positivos. No caso de perda de uma parcela, os autovalores de $\mathrm{V}$ são $a^{2}$ com multiplicidade $\left.(t-1) C b-1\right)+$ $(t-2)=t b-b-1 ; \quad \alpha_{0}^{2}+t \sigma_{b}^{2}$ com multiplicidade $b-1 e$ $\sigma_{0}^{2}+(t-1) \alpha_{b}^{2}$ com multiplicidade 1. Sob as condicões menos restritivas e que estes autovalores são positivos.

Sabemos que $V\left(\hat{y}_{\mathrm{pq}}{ }^{2}>V\left(\hat{y}_{\mathrm{p}}\right.\right.$. $)$. Assim se uma estimativa da parcela é desejada, $\hat{y}_{p}$ é melhor que $\hat{y}_{p q}$. Infelizmente $\hat{y}_{p}$. não é de variância minima uniformemente impacial (M.M. V.).

E importante e suficiente que as médias dos tratamentos restantes $\left.\hat{y}_{i}, c_{i}=1, \ldots, p-1, p+1, \ldots, t\right)$. 
39.

Tenham variância $c \sigma_{0}^{2}+t \sigma_{b}^{2} \partial b$ e sejam uniformemente imparciais para as médias das parcelas

$$
\left.\mu_{i}=c_{i}=1, p-1, p+1, \ldots, t\right) .
$$

\subsubsection{Caso em que Ambos fatores sao Aleatórios}

Quando os dois fatores são al eatórios, o mode10 de médias para o delineamento vem dado por

$$
y_{i j}=\mu+t_{i}+b_{j}+e_{i j}
$$

onde $\mu$ é constante $e t_{i}, b_{j} e e_{i j}$ săo todos aleatórios $\theta$ mutuamente independentes, então a esperanca das observacões do delineamento é $E\left[y_{i j}\right]=\mu$ sua covariância vem dada por

$$
\begin{aligned}
& \operatorname{cov}\left[y_{i j} y_{i j}\right]=\sigma_{\theta}^{2}+o_{b}^{2}+\alpha_{i}^{2} \\
& =\alpha_{b}^{2} \\
& =\sigma_{i}^{2} \\
& =0 \\
& \text { para } i=i, j=j \text { ' } \\
& i \neq i \cdot, j=j \\
& i=i \cdot, j \neq j \\
& \text { em outros casos } \\
& \operatorname{cov}\left(y_{i j} y_{i \cdot j}\right) \quad=E\left[y_{i j}-E\left(y_{i \cdot j}\right)\right]\left[y_{i \cdot j}-E\left(y_{i \cdot j}\right)\right] \\
& \text { para } i=i, j=j \text {, } \\
& =E\left\langle Y_{i j}^{2}-\left[E\left(Y_{i j}\right]^{2}\right\}\right. \\
& =E\left[\left(\mu+t_{i}+b_{j}+e_{i j}\right)^{2}-\left[E\left(\mu+t_{i}+b_{j}+e_{i j}\right)\right]^{2}\right. \\
& \operatorname{cov}\left(y_{i j} y_{i \cdot j}\right)=\sigma_{i}^{2}+\alpha_{b}^{2}+\sigma_{\theta}^{2} \\
& \text { Para o caso de } \\
& i \neq i, \quad \theta \quad j=j \text {, } \\
& \left.=E\left(t_{i} t_{i}\right)+\sigma_{b}^{2}+E c e_{i, j}\right) E c e_{i j}{ }^{2} \\
& \operatorname{cov}\left(\boldsymbol{y}_{i j} \boldsymbol{y}_{i \cdot j}\right)=\sigma_{b}^{z}
\end{aligned}
$$


Segue-se o mesmo procedimento para o caso quando $i=i$ e $j \neq j$, pode-se mostrar que $y_{p q}$ é imparcial para $\mu_{p q}$

\section{Sendo}

$V\left[y_{\mathrm{Fq}}\right]=\left[\sigma_{\theta}^{2} c t+b-12<c t-12 c b-12\right]+\alpha_{2}^{2}+\alpha_{b}^{2}$, um estimador alternativo a média geral é

$$
\left.\bar{y} \ldots=\sum_{(i, j)} y_{i, p)}, c t b-1\right)
$$

sendo imparcial tambén para a média u tendo como variancia

$$
v(\bar{y},)^{2}=\frac{\sigma^{2}}{(t b-1)}+\frac{\left(t^{2} b-2 t+12 \sigma_{b}^{2}+c t b^{2}-2 b+1\right) \sigma_{t}^{2}}{(t b-1)^{2}}
$$

novamente pode ser mostrado que

$$
v \hat{y}_{p q}>V(\bar{y}, \text { ) }
$$

se $\alpha_{\theta}^{2}, \alpha_{b}^{2} e \alpha_{t}^{2}$ são todos positivos.

Conclui-se que o processo de estimacão no caso de perda de parcelas no delineamentos, de blocos casualizados, quando os tratamentos e blocos são aleatórios, sua estimativa é imparcial, mas não tem variância mínima, só terá variância minima quando os tratamentos e blocos são fixos.

As variâncias das estimativas das parcelas perdidas nos diferentes tipos de delineamentos apresenta a seguinte desigual dade.

$\operatorname{Var}(f a c . f i x o)(\operatorname{var}(f a c . m i s t o)<\operatorname{var}(f a c$. aleatório) 
3. METODOLOGIA

\subsection{Conectividade}

3.1.1. Conceito de conectividade

A idéia de delineamentos conexos foi introduzida por BOSE (1949) na forma de uma cadeia entre blocos e tratamentos. Um bloco e um tratamento são conectados se perder formar uma cadeia de tratamentos e blocos da forma: tratamento-bloco-tratamento- bloco-...-tratamento, comecando com o fator A (tratamentos passando através da cadeia (blocol para associar-se, dessa forma, vários blocos na cadeia são associados mediante tratamentos adjacentes entre si. Posteriormente CHAKRABARTI (1963) define conectividade do seguinte modo, um delineamento é conectado se a matriz $\mathbb{C}$ (item 2.5) é de posto $v-1$; essa definicão é equivalente à dada por BOSE (1949), o autor trabalhou com blocos casualisados de efeitos fixos com parcela perdida.

HEEKS \& WILLIAMS (1964) definem a conectividade da seguinte forma: " um modelo é conectado se todo contraste simples de diferencas de dois niveis de um fator é estimável ". 


\subsubsection{Definiçónes e teoremas}

DEFINICĂO 3.1.2.1. [RAGHAVARAO, 1971]: Def̊ine a conectividade como: Un delineamento é dito conectado se todos os contrastes elementares são estimáveis. Se não acontece isto, ó chamado delineamento desconexo. Todos os autores citados restringiram o conceito de conectividade aos delineamentos de dois fatores sem interacăo.

TEOEEMA 3.1.2.1 [FAGHAVAFAO, 1971$]$ : A matriz [ de delineamento de um bloco (EIE) que satisfaz

$$
c_{V} E_{1}=0
$$

onde $\mathfrak{C}$ é uma matriz singular e tem $E_{1}$ como um vetor característico igual a zero, $\mathbb{C}$ é de posto máximo igual a $v-1$, de fato o posto da matriz $\mathbb{C}$ é relacionado à propriedade das conexões do delineamento.

TEOREMA 3.1.2.2 [RAGHAVARAO, 1971]: Um delineamento de blocos incumpletos é conectado se e somente se o posto da ma$\operatorname{triz} \mathbb{C}$ é $v-1$

TEOREMA 3.1.2.3 [RAGHAYARAO, 1971]: Num delineamento conectado os elementos da diagonal principal da matriz $\mathbb{C}$ são todos positivos. Além disso os menores principais de todos as ordens $(1,2, \ldots, v-1)$ da matriz $\mathbb{C}$ são todos positivos. TEOREMA 3.1.2. 4 [RAGHAVARAO, 1971]: Num delineamento conectado, os cofatores de todos os elementos da matriz $C$ tem o mesmo valor positivo.

Das definicões enunciadas pode-se inferir uma propriedade importante que caracteriza os delineamentos em 
blocos: A conectividade fornece estimadores não viesados dos contrastes elementares dos tratamentos.

ECCLESTON \& HEDAYAT (1974) classificam os delineamentos conexos, procurando otimizar as análises dos experimentos com essa característica.

$$
\text { Estes autores classificam os delineamentos de }
$$

blocos incompletos conexos en três categorias:

a Corexbes Locals: Um delineamento ó dito ser conectado localmente quando nac todas as observacose participam na estimaço.

b) Conexões Globais: Um delineamento é dito ser conectado globalmente quando todas as observacões participam na estimação.

c) Conexões Pseudo-Globais: Este tipo de delineamento reune as duas características do delineamento local

- do delineamento global.

Atendendo a estrutura dos dados, pode-se caracterizar a conectividade como:

1) De estrutura Conexa: Deste modo abrange todos os delineamentos de blocos incompletos, sejam estes balanceados ou parcialmente balanceados, mais um setor dos BNB.

2) De estrutura Desconexa: constituido pelo restante do setor de blocos não balanceados, como se observa no gráfico. 


\section{DELINEAMENTOS EM BLOCOS INCOMPLETOS}

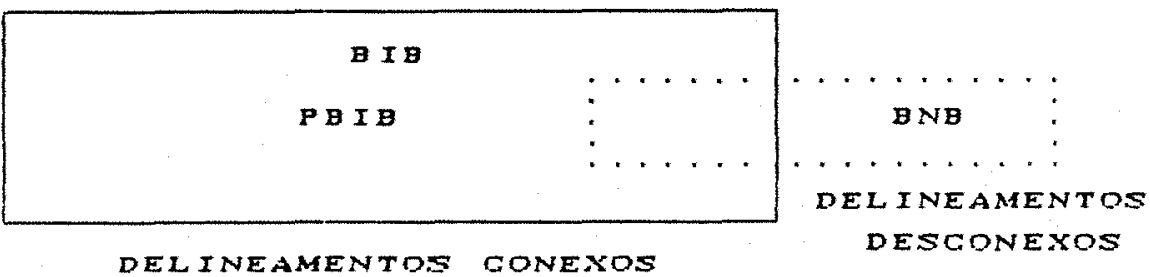

DEFINICAO 3.1.2.2 [RAGHAVARAO, I971]: Um delineAmEnto balarceado se todos os contrastes elementares säo estimáveis com a mesma precisăo. Essa é uma condicăo necessária a suficiente de bal anceamento nos delineamentos conexos.

Segundo RAO (1958), afirma que um delineamento é balanceado se e só se todas as raízes características da matriz $\mathbb{C}$ são diferentes de zero e iguais entre si.

3.2. Modelos de Médias

\subsubsection{Conectividade em modelo de medias}

GRAYBILL (1961) apresenta um modelo de efeitos fixos como segue:

$$
\mathbf{Y}=\not \mathbb{\beta} \beta+\varepsilon
$$

$Y, X R$, e $\beta$ são parâmetros $j a ́$ conhecidos. o vetor $\varepsilon \sim(0, I \circ C)$. - modelo apresentado não contempla interacão entre blocos e tratamentos. A equação do modelo é:

$$
Y_{i j k}=\mu+\tau_{i}+\beta_{j}+\varepsilon_{i j k}
$$

onde $i=1,2, \ldots, v ; j=1,2, \ldots, b ; k=0,1,2, \ldots, n_{i j} \theta \theta$ denota o vetor de parâmetros de dimensão $v+b+1$, no caso de 
45.

total de parcelas (delineamentos conexos) a matriz lR é de posto $v+b-1$ es componentes individuais de $\theta$ năo são estimáveis individualmente, o valor esperado na parcela $i, j$ - chamado de média da parcela $i, j$ simbolizado por $\mu_{i j}$ Assim

$$
\left.E C Y_{i j k}\right)=\mu_{i j}=\mu+\tau_{i}+b_{j}
$$

Uma alternativa para a expressão [3.2.1a] em termos do valor esperado é:

$$
\begin{gathered}
Y_{i j k}=\mu_{i j}+E_{i j k} \\
\text { modelo }[3.2 .1 \mathrm{~d}] \text { contém vb paràmetros, os }
\end{gathered}
$$
possiveis valores que assume a expressăo $\{3.2 .1$ c năo são funcionalmente independentes, e sua relacão funcional vem dada por:$$
\mu_{i j}-\mu_{i-j}-\mu_{i j}+\mu_{i \cdot j-}=0
$$$$
\text { [3.2.1e] }
$$$$
\operatorname{com} i, i=1, \ldots, v ; j, j=1, \ldots, b \quad i \neq i, e j \neq j \text {. }
$$

A expressăo [3.2.1e] é conhecida como "Condicão de não Interacão", a qual pode-se escrever de modo equi valente.

$$
\mu_{i j}-\mu_{v j}-\mu_{i b}+\mu_{v b}=0
$$

$i=1, \ldots,(v-1) ; j=1, \ldots,(b-1)$.

Por quanto existem somente vb $-(v-1)(b-1)=$ $=v+b-1$ parâmetros definidos a serem estimados.

As médias restantes são obtidas a partir de [3.2. $1 \mathrm{f}]$. 
46.

\subsubsection{Exemplo do modelo de Graybill}

A seguir apresenta-se um exemplo simples que ilustra o modelo apresentado por GRAYBILL (1901). Trata-se de um delineamento em blocos completos com dois tratamentos e duas repeticões.

O modelo considerado é:

$$
Y_{i j k}=H+t_{i}+b_{j}+\varepsilon_{i j k}
$$

$\operatorname{con} i=1,2 ; k=1,2 ; k=1,2$.

Sua expressăo matricial será:

$$
\left[\begin{array}{l}
y_{11} \\
y_{12} \\
y_{21} \\
y_{22}
\end{array}\right]=\left[\begin{array}{lllll}
1 & t_{1} & t_{2} & b_{1} & b_{z} \\
1 & 1 & 0 & 1 & 0 \\
1 & 0 & 1 & 1 & 0 \\
1 & 0 & 1 & 0 & 1
\end{array}\right]\left[\begin{array}{l}
t_{1} \\
t_{2} \\
b_{1} \\
b_{z}
\end{array}\right]+\left[\begin{array}{l}
e_{11} \\
e_{12} \\
e_{21} \\
e_{22}
\end{array}\right]
$$

Sem considerar perda de parcelas, a expressão matricial em termos das médias da "condicão de não interacão" deve conter vb $=4$ parâmetros 1 inearmente independentes. 


$$
\begin{aligned}
& \mu_{11} \mu_{12} \mu_{21} \mu_{22}
\end{aligned}
$$

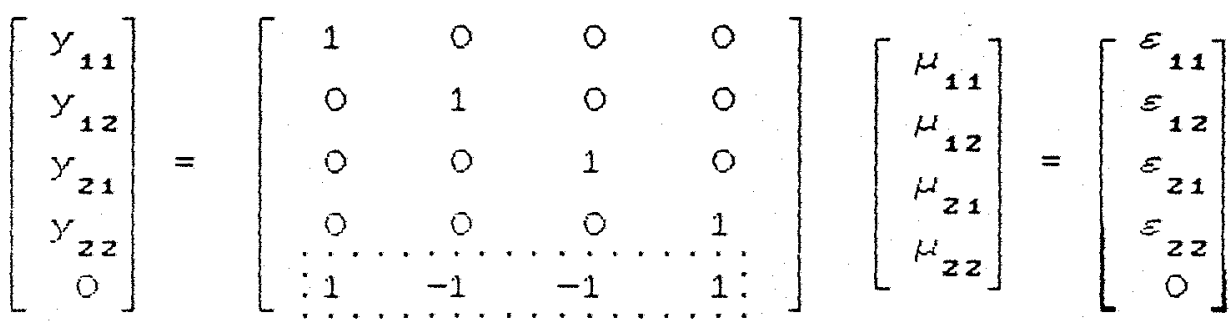

$$
\begin{aligned}
& \rightarrow \text { restricão de condicão } \\
& \text { DE NÄO INTERACÃO }
\end{aligned}
$$

3.2.3. Modelo de médias simplificado

$$
\text { MURRAY }=\text { SMITH C1985 fizeram contribuigóes }
$$

nas áreas de estimabilidade, conectividade e testabilidade para o modelo linear de posto incompleto de efeitos fixos no caso de perda de parcelas. A perda de parcelas determina o grau de estimabilidade dos parâmetros, o que condiciona a possibilidade de formulacão de testes de hipóteses envolvendo os paràmetros mencionados. Somente serão testáveis hipóteses que envol vam parâmetros pertencentes a grupos conexos.

Os autores mencionados alertam o pesquisador desprevenido para a utilizacão cautelosa de pacotes computacionais, já que muitos destes não consideram casos de desconexão.

$$
\text { - modelo apresentado por MURRAY \& SMITH }
$$
(1985) descreve uma parcela qualquer em termos das médias populacionais, como segue:

$$
\mathbf{Y}=\mathbf{w}_{\mu}+\varepsilon
$$

sujeito à restricão

$$
\mathbf{G}_{\mu}=\mathbf{g}
$$


no qual $Y$ é definido como o vetor das observacöes, $\mid \dot{\theta}$ a matriz de variáveis indicadoras cujos componentes da diagonal são vetores coluna de uns de extensão $n_{i}$ Ccada un desses vetores é denotado por $J_{i}$ l onde $n_{i}$ é o número de observacoues da i-ésima popularăos, o vetor $\mu$ tem $\mu_{i}$ componentes correspondentes às médias populacionais. A matriz $G$ é de dimensão Exp Conde s ó posto de $G e p$ é o número de populacões: 0 vetor g define uma série de combinarbes lineares de parametros que assumem valor zero.

Quando se estabelece uma relacăo linear de parâmetros (médias) como em [3.2.3b] o modelo é chamado de restrito, quando não existirem essas relacôes o modelo é chamado de irrestrito.

A titulo de exemplo toma-se o modelo de médias de dois fatores sem interacăo descrito em 3.2. nas expressöes [3.2.1b] ou [3.2.1d] e[3.2.1f], na qual a forma matricial é dada como

$$
x^{\prime}=\left[y_{112}, y_{112}, \ldots, y_{v b n_{v b}}\right]
$$

sendo

$$
\begin{aligned}
& w=d i \text { agonal } C_{j} j_{i j} i=1,2, \ldots, v \otimes j=1,2, \ldots, b \\
& \left.\mu^{2}=C_{\mu_{11}}, \mu_{12}, \ldots, \mu_{v b}\right)^{2} \\
& G=D_{v} \otimes D_{b} \\
& g=0
\end{aligned}
$$

onde denota o produto de KRONECKER e as matrizes $\mathrm{D}$ são definidas da forma:

$$
D_{a}=\left[\begin{array}{l:l}
I_{(a-1)} & -J(a-1)
\end{array}\right]
$$


49.

onde I é uma matriz identidade de dimencão a-1, e $J$ é um vetor coluna de uns de extensão a-1.

Ao rearranjar as colunas da matrig $G$, determina a particăo da matriz $G$ original em duas submatrizes $G_{1}$ Cde dimensäo sxip-si) e $G_{z}$ (de dimencăo sxs e posto s. Assim este rearranjamento condiciona uma modificaräo da ordem das linhas de h para corresponder a particão de $G$, da seguinte forma:

$$
\mu^{\prime}=C_{H}^{\prime} H_{2}^{\prime}
$$

Em funcüo disso [3.2.1b] pode ser reescrita

como a segue:

$$
G \mu=G_{1} \mu_{1}+G_{2} \mu_{2}=0
$$

$G$ tem posto completo, e existe uma solucão para $\mu$ em termos de $\mu_{1} \ominus$ é $\mu_{2}=-G_{2}^{-1} G_{1} \mu_{1}$ pois se $G_{2} \mu_{2}=-G_{1} \mu_{1}$, pré-multiplicando por $G_{2}^{-1}$ se tem $G_{2}^{-1} G_{2} \mu_{2}=-G_{2}^{-1} G_{1} H_{1}$

$$
\mu_{2}=-G_{2}^{-1} G_{1} \mu_{1}
$$

A particão de $\mu$ é independente dos dados obtidos e independente do número de parcelas perdidas $m$ e sua local i zação.

A participacão depende unicamente da matriz G e das relacôes lineares amostrais das médias.

Assim a expressão [3.2. 3a) pode ser reescrita em termos de $[3.2 .3 j]$, resul tando:

$$
y=\left(w_{1} w_{2}\right)\left[\begin{array}{l}
\mu_{1} \\
\mu_{2}
\end{array}\right]+e \cdot[3.2 .3 k]
$$

sendo

$$
Y=C w_{1}: w_{2}{ }^{2}\left[\begin{array}{c}
I \\
-G_{2}^{-1} G_{1}
\end{array}\right] \mu_{1}+e \quad[3.2 .31]
$$


pois $\mu_{2}=-G_{2}^{-1} G_{1} \mu_{1} \quad \dot{e} v=w_{1}-w_{2} G_{2}^{-1} G_{1}$ se tem

$$
y=v_{\mu_{1}}+e
$$

[3. 2. 3m]

sendo $v$ do posto $N_{x}(p-s)$ onde $N$ é o número de observacões: y'y é năo singular, entäo pode-se aplicar o método de minimos quadrados para o modelo de posto completo não restrito, obtendo-se o estimador BLUE para $\mu_{1} e$

$$
\hat{\mu}_{1}=\left(V^{\prime} y\right)^{-1} V^{\prime} Y
$$

o estimador BLUE de $\mu_{z} \dot{0}$

$$
\ddot{H}_{2}=-G_{2}^{-1} G_{1} \ddot{r}_{1}
$$

Se não existir perda de parcelas o posto de $V$ é $(p-s)$; onde $p$ é o número de médias a serem estimadas e ó - posto da matriz G; se existir perda de parcelas p pode ainda ter posto (p-s) nestes casos as expressões [3.2. 3n] a [3.2.30] são ainda estimadores BLUE únicos de $\mu_{1} \odot \mu_{2}$. Se o posto de $V$ for menor que $(p-s)$ então está-se no modelo de médi as superparametrizado $(3.3 .1)$.

Como consequência do exposto tem-se uma nova definicăo de conectividade.

DEFINICÃO 3.2.3.1 [MURRAY \& SMITH, 1985]: Um experimento que consta de um conjunto de dados associados ao modelo de médias $\mu$, é conectado se unicamente se puder ser estimado linearmente, esta defincão é válida tanto para o modelo restrito como para o modelo irrestrito.

Resulta importante mencionar que a verificacão geométrica de conectividade para dois fatores năo é válida para delineamentos de maior número de fatores. 
Quando Y não é de posto coluna completo, năo é possivel achar $\left(v^{\prime} v\right)^{-1}$, utiliza-se no seu lugar uma inversa generalizada, năo é aconsel hável o uso do modelo dado em [3.2.3m] nos casos de posto incompleto.

Nos casos de desconexăo é necessário que o experimento seja minuciosamente examinado, para ver a quantidade de informacão perdida na perda de parcelas e quanto de informaç̃o é disponível.

$$
\text { Quando existir perda de parcelas é possivel }
$$

estimar quaisquer parcelas pela combinaräo das outras, mediante a restriøão $[3.2 .3 b]$.

Porém em outros casos, estas poderam ser estimadas unicamente mediante combinaçöes lineares das parcelas crescentes.

\subsection{Teste de hipóteses}

No estudo dos modelos com perda de parcelas, um dos fatores de maior interesse a a apresentacão de diferentes programas computacionais na análise de variâneia das médias das parcelas.

Ao adotar um modelo para um determinado experimento, o fazemos com o interesse de examinar certas funcões lineares das médias das parcelas. Esta investigacão assumida é proposta pela hipótese linear:

$$
H_{\mu}=O
$$


52.

onde $H$ é de dimensăo hxp de posto h e sua alternativa é

$$
\text { Hes } \neq 0 \text {. }
$$

A perda de parcelas permite considerar as seguintes situaröes:

a) f possivel testar estas hipóteses;

b) caso contrário pode ser reestruturada uma nova hifótese.

A resposta à primeira consideracăo é que se o modelo é conectado é possivel testar a hipótese original, podendo ser reescrito om termos da média $\mu_{1}$ fazendo o conveniente rearranjamento e a particão de $G$ e $\mu$ na relacăo $[3,2,4 a]$.

Se $H$ é igualmente rearranjada e particionada, então [3.2.4a] tem sua forma equivalente a

$$
C H_{1}-H_{2} G_{2}^{-1} G_{1} J_{1}=0
$$

Se o modelo não é conectado então a hipótese original pode não ser testável, sendo no entanto testável algum sub-conjunto de hipóteses originais. Esta é a chamada também hipótese efetiva le um subconjunto de funcões originais que são possiveis de ser observadas as parcelas perdi das.

MURRAY \& SMITH (1985) sugerem que nos casos não conectados não tem sentido apresentar uma tabela de análise de variância a qual dê um teste para um efeito particular (por exemplo ou efeito médio ou interacão). 
53.

\subsubsection{Modelos conectados}

\subsubsection{Conceituaçăo}

GRAYBILL (1970) define os modelos conectados de dois fatores a partir da equacão

$$
y_{i j k}=\mu+\alpha_{i}+\tau_{j}+\varepsilon_{i j k}
$$

onde $k=0,1, \ldots, n_{i j} ; \quad i=1,2, \ldots, v>1 \Leftrightarrow j=1, \ldots, b>1, n \dot{\theta}$ um inteiro näo regativo e o experimento deve ser conectado. o modelo apresentado tem a caracteristica de ser superparametrizado sem interacão de efeitos fixos é de posto incompleto.

Se o conjunto dos $n_{i j}$ cumpre a condicão de que todos os contrastes $\alpha_{i}-\alpha_{i}$, são estimáveis para $i, i=1,2, \ldots$ $\ldots, e_{i} x_{i}$, entăo o modelo é definido como A-conectado.

$$
\text { Se } \tau_{j}-\tau_{j} \doteq \text { estimável para } j, j=1,2, \ldots, b \text { e }
$$
$j^{\prime} j$, então o modelo é definido como modelo conectado-T.

Desse modo se o modelo A é conectado, também I é conectado, e vice-versa.

Para se esclarecer esta definicăo de conexão, apresenta-se o seguinte teorema.

TEOREMA 3.2.5.1.1 [GRAYBILL, 1976]: Se $\varepsilon_{i j} \sim N C \mu, \sigma^{2}$ ) ou também no caso em que os erros $\varepsilon_{i j} \sim$ NCO, $\alpha^{2}$, então, somente serão estimáveis as combinacões lineares de $\alpha_{i}$ que sejam contrastes. O delineamento será A-conectado se e somente se todos os contrastes dos $\alpha_{i}$ são estimáveis e em forma equivalente define-se para o caso dos contrastes ${ }{ }_{j}$ esti máveis. 
54.

\subsubsection{Exemplo aplicativo}

Para exemplificar os conceitos colocados anteriormente escolheu-se um delineamento inteiramente ao acaso com arranjo de tratamentos fatorial de dois fatores. Iratase de um arranjo fatorial axe com o seguinte numero de repetiços:

\begin{tabular}{l|l|l|} 
& $\tau_{1}$ & $\tau_{z}$ \\
\hline$\alpha_{1}$ & 2 & 2 \\
\hline$\alpha_{2}$ & 1 & 2 \\
\hline
\end{tabular}

- modelo matemático superametrizado com inte-

racão é

$$
y_{i j k}=\mu+\tau_{i}+b_{j}+\gamma_{i j}+\varepsilon_{i j k}
$$

cuja matriz de delineamento é

$$
R=\left[\begin{array}{ccccccccc}
\mu & t_{1} & t_{2} & b_{1} & b_{2} & t_{1} b_{1} & t_{1} b_{2} t_{2} b_{1} t_{2} t_{2} \\
1 & 1 & 0 & 1 & 0 & 1 & 0 & 0 & 0 \\
1 & 1 & 0 & 1 & 0 & 1 & 0 & 0 & 0 \\
1 & 1 & 0 & 0 & 1 & 0 & 1 & 0 & 0 \\
1 & 0 & 1 & 1 & 0 & 0 & 0 & 1 & 0 \\
1 & 0 & 1 & 0 & 1 & 0 & 0 & 0 & 1 \\
1 & 0 & 1 & 0 & 1 & 0 & 0 & 0 & 1
\end{array}\right]
$$

- modelo matemático de médias com interacão é

$$
y_{i j k}=\mu_{i j}+e_{i j k}
$$

De acordo com a expressão [3.2.3a] a matriz de delineamento $w$ pode-se construir mediante as colunas das interações $\gamma_{i j}$ como segue 


$$
W=\left[\begin{array}{llll}
\mu_{11} & \mu_{12} & \mu_{21} & \mu_{22} \\
1 & 0 & 0 & 0 \\
0 & 1 & 0 & 0 \\
0 & 1 & 0 & 0 \\
0 & 0 & 1 & 0 \\
0 & 0 & 0 & 1 \\
0 & 0 & 0 & 1
\end{array}\right]
$$
pressăo [3.2.5.10] a matriz de delineamento w é de posto completo, o o número de observacóes é diferente para cada tratamento o que faz mais viável o uso do modelo de médias.

3.2.6. Modelo de médias e algoritmo geométrico apresentado por Searle

\subsubsection{Conceituaçăo}

Esse algoritmo é apresentado por SEARLE (1987) para o estudo do modelo de dois fatores com classificacão cruzada ou de um fator com uma restricão na casualizacão. Nesse trabalho o autor apresenta um modelo de médias para salvar as dificuldades de analise apresentadas pelos modelos super par ametrizados.

Quando a ocorréncia de parcelas ocupadas entre parcelas de dados vazios é suficientemente dispersa então algum conjunto de funcões, podem não ser estimáveis. Assim 
por exemplo no caso do modelo sem interacăo, ECY $Y_{i j k} k^{\prime}=\mu_{i}+\tau_{j}$ algumas diferencas da forma $\mu_{i}-\mu_{i}$. para $i \neq_{i} \otimes \tau_{j}-\tau_{j}$, para jłj podem não ser estimáveis. Quando todas as diferencas podem ser estimadas, entăo pode-se estimar todo o conjunto de parcelas de un modelo, isto é $\mu_{i j}=\mu_{i}+\tau_{j} \dot{e}$ estimável $\forall_{i}, \forall_{j}$ embora existam parcelas vazias. Essa característica tipifica os delineamentos conexos.

Na continuacão apresenta-se um exemplo que caracteriza a posibilidade de estimarão de uma determinada média a partir de uma combinacão linear de outro conjunto de médias conhecidas num experimento com perda de parcelas. Assim tem-se as seguintes médias $\mu_{11}, \mu_{23}, \mu_{21}$ das parcelas ocupadas, e a partir dessas três médias pode-se obter a média $\mu_{13}$ como se segue:

$$
\begin{aligned}
\mu_{13} & =\mu_{1}+\tau_{3}=\mu_{1}+\tau_{1}+\mu_{2}+\tau_{3}-\left(\mu_{11}+\tau_{1}{ }^{2}\right. \\
= & \mu_{11}+\mu_{23}-\mu_{21}
\end{aligned}
$$

Portanto é possivel se obter seus BLUES, assim - BLUE da parcela 1,3 no modelo sem interacão é obtido mediante a restricão.

$$
\begin{array}{r}
\quad \mu_{i j}-\mu_{i j}-\mu_{i j}+\mu_{i j}=0 \\
\therefore \quad \hat{\mu}_{13}=\hat{\mu}_{11}+\hat{\mu}_{23}-\hat{\mu}_{21}=\hat{\mu}_{1}+\tau_{3}
\end{array}
$$

\subsubsection{Un exemplo gráfico}

No gráfico 1 apresenta-se um diagrama representando as parcelas ocupadas, simbolizadas mediante o sím- 
bolo $v$, os sub indices $i$ correspondem às linhas e os j às col unas.

\begin{tabular}{|c|c|c|c|}
\hline & & $v^{--}$ & $-v$ \\
\hline & $v^{--}$ & $-v$ & $v$ \\
\hline$v--$ & $-v$ & & \\
\hline
\end{tabular}

Gráfico 1. Diagrama representando um caso em que pode ser estimada uma parcela a partir das demais.

\begin{tabular}{|l|l|l|l|}
\hline & & $\vartheta--$ & $-v$ \\
\hline & & $v--$ & $-v$ \\
\hline$v$ & $v$ & & \\
\hline
\end{tabular}

Gráfico 2. Di agrama representando um caso em que não pode ser estimada uma parcela a partir das demais.

Pode-se observar que no Gráfico 1 a média da parcela 1,2 pode ser estimada, através das parcelas 1,4; 2,4 e 2,2 que estão presentes e ainda esta estimacão constitue um. BLUE, de modo que ao serem estimáveis esses dados são conectados. Num modelo com interacão isso não acontece, a parcela 1,2 não teria BLUE por que a parcela é vazia.

Ja no Gráfico 2 a ausência da parcela 2,2 impede a estimacão da parcela 1,2 assim esses dados são desconectados.

DEFINIGĂO 3.2.6.2.1 (SEARLE, 1987): Dados conectados são aqueles nos quais para todos os efeitos médios dos fatores, todas as diferencas entre os níveis de um determinado fator são esti máveis. 
58.

SEARLE (1987) apresenta um algoritmo geométrico para os modelos de classificacão cruzada dos fatores. Um modelo desse tipo é conectado se as parcelas ocupadas, num reticulado similar aos graficos 1 e 2 , podem ser ligadas por uma linha contínua com as seguintes características: a linha contém unicamente segmentos horizontais e verticais, que mudam de direcão unicamente no caso em que as parcelas estăo ocupadas. Se todas as parcelas estä ocupadas obviamente o delineamenmto é conectado.

A continuacão apresentam-se dois gráficos que ilustram duas situaçóes de conectividade:

\begin{tabular}{|c|c|c|c|c|c|}
\multicolumn{2}{c}{1} & 2 & 3 & 4 & 5 \\
\hline 1 & $v^{-}$ & $--v--$ & ---- & $-v-v$ & $-v$ \\
\hline 2 & $v-$ & $--v--$ & $-v$ & & $v$ \\
\hline 3 & & & $v-v$ & $-v$ & \\
\hline
\end{tabular}

Gráfico 3. Diagrama de um delineamento conexo.

\begin{tabular}{|c|c|c|c|c|c|}
\hline & 1 & 2 & 3 & 4 & 5 \\
\hline 1 & $v--$ & $-\cdots--$ & $--?$ & & \\
\hline 2 & & $y^{--}$ & $--i^{--}$ & $--v-$ & $--v$ \\
\hline 3 & & 1 & $v$ & & \\
\hline 4 & & $v-$ & $-\cdots$ & --2 & \\
\hline
\end{tabular}

Gráfico 4. Diagrama de um delineamento desconexo.

No gráfico 3 representa-se um delineamento conexo, e o gráfico 4 um delineamento desconexo, no entanto no gráfico 4 caracteriza-se como um delineamento desconexo pelo 
59

fato que existe duas sequencias de linhas contínuas, que permitem a identificacão clara de dois grupos de conexão.

3.2.7. Modelo de médias de efeitos fixos de Horking

HOCKING (1985) apresenta um modelo de médias para dois fatores na forma matricial.

$$
\begin{gathered}
y=\text { Wht } \\
\text { [3.2.7a] } \\
\text { Sujeito a restricád G }=9
\end{gathered}
$$

como o descrito no item $[3.2 .31, y$ é o vetor de respostas $H=D_{p}\left(J_{n}\right) e$ uma matriz diagonal de dimensão nxp chamada matriz de incidência, a qual indica um número de observacões em cada população, $J_{n}$ é um vetor de uns referente as observacões do tratamento i. O vetor $\mu$ é composto por médias, $G$ e g são matrizes análogas as definidas no item 3.2.2.

No caso do modelo de dois fatores são utilizados dois sub-indices para descrever as médias,

$$
\begin{aligned}
\mathbf{Y}_{i j k} & =\mu_{i j}+e_{i j k} \\
i & =1, \ldots, v \\
j & =1, \ldots, b \\
k & =1, \ldots, n_{i j} \\
e & \left.\sim N C O, I \sigma^{2}\right) .
\end{aligned}
$$

O número de populacões é obtido multiplicando-se $v \times b=p$. Esse modelo contempla a possibilidade de perda de parcelas.

No modelo de um fator não é necessário o uso de restricão, porém no modelo de dois fatores sua utilização 
6.

é frequente. Essa restricăo é identica a utilizada nos modelos de médias já expostos nos itens 3.2.3, 3.2.5 e 3.2.6, ou seja

No modelo de dois fatores sem interacăo, irrestrito, com $n_{i j}>0$ é possivel estimar a média

$$
\begin{aligned}
\hat{\mu}_{i j}=\bar{Y}_{i j} \sim N \mu_{i j} & =\sigma^{2} / n_{i j}{ }^{2} \\
1 & \leq i \leq v \\
1 & \leq j \leq b
\end{aligned}
$$

As estimativas $(\hat{\mu}) s a$ independentes.

No caso do modelo restrito näo interativo, a

restriçăo:

$$
\begin{aligned}
\mu_{i j}-\mu_{v j} & -\mu_{i b}+\mu_{v b}=0 \\
i & =1, \ldots, v-1 \\
j & =1, \ldots, b-1
\end{aligned}
$$

pode ser também escrita de forma equivalente,

$$
\begin{aligned}
\mu_{i j}-\mu_{i .} & -\mu . j+\mu, \ldots \\
i & =1, \ldots, v-1 \\
j & =1, \ldots, b-1
\end{aligned}
$$

Note-se que no processo de estimacão tanto para o modelo irrestrito, quanto para o restrito, os contrastes envolvendo médias de parcelas ocupadas $\left[n_{i j}>\right.$ OS serão estimáveis. Porém, no caso da existência de parcelas perdidas, somente poderão ser estimáveis contrastes provenientes da aplicacão do modelo restrito quando o delineamento for conexo ou quando as médias pertencerem a um mesmo grupo de conexão. Os conceitos de estimabilidade mencionados aplicam-se na el aboracão de testes de hipóteses e intervalos de confianca. 
61.

\subsubsection{Modelo reduzido}

Dentre os modelos restritos uma alternativa é - Modelo Reduzido, que permite obter estimadores utilizandose uma restricão $\mathrm{G} \theta=g$, conde $\theta$ é o vetor de paràmetrosl, para reduzir o número de paràmetros. O modelo é o seguinte:

$$
Y=\mu_{1} \mu_{1}+H_{2} \mu_{2}+e
$$

sujeito à restricão

$$
G_{1} \mu_{1}+G_{2} \mu_{2}=g
$$

$\operatorname{com} G_{1}$ matriz não singular e onde

$$
\begin{aligned}
\mu_{1}\left\{\mu_{i j} i\right. & =1, \ldots, v-1 ; \\
j & =1, \ldots, b-1 ; \\
\mu_{2}\left\{\mu_{i b} i\right. & =1, \ldots, a-1 \\
\mu_{v} j & =1, \ldots, b .
\end{aligned}
$$

Assim se $g=0$ o modelo reduzido pode-se expressar como:

$$
Y_{R}=W_{R} H_{R}+e
$$

onde

$$
W_{R}=W_{2}-W_{1} G_{1}^{-1} G_{2}
$$

$\ominus \mu_{R}=\mu_{2}$, pois $G_{1} \mu_{1}+G_{2} \mu_{2}=0 \ominus W_{R} \mu_{R}=H_{1} \mu_{1}+W_{2} \mu_{2}$

Da expressão [3.2.7.2b] premultiplicando-a por $G_{1}^{-1}$ e despejando $H_{1}$ tem-se:

$$
\begin{aligned}
& G_{1}^{-1} G_{1} \mu_{1}+G_{1}^{-1} G_{2} \mu_{2}=G_{1}^{-1} g \\
& \mu_{1}=G_{1}^{-1} g-G_{1}^{-1} G_{2} H_{2} .
\end{aligned}
$$

DEFINIGĂO 3.3.5.1 HOCKING (1985): Um modelo é dito conexo se todos os componentes de $\mu$ são linearmente estimáveis, e tais que $G_{m m}=I_{m}(m=v+b)$ 
62.

No caso do modelo irrestrito, a condicão de conexăo requer que $n_{i j}>0$. Já no restrito, a condicão é que G seja não singular, portanto não depende do suposto que $n_{i j}>0$. Porém existe uma dificuldade proveniente do fato de que, ao estimar $H_{R}$, se requer que $W_{R}$ tenha posto coluna completo.

TEOREMA 3.2.7. [HOCKING, 1985]: As médias das parcolas săo conectadas se, é somente se a matriz $W_{R}$ do modelo reduzido tem posto coluna completo.

Se $W_{R}$ năo tem posto coluna completo procede-se de duas formas: al Aceitar o modelo efetivo, reparâmetrizando e aplicando restricões ao modelo inicial cesse tópico é desenvolvido nos capítulos IV, $V$ e VI da obra mencionada de HOCKING (1985)), ou b) anular $m-t$ colunas em $W_{R}$ onde $t$ é - posto de $G_{m m}$ de forma que a matriz resultante tem pocto coluna completo. Assinalando-se o valor zero para os parâmetros correspondentes, então os componentes restantes de $\mu_{k}$ são estimados de maneira usual ${ }^{\prime}$ é estimada por [3.2.7.1f]. Este procedimento é aplicado comumente no uso do modelo reduzi do.

A título de ilustracão considera-se o seguinte exemplo:

Exemplo 1: Considere a parcela perdida $\Omega_{11}=0$ é conhecidas as estimativas das seguintes médias $\mu_{12} \mu_{21} \ominus \mu_{22}$ ' num del ineamento conectado.

Sabe-se que $\mu_{11}=\mu_{12}+\mu_{21}-\mu_{22}$ 
63.

Sabemos que $\mu_{i j}=\mu_{i}+t_{j}$ então a estimativa de $\hat{\mu}_{11}$ em funcão outras médias é

$$
\hat{\mu}_{11}=\hat{\mu}_{12}+\hat{\mu}_{21}-\hat{\mu}_{22}
$$

pois

$$
\begin{gathered}
\hat{\mu}_{11}=\hat{\mu}_{1}+\hat{t}_{2}+\hat{\mu}_{2}+\hat{t}_{1}-\hat{\mu}_{2}-\hat{t}_{2} \\
\cdot \hat{\hat{\mu}_{11}}=\hat{\mu}_{1}-\hat{t}_{1}
\end{gathered}
$$

No caso de um delineamento desconexo do modelo irrestrito, considere o seguinte exemplo 2 .

$$
\begin{array}{ccc}
n_{11} & n_{12} & 0 \\
n_{21} & n_{22} & 0 \\
0 & 0 & n_{33}
\end{array}
$$

Pode-se observar que as restricões de não interacão do modelo irrestrito não são de ajuda na estimacão das médias de parcelas perdidas; assim no exemplo 2 se tem dois conjuntos desconexos, o primeiro formado pelas parcelas $n_{11}, n_{12}$ e $n_{21}$ e $n_{22} ; 0$ segundo subconjunto consta de uma única, a parcela (3.3).

\subsubsection{Modelo efeti ro}

Dado o modelo restrito

$$
y=w \mu+e
$$

[3.2.7.2a]

com a restricão $G_{\mu}=g$

[3.2.7.2b]

então a matriz de Delineamento escrever-se na forma particionada

$$
w=\left[W_{m}, W_{0}\right]
$$


64.

$$
\mu=\left[\begin{array}{l}
\mu_{m} \\
\mu_{c}
\end{array}\right]
$$

onde ${ }_{m}$ é uma matriz de zeros de dimensăo $n \times \mathrm{m} e$ wo $=$ $D_{p-m}\left(j_{n i}\right), \mu_{m}$ e $\mu_{0}$ săo os vetores de médias correspondentes as parcelas perdidas e as parcelas observadas.

Do mesmo modo pode-se particionar a matriz $\mathfrak{G}$ como

$$
G=\left[\begin{array}{l:l}
G_{m} & G_{0}
\end{array}\right]
$$$$
[3.2 \cdot 7 \cdot 2 e]
$$

Nós devemos eliminar $\mu_{m}$ do modelo para expressá-lo em termos de $\mu_{0}$ usando as restricões e logrado isto mediante a reducão das linhas em $G=g$ em [3.2.7.2e] obtendo-se

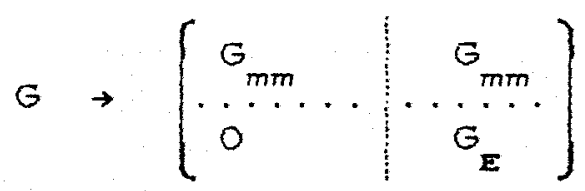

$$
\begin{aligned}
& \theta g \rightarrow\left[\begin{array}{c}
G_{m} \\
G_{E}
\end{array}\right]
\end{aligned}
$$

Se a matriz $G_{m m}$ for não singular cdeposto Iinha completos, o delineamento é conexo, e as parcelas perdidas são estimáveis assim como os contrastes entre os niveis de fatos $\alpha$ ou $\beta$.

Se a matriz $G_{m m}$ for singular o delineamento desconexo, o que implica que nem todas as parcelas perdidas são estimáveis portanto, nem todos os contrastes entre os níveis do fator $\alpha$ ou níveis do fator $\beta$ são estimáveis. 
Assim no caso de parcelas vazias define-se o modelo efetivo como:

$$
y=\mu_{0}+e
$$

restrito a $G_{E_{0}} \mu_{0} g_{E}$ chamada restricăo efetiva.

3.2.7.3. Exemplo do modelo reduzido de médias de HOCKING

$$
\text { Tem se dirigido um experimento para estudar os }
$$
efeitos de períados extensos de congelacăo no cresciment.o da massa do pão. Um fator de interesse neste estudo foi o tipo de farinha fina usada. O experimento consiste no preparo de quatro fornadas de massa de farinha com cada três tipos de farinhas fina e congelacão para um determinado tempo. Os dados são apresentados na tabela 3.2 onde as respostas anotadas de volume fermentado depois de quatro horas de removido do congel ador.

\begin{tabular}{|c|c|c|c|c|c|c|}
\hline & & $\begin{array}{c}\text { nível } 1 \text { do } \\
\text { niveis do } \\
1\end{array}$ & $\begin{array}{c}\text { fator } \varnothing \\
\text { ator } \alpha\end{array}$ & ní & $\begin{array}{l}\operatorname{rel}_{1} \mathrm{~d} \\
\operatorname{reis}\end{array}$ & $\begin{array}{l}\text { do fator } 0 \\
\text { lo fator } a \\
2 \quad 3\end{array}$ \\
\hline & 1 & $y_{111} y_{211}$ & $Y_{311}$ & $y_{121}$ & $y_{221}$ & $y_{321}$ \\
\hline fornadas & 2 & $y_{112} y_{212}$ & $\mathbf{Y}_{312}$ & $y_{122}$ & $y_{222}$ & $Y_{322}$ \\
\hline repetições & 3 & $y_{113} \quad y_{213}$ & $Y_{\mathbf{3 1 3}}$ & $y_{123}$ & $y_{223}$ & $y_{323}$ \\
\hline$P$ & 4 & $y_{114} y_{214}$ & $y_{314}$ & $Y_{124}$ & $y_{224}$ & $y_{324}$ \\
\hline
\end{tabular}

Tabela 3.2

Onde o modelo superparametrizado tem a seguinte caracterizacão. 


$$
Y_{i j k}=\mu+\sigma_{i}+\theta_{j}+\rho_{k}+C a \theta_{i j}+E_{i j k}
$$

onde

$$
\begin{aligned}
& i=1,2,3 \text { indica os níveis do fator a } \\
& j=1,2 \text { indica os niveis do fator } \emptyset \\
& k=1, \Xi, 3,4 \text { indica o número de repeticós } \rho . \\
& Y_{\text {, jk }} \text { denota a resposta do i-ésimo nivel a, no j-ésimo } \\
& \text { nível de fiator } 0 \text { na k-ésima repeticão } o \text {. } \\
& \text { amo é nosso interesse exempliticar o modelo } \\
& \text { de módias vai se supor segundo os resultados teoridos apre- } \\
& \text { seritatos em HOCKING (1985) o seguinte modelo de médias. } \\
& Y_{i j k}=\mu_{i j}+e_{i j k}
\end{aligned}
$$

Nesse caso, dada a restricão imposta no modelo de năo interacăo segundo a expressão [3.2.7g], e considerando que o efeito do fator $\varnothing$ vai ter a mesma repercursăo nas repeticões temos que o modelo [3.2.7.3a] caracteriza o já conhecido modelo de dois fatores sem interacăo

$$
\begin{gathered}
\mathbf{Y}_{i j k}=\mu+\alpha_{i}+\phi_{j}+e_{i j k} \\
\operatorname{com} i=1,2,3, \quad j=1,2 \quad k=1, \ldots, n_{i j}
\end{gathered}
$$

A partir de agoro se considerarmos que

$$
\mu_{i j}=\mu+\alpha_{i}+\theta_{j}
$$

então

$$
\mathbf{Y}_{i j k}=\mu_{i j}+E_{i j k}
$$

A partir desse modelo de médias, vai-se mostrar a matriz

$$
\begin{gathered}
W=D_{0}(1)^{2} \\
\text { Nota-se que cada observacão esta dada pela } \\
\text { combinacão de suas médias, na qual } i=1,2,3 \text { (tipos) } \theta
\end{gathered}
$$


$j=1,2$ (vezes) com $k=1,2,3,4$ repeticões o que implica que existam $\mu_{i j}=6$ combinacões cada uma total de 24 observacões como segue.

$$
\begin{aligned}
& y_{111}=\mu_{11}=\mu_{12}+\mu_{31}-\mu_{32} \\
& y_{211}=\mu_{21}=\mu_{22}+\mu_{31}-\mu_{32} \\
& y_{311}^{\vdots}=\mu_{31}=\mu_{11}-\mu_{12}+\mu_{32} \\
& y_{121}=\mu_{12}=\mu_{11}-\mu_{31}+\mu_{32} \\
& y_{221}=\mu_{22}=H_{21}-\mu_{31}+\mu_{32} \\
& y_{321}=H_{32}=H_{22}-H_{21}+H_{31} \\
& =\left[\begin{array}{llllll}
\mu_{11} & \mu_{12} & \mu_{z 1} & \mu_{z 2} & \mu_{31} & \mu_{3 z} \\
1 & 0 & 0 & 0 & 0 & 0 \\
1 & 0 & 0 & 0 & 0 & 0 \\
1 & 0 & 0 & 0 & 0 & 0 \\
1 & 0 & 0 & 0 & 0 & 0 \\
0 & 1 & 0 & 0 & 0 & 0 \\
0 & 1 & 0 & 0 & 0 & 0 \\
0 & 1 & 0 & 0 & 0 & 0 \\
0 & 1 & 0 & 0 & 0 & 0 \\
0 & 0 & 1 & 0 & 0 & 0 \\
0 & 0 & 1 & 0 & 0 & 0 \\
0 & 0 & 1 & 0 & 0 & 0 \\
0 & 0 & 1 & 0 & 0 & 0 \\
0 & 0 & 0 & 1 & 0 & 0 \\
0 & 0 & 0 & 1 & 0 & 0 \\
0 & 0 & 0 & 1 & 0 & 0 \\
0 & 0 & 0 & 1 & 0 & 0 \\
0 & 0 & 0 & 0 & 1 & 0 \\
0 & 0 & 0 & 0 & 1 & 0 \\
0 & 0 & 0 & 0 & 1 & 0 \\
0 & 0 & 0 & 0 & 1 & 0 \\
0 & 0 & 0 & 0 & 0 & 1 \\
0 & 0 & 0 & 0 & 0 & 1 \\
0 & 0 & 0 & 0 & 0 & 1 \\
0 & 0 & 0 & 0 & 0 & 1
\end{array}\right]
\end{aligned}
$$

Observa-se que na tabela 3.2 não existe parcelas vazias pelo qual não é necessărio estabelecer nenhum tipo de restricão. 
68.

Supondo agora que a partir desta tabela năo existem as observacões $\gamma_{111}$ e $y_{211}$; mas nota-se que é possivel estimar ditas parcelas pois,

$$
\begin{aligned}
& y_{111}=\mu_{11}+e_{11 k} \\
& y_{211}=\mu_{21}+e_{21 k}
\end{aligned}
$$

Dada a restricăo do modelo de média [3.2.7g]

pode-se estruturar

$$
G_{\mu}=\left[\begin{array}{l}
\mu_{11}-\mu_{12}-\mu_{31}+\mu_{32} \\
\mu_{21}-\mu_{22}-\mu_{31}+\mu_{32}
\end{array}\right]=\left[\begin{array}{l}
0 \\
0
\end{array}\right]
$$

Uma consequència deste fiato é que

$$
\mu_{11}=\mu_{12}+\mu_{31}-\mu_{32}
$$

que no caso do modelo superparametrizado seu equi valente é

$$
\begin{gathered}
\mu_{11}=\mu+\alpha_{1}+\theta_{2}+\mu_{3}+\theta_{1}-\mu-\alpha_{3}-\theta_{2} \\
\mu_{11}=\mu_{1}+\alpha_{1}+\emptyset_{1}
\end{gathered}
$$

No que segue utiliza-se o modelo reduzido de médias com o objetivo de eliminar dois parâmetros utilizando a restricão já conhecida.

- modelo reduzido vem dado pela sua forma, matricial

$$
\mathbf{Y}=\mathbb{W}_{\mathbf{R}} \mu_{\mathbf{R}}+e
$$

onde o vetor de médias reduzido é $\mu=\mu_{12}, \mu_{22}, \mu_{31}, \mu_{32}$ 'é a matriz de coeficientes $\mathrm{H}_{\mathbf{R}} \mathrm{e}$ 
69.

$$
N_{R}=\left[\begin{array}{cccc}
\mu_{12} & \mu_{22} & \mu_{31} & \mu_{32} \\
1 & 0 & 1 & -1 \\
1 & 0 & 1 & -1 \\
1 & 0 & 1 & -1 \\
1 & 0 & 1 & -1 \\
1 & 0 & 0 & 0 \\
1 & 0 & 0 & 0 \\
1 & 0 & 0 & 0 \\
1 & 0 & 0 & 0 \\
0 & 1 & 1 & -1 \\
0 & 1 & 1 & -1 \\
0 & 1 & 1 & -1 \\
0 & 1 & 1 & -1 \\
0 & 1 & 0 & 0 \\
0 & 1 & 0 & 0 \\
0 & 1 & 0 & 0 \\
0 & 1 & 0 & 0 \\
0 & 0 & 1 & 0 \\
0 & 0 & 1 & 0 \\
0 & 0 & 1 & 0 \\
0 & 0 & 1 & 0 \\
0 & 0 & 0 & 1 \\
0 & 0 & 0 & 1 \\
0 & 0 & 0 & 1 \\
0 & 0 & 0 & 1
\end{array}\right]
$$

A notacão compacta mediante o produto de Kronecker é $=D_{0} \otimes j_{4}$

$$
w_{R}=\left[\begin{array}{cccc}
J_{4} & 0 & J_{4} & -J_{4} \\
J_{4} & 0 & 0 & 0 \\
0 & J_{4} & J_{4} & -J_{4} \\
0 & J_{4} & 0 & 0 \\
0 & 0 & J_{4} & 0 \\
0 & 0 & 0 & J_{4}
\end{array}\right]
$$

Uma consequência deste tipo de estimaç̃o de parcelas faltantes e que a estrutura do delineamento é conexo. 
a) Caso de Conectividade

Considere-se o exemplo 3.2.7. 4 na qual as parcelas $\{(2,3)(3,1)$ e $(3,2)\}$ são perdidas, e atribuindo a parcela ferdida o valor zero pode-se construir do seguinte modo.

$$
\left[\begin{array}{lll}
n_{11} & n_{12} & n_{13} \\
n_{21} & n_{22} & 0 \\
0 & 0 & n_{33}
\end{array}\right]
$$

Da definirăo de modelo de médias apresentada na serio $[3.2 .7 .2]$ o levando em consideracá [3.2.7.20]. Temos a forma particionada se tem $W^{\prime}=\left[\begin{array}{lll}n_{3} & i & n^{W}\end{array}\right]$ onde $n=\Sigma$ $n_{i}$ expressando [3.2.7.2d] como $\mu^{\prime}=\left[\mu_{m}, \mu_{0}\right]=\left[\mu_{23}, \mu_{31}, \mu_{32} \mu_{13} \mu_{11}, \mu_{12^{\prime}} \mu_{21}, \mu_{22}, \mu_{33}\right]$ Levando em consideracão a restricão [3.2.7g]; nota-se que pode ser construído o seguinte sistema de equacões as quais permitem estimar a média das parcelas faltantes.

$$
\begin{array}{ll}
\text { i) } \mu_{23}-\mu_{13}+\mu_{11}-\mu_{21}=0 & (i=1,2 ; j=1,3) \\
i i) \mu_{31}-\mu_{13}+\mu_{11}-\mu_{33}=0 & c i=1,3 ; j=1,3) \\
i i i) \mu_{32}-\mu_{13}-\mu_{12}+\mu_{33}=0 & (i=1,3 ; j=2,3) \\
i v) \mu_{11}-\mu_{12}-\mu_{21}+\mu_{22}=0 & c i=1,2 ; j=1,2)
\end{array}
$$

Tendo em consideração a particão de $G=\left[\begin{array}{lll}G_{m} & G_{0}\end{array}\right]$ se tem a matriz de coeficientes cdepois de estabelecer a matriz escalonada $G_{m}$. 
$G=\left[\begin{array}{ccc:cccccc}\mu_{23} & \mu_{31} & \mu_{32} & \mu_{13} & \mu_{11} & \mu_{12} & \mu_{21} & \mu_{22} & \mu_{23} \\ 1 & 0 & 0 & -1 & 1 & 0 & -1 & 0 & 0 \\ 0 & 1 & 0 & 1 & -1 & 0 & 0 & 0 & -1 \\ 0 & 0 & 1 & -1 & 0 & -1 & 0 & 0 & 1 \\ \hdashline 0 & 0 & 0 & 0 & 1 & -1 & -1 & 1 & 0\end{array}\right]$

Da última linha da matriz reduzida $G$ obtém-se a restricăo efetiva $\mu_{11}-\mu_{12}-\mu_{21}+\mu_{22}=0$ e as três primeiras linhas definem a única relarä entre as parcelas perdidas e as paroelas observadas, mediante as quas verificamos as conexões.

\section{Assim se tem}

$$
\begin{aligned}
& =[0,1,-1,-1,1,0]\left[\begin{array}{l}
\mu_{13} \\
\mu_{11} \\
\mu_{12} \\
\mu_{21} \\
\mu_{22} \\
\mu_{33}
\end{array}\right] \\
& \text { GE } \mu_{0}=\mu_{11}-\mu_{12}-\mu_{21}+\mu_{22} .
\end{aligned}
$$

Deste modo a restricão do modelo $y=w_{0} \mu_{0}+e$ sujeito a $G_{E} H_{0}=g_{E}$ é chamada restricão efetiva se converte em modelo efetivo.

É usando o modelo reduzido pode-se estimar $\mu_{R}$ e as outras $\mu_{i j}$ são estimadas pela a restricão

$$
\mu_{i j}=\mu_{i b}-\mu_{v j}-\mu_{v b}
$$


b) Caso de Desconexão

Seguidamente estuda-se o caso de desconexão para o qual utiliza-se o exemplo [3.2.7.3] na qual a parcela $n_{13}=0$ o que determina que:

$$
n_{23}=n_{31}=n_{32}=n_{13}=0
$$

$W=\left[n_{4}^{*} n^{W}\right]$

$\mu=\left[\begin{array}{lll}\mu_{m} & H_{0}\end{array}\right]=\left[\mu_{13} \mu_{23} \mu_{31} H_{32} \mu_{11} \mu_{12} \mu_{21} \mu_{22} H_{33}\right]$

enta a a restricăo terá as combiracbes seguintes:

$$
\begin{aligned}
& \text { i) }-\mu_{11}+\mu_{13}+\mu_{31}-\mu_{33}=0 \\
& \text { ii } \mu_{23}-\mu_{13}+\mu_{11}-\mu_{21}=0 \\
& \text { iii) } \mu_{32}+\mu_{13}-\mu_{12}-\mu_{33}=0 \\
& \text { iv) } \mu_{11}-\mu_{12}-\mu_{21}+\mu_{22}=0
\end{aligned}
$$

Ordenando se tem a matriz

$\left.\begin{array}{cccc:ccccc}\mu_{23} & \mu_{31} & \mu_{32} & \mu_{13} & \mu_{11} & \mu_{12} & \mu_{21} & \mu_{22} & \mu_{33} \\ 1 & 0 & 0 & -1 & 1 & 0 & -1 & 0 & 0 \\ 0 & 1 & 0 & 1 & -1 & 0 & 0 & 0 & -1 \\ 0 & 0 & 1 & 1 & 0 & -1 & 0 & 0 & -1 \\ \hdashline 0 & 0 & 0 & 0 & 1 & -1 & -1 & 1 & 0\end{array}\right]$

Sendo a restricão efetiva a mesma que anteriormente agora temos várias expressōes para as parcelas perdidas em termos das parcelas observadas. Então pode-se estimar as funcões lineares das médias não observadas, tomando os contrastes.

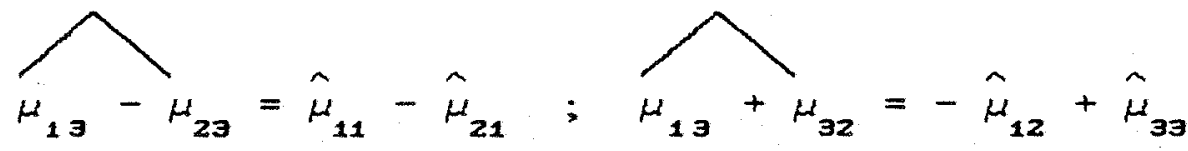


Pode-se concluir que en casos desconectados no modelo de médias observadas, possivel determinar funcões lineares paramétricas estimáveis das médias năo observadas em termos das médias observadas como foi ilustrado acima.

3. 3. O Modelo Aditivo de Classificaçao de Dois Fatores de Efeitos Fixos Sem Interaçăo ou Modelo de DODGE (1985)

3. 3.1. Conceituarăo

- Modelo aditivo de classificacăo dupla tem a seguinte notacão:

$$
y_{i j k}=\mu+\alpha_{i}+\beta_{j}+e_{i j k}
$$

sendo que $\left(y_{i j k}\right)$ é o conjunto de variáveis aleatórias independentes distribuidas normalmente cada uma com variancia $\sigma^{2}$, onde: $i=1,2, \ldots, v$

$$
\begin{aligned}
& j=1,2, \ldots, b \\
& k=1,2, \ldots, n_{i j} \\
& v=\text { número de tratamentos } \\
& b=\text { número de blocos } \\
& k=\text { número de parcelas por bloco }
\end{aligned}
$$

Quando $n_{i j}=0$, nenhum valor da variável exposta é observada para o tratamento i no bloco j., com a seguinte caracterização:

$$
\begin{aligned}
& n_{i \cdot}=\sum_{j} n_{i_{j}} \neq 0 \text { para } i=1,2, \ldots, v \\
& n_{. j}=\sum_{i} n_{i j} \neq 0 \text { para } j=1,2, \ldots, b
\end{aligned}
$$


Determinando que cada linha e que cada coluna tenha no minimo uma observacão.

Se a matriz de delineamento $x=C 1$ A B S então a matriz de ircidencia sera: $M=A^{\prime} \mathrm{B}$.

Dois niveis do fator 1 , dois niveis do fator 2, ou um nível do fator 1 um nível do fator 2 săo conexos se e possivel passar de um para o outro por meio de uma cadeia consistindo, alternativamente de niveis do fator 1 e rivel do fator $ق$, tais que, quasuer dos membros adjacentos da cadeia sao associados.

A matriz 2 de delineamento associado com uma matriz de incidência $N$ tem posto máximo,

$$
\text { posto }(2)=v+b-1
$$

se somente se o delineamento é conexo.

Consideremos o exemplo 1. Un delineamento experimental na qual $v=4, b=4, r=2, k=2, \lambda=1$, tem-se quatro tratamentos; $1,2,3$ e em quatro blocos I, II, III e IV, o número de parcelas por bloco é 2 , repetindo-se uma única vez cada par de parcelas de modo que fica

\section{blocos}

$\begin{array}{cccc}I & I I & \text { III } & \text { IV } \\ 1 & 3 & 1 & 2 \\ 2 & 4 & 3 & 4\end{array}$

ou expressado em termos da matriz de incidência

\section{BLocos}

\begin{tabular}{|c|c|c|c|c|}
\hline & & $I$ & II & III \\
\hline \multirow{4}{*}{$N=$ trat } & 1 & 1 & 0 & 1 \\
\hline & 2 & 1 & 0 & 0 \\
\hline & 3 & 0 & 1 & 1 \\
\hline & 4 & 0 & 1 & 0 \\
\hline
\end{tabular}


Sendo que $n_{i j}$ é o número de vezes que o $i$-ésimo tratamento ocorre no j-ésimo bloco, no BIB $n_{i j}$ adota 1 ou o, segundo a observacão está presente ou ausente.

No exemplo 1, utilizando o procedimento grăfico a partir da matriz de Incidência $N$ e unindo os diferentes niveis do fator tratamento (parcelas presentes) com os niveis do fator blocos, mediante uma cadeia tem-se:

$$
H=\left[\begin{array}{llll}
1 & 0 & 1 & 0 \\
1 & 0 & 0 & 1 \\
0 & 1 & 1 & 0 \\
0 & 1 & 0 & 1
\end{array}\right] \Rightarrow\left[\begin{array}{rrr}
1-0--1 & 0 \\
1--0 & 0-0--1 \\
0 & 1--1 & 0 \\
0 & 1-0-0-1
\end{array}\right]
$$

- que implica que o delineamento é conexo.

o mesmo resultado é obtido pelo processo $R$ no que segue.

Em DODGE (1985) apresenta-se um conjunto de definicões e teoremas que descrevem o processo $R$, o que permite estimar um conjunto de funcões associadas aos fatores no caso de perda de parcelas. Enuncia-se a sequência teórica no processo de obtenção do Triângulo Contador, a partir do qual se geram os contrastes estimáveis no delineamento de dois fatores.

A dimensão do espaco vetorial dos contrastes $\alpha$ estimáveis é $f_{\alpha}=a-s=$ postock $-b$, onde $s$ é o número de grupos conexos no delineamento.

A matriz de Incidência "N" é definida como: A matriz de dimensões $v \times b$ por elementos $n_{i j}$ onde $n_{i j}$ denota 0 número de observacões do tratamento $i$ no bloco $j, v$ denota o número de tratamentos e b denota o número de blocos. 
76.

A matriz "M" é definida como a matriz vxb das mesmas dimensões que a matriz de Incidencia N e cujos elementos zeros são substituídos por uma medida que se estabelece uma cadeia, determinando quais das esperancas das observacöes săo estimáveis.

O triàngulo contador $C_{a}$ se define como aquela porcăo subdiagonal do produto MM' na qual todos os componentes diferentes de zero foram substituidos por 1.

$$
\sigma_{i j}^{c \alpha}=\left\{\begin{array}{l}
1=\sum_{k=1} m_{i k} m_{j k}=0 \\
0 \text { se } \underset{k=1}{v} m_{i k} m_{j k}=0
\end{array}\right.
$$

Associado com o triângulo contador $C_{a}$ define-se I como sendo o conjunto:

$$
\begin{aligned}
I_{\alpha}= & \left\{i: C_{i j}^{(a)}=1 \text { para algum } j, 1 \leq j<i\right\} \\
& 0 \text { conjunto das diferencas entre os niveis de } \alpha
\end{aligned}
$$
$\left\{\alpha_{i}-\alpha_{j(i)}: i \in I \alpha^{\}}\right.$constitui uma base para espaco vetorial $\bar{A}$ dos contrastes estimáveis $a$.

Com o mesmo critério uma base para o espaco vetorial $\bar{B}$ pode ser construida a partir dá diferencas estimáveis de $\beta$ ou $\beta_{i}-\beta_{j}(1 \leq i, j \leq b)$ estimável se e somente se os elementos $C i, j$ de $M$ 'M são não nulos. Assim o conjunto das diferencas $\beta\left[\beta_{i}-\beta_{j(i)}: 1 \in I_{\beta}\right]$ constitui uma base para o espaco vetorial $\bar{B}$ de contrastes $\beta$ estimáveis, onde a dimensão de $\bar{B} \dot{e} f_{\beta}=b-s=$ posto $(\infty)-v$ onde esse $s$ o número de grupos conexos. 
Define-se o triängulo contador $C_{\beta}$, como sendo a porட̧̃o subdiagonal de $M^{\prime} M$ com todos as elementos não nulos substituidos por uns $e$ associados com $C_{\beta} \circ$ conjunto $I_{\beta}=\left\{i=C_{i j}^{(\beta)}=1\right.$ para algum $j, 1<j<i>$.

o conjunto das diferencas entre os $\beta \beta_{i}-\beta_{j}\left({ }_{k}\right.$ $: I \in I_{\beta}>$ constitui uma base para o espaco vetorial $\bar{B}$ dos contrastes estimáveis entre os níveis do fator $\beta$.

$$
\bar{A} \text { - } \bar{E} \text { sáo subespacos de } \theta \text { o espaco vetorial }
$$

das funcoes lineares paramétricas estimáveis.

$$
\operatorname{dim} \bar{\theta}=\operatorname{dim} \Omega=\operatorname{posto}\left(\infty=\tilde{f}_{\alpha}+\dot{f}_{\beta}+S\right.
$$

Então uma base para $\bar{\ominus}$ consiste da adicăo 1 inear dá funções paramétricas independentes de $\bar{A}, \bar{B}$ e $S$. Assim seja

$$
i_{(k)}=\operatorname{minimo}\left\{i: i \in I_{k}\right\} \quad e j_{(k)}=\operatorname{minimo}\left\{j: j \in J_{k}\right\}
$$

para $k=1,2, \ldots$, s. Então:

$$
\left\{\mu+\alpha_{i\langle k\rangle}+\beta_{j(k)} \cdot \operatorname{para} k=1,2, \ldots, s\right\}
$$

- um conjunto de $s$ não funcões lineares paramétricas estimáveis a que săo linearmente independentes entre eles mesmos e dos elementos de $\bar{A}$ e $\bar{B}$.

$\vec{\varepsilon}$ denota-se como o espaco vetorial gerado por este conjunto e seja $f_{e}=\operatorname{dim} \bar{\varepsilon}=S$. Então o conjunto acima descrito é uma base para $\bar{\varepsilon}$.

Uma outra base para $\bar{\varepsilon}$ é dado. por:

$\left\{\mu+\alpha_{i(1)}+\beta_{j(1)}, \alpha_{i(1)}-\alpha_{i(k)}+\beta_{j(1)}-\beta_{j(k)}: k=2,3, \ldots, s\right\}$

Assim se tem que uma base para $\bar{\theta}$ o espaco vetorial das funcões lineares paramétricas estimáveis e dadas pela adição $\bar{\theta}=\bar{A} \oplus \bar{B} \oplus \bar{\varepsilon}$. 
A seguir, apresenta-se o algoritmo $R$ e ilustra-se mediante um exemplo. Todo o processo para construir uma base para o espaco vetorial $\bar{\theta}$ das funcóes lineares paramétricas estimávois.

3.3.2. O processo $\mathrm{R}$

Este método apresentado por DODGE C1985y tra-

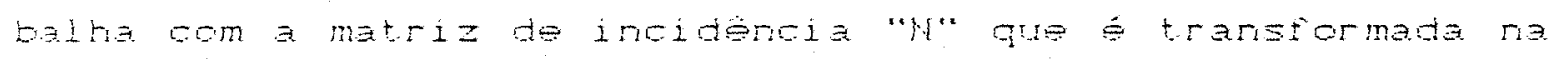
matriz final M formada exclusivamente de zeros e uns, toda informacão sobre conectividade săo obtidos a partir da matriz final $M$, utilizando operacõos simples com variáveis bi nárias.

Passos do proceso $R$

$1)$ considera-se a matriz $M$ de dimensão $v \times$ b de componentes zeros;

2) para cada par $i, j$ se existe $n_{i j}=0$, então $m_{i j}=1$;

3) para cada par $i, j$ se existe os elementos $k$ e $l$ de modo que se cumpra $m_{i l}=m_{k l}=m_{k j}=1$, então $m_{i j}=1$ Cgraficamente se adicionará um quarto vértice sempre que aparecem os três vértices de um retângulo na matriz $M$;

4) continuar o passo 3 usando os originais e novos $\mathrm{m}_{i j}$ não zeros como vértices de novos retângulos, até que nenhum outro elementos possa ser mudado. 
79

Observa-se que a matriz final $M$ e uma matriz de dimensăo igual a matriz N; no caso de ser todos os $n_{i j}=1$, a formaç̃o da matriz M e imediata.

A continuaräo por conveniencia vai ser particionar os indices das linhas e colunas da matriz final M formando grupos de indices.

1) Seja $y_{1}$ o conjunto de indices das colunas de M que possuen 1 ra primeira linta $=$ onde $I_{1} \neq 0$ por guanto supossemos que $n_{i}$. 0 far $\Rightarrow$ todo $i=1,2, \ldots, v$.

2) Seja $j=J_{1}$ e denotemos por $I_{1}$ ao conjunto dos indices das linhas de $M$ que tem 1 na coluna $j$.

3 A continuacão escolhemos $i \notin I_{1}$ e denotamos por $J_{2}$ ao conjunto dos indices das colunas de $M$ que tem $j$ na Iinhai.

4) Escolhemos $j_{2} \in J_{2}$ e denotamos por $I_{2}$ ao conjunto dos indices das 1 inhas de $M$ que tem 1 na coluna $j_{z}$.

5) Continuamos este processo até esgotar todos os indices das I inhas da matriz $M$.

Esta sequência de passo nos determina a união disjunta

$$
\{1, \ldots, v\}=\bigcup_{k=1}^{s} I_{k} \in\{1, \ldots, b\}=\bigcup_{k=1}^{s} J_{k}
$$

A partir desta informacão conclui-se que $m_{i j}=1$ se e somente se $k$ existe no intervalo $1 \leq k \leq s$, tais que $i \in I_{k} e j \in J_{k}$ então os pares $\left(I_{1}, J_{1}\right),\left(I_{2}, J_{2}\right)$, ... $\mathrm{CI}_{s}$, J $\mathrm{J}_{\mathrm{s}}$ descrevem as por cões conectadas do delineamento, estas porcões conectadas são visualizadas em termos da 
80.

matriz final $M$, após de arranjar as linhas e colunas de tal maneira que as 1 inhas e colunas indexadas pelos elementos de $I_{1}$ e I respectivamente ocorram primeiro, seguidamente ocorrem as linhas e colunas indexadas por $I_{z}$ e $J_{z}$ na ordem respectiva, e assim por diante. Este arranjo de linhas e colunas nos conduzirá à seguinte matriz:

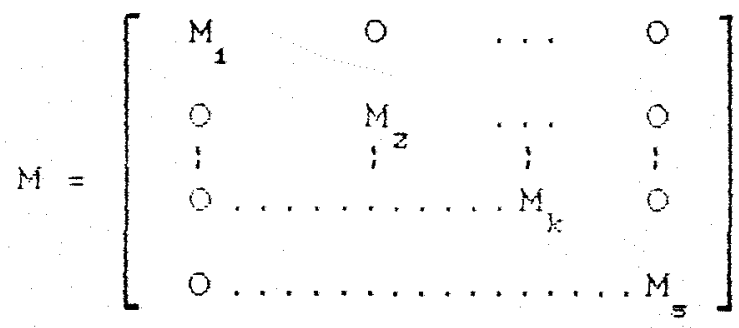

onde $M_{k}$ é uma matriz $v_{k} \times b_{k}$ de uns com $v_{k}=\#\left(I_{k}{ }^{2}\right.$ e $b_{k}=\not$ $\left(J_{k}{ }^{2}\right.$ para todo $k=1, \ldots, s$ onde \# representa o número de elementos.

Processo Interativo para obter a matriz M para o exemplo 1.

Para o valor $m_{12}$ que, a priori é igual a 0 onde $i=1 \odot j=2$, se existir $k$ e $l$ tal que $m_{i \ell}=m_{k \ell}=m_{k j}$ $=1$ então será $m_{12}=1$, caso contrário permanecerá igual a zero.

$$
\begin{aligned}
& \text { para } k=1 \quad z=1 \\
& m_{11}=m_{11}=m_{12}=1 \\
& 1=1 \neq 0 \neq 1
\end{aligned}
$$

não satisfaça a condicão.

Pode se observar para $k=1$, a condicão não será satisfeita porque $m_{k j}=m_{22}=0$. Também para $k=2$ năo será satisfeita porque $m_{k j}=m_{2 z}=0$. 
81.

$$
\begin{aligned}
& \text { para } k=3 \quad t=1 \\
& m_{11}=m_{31}=m_{32}=1 \\
& 1 \neq 0 \neq 1 \neq 1
\end{aligned}
$$

năo cumpre a condicăo

$$
\begin{aligned}
& \text { para } k=3 \quad 1=2 \\
& m_{12}=m_{32}=m_{32}=1 \\
& 0 \neq 1 \neq 1 \neq 1
\end{aligned}
$$

näo cumpre a condicăo

$$
\begin{aligned}
& \text { Fara } k=3 \quad l=3 \\
& m_{13}=m_{3 \boldsymbol{3}}=m_{\boldsymbol{3} \mathbf{z}}=1 \\
& 1=1=1=1
\end{aligned}
$$

cumpre a condi ção.

$$
\text { Então } m_{12} \text { assume o valor } 1 \text {, o processo conti- }
$$
nua até fazer todo um ciclo de operacöes cpor substituifões dos zeros por unsl sem se manifeitar nenhuma troca de valores.

o processo $R$ é util pois é utilizado como um algorismo computacional de fácil programação.

\section{3. 3. Um processo al ternativo}

Uma outra alternativa é pelo processo de semelhanca ou aproximacão.

Assim, no caso do exemplo inicial se enumera as parcelas e se vão colocando na ordem atendendo as suas semelhancas. No nosso caso se tem as parcelas $(1,1),(1,3)$, $(2,1),(2,4),(3,2),(3,3),(4,2),(4,4)$. 
82.

Disponindo-se na ordem se tem

$(1,1),(2,1),(3,2),(4,2)$

$(1,3),(2,4),(3,3),(4,4)$

Nota-so gue nerhuma parcola fira isolada, o que determina ser linearmente conectada. Se existirem parcelas isoladas diz-se que o delineamento năo é conectado.

o método gráfico nos permite chegar ao mesmo resultado, Esto metodo atirma que sempre gue aparecem tros vertices de um retangulo na matriz M se adiciona um guarto vértice. Assim, considera-se como vértices os componentes $m_{13}, m_{32}$ e $m_{33}$ se unimos com uma linha se obtém $m_{12}$ que é o quarto vértice assim por diante.

Um caso aplicativo de Desconeccão

\section{3. 4. Exemplo modelo}

Este exemplo está contido num trabalho apresentado pelo autor no $3^{\circ}$ Simpósio de Estatística Aplicada $\dot{A}$ Experimentacão Agronômica (julho 1979). Lavras - MG.

Num experimento de dois fatores BIB no qual se tem registrado perda de parcelas se tem os seguintes arranjos de pontos $e$ de $x$, onde um ponto representa uma parcela vazia e x representa uma parcela ocupada. 
83.

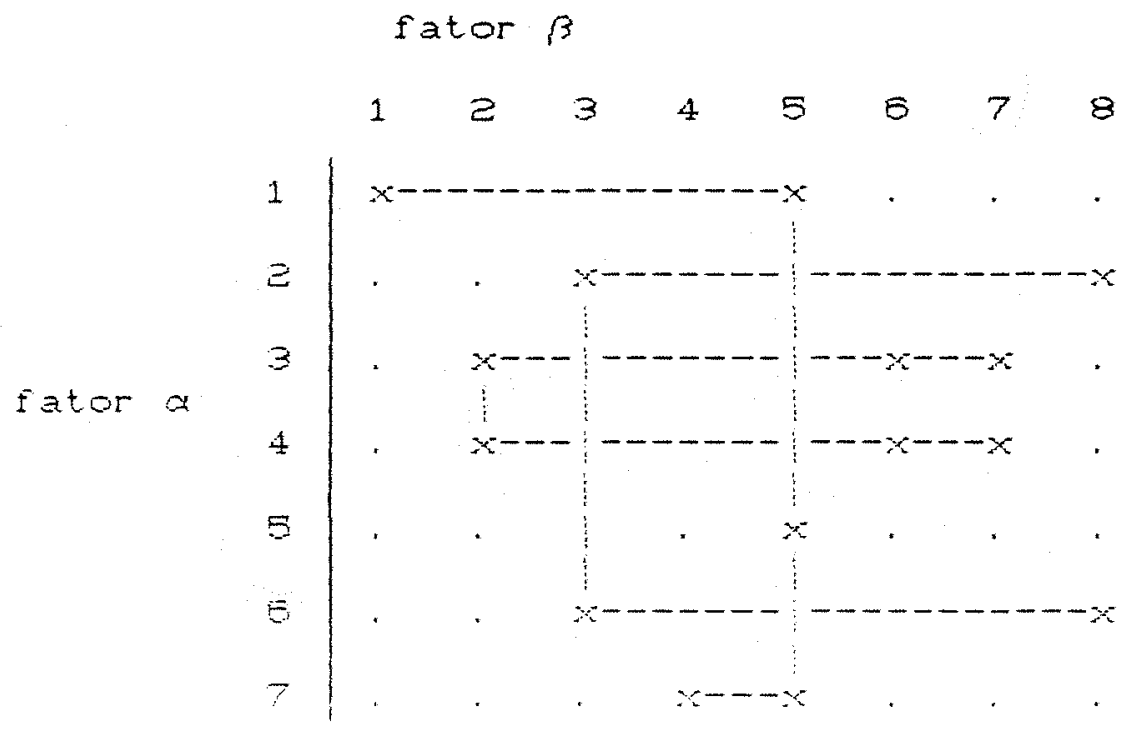

onde a matriz de incidência $\mathrm{N} e ́$

$$
N=\left[\begin{array}{llllllll}
2 & 0 & 0 & 0 & 1 & 0 & 0 & 0 \\
0 & 0 & 2 & 0 & 0 & 0 & 0 & 4 \\
0 & 3 & 0 & 0 & 0 & 2 & 1 & 0 \\
0 & 1 & 0 & 0 & 0 & 3 & 5 & 0 \\
0 & 0 & 0 & 0 & 1 & 0 & 0 & 0 \\
0 & 0 & 1 & 0 & 0 & 0 & 0 & 2 \\
0 & 0 & 0 & 2 & 2 & 0 & 0 & 0
\end{array}\right]
$$

Aplicando o processo $R$ à matriz de incidência $N$ obtém-se a matriz final $M$.

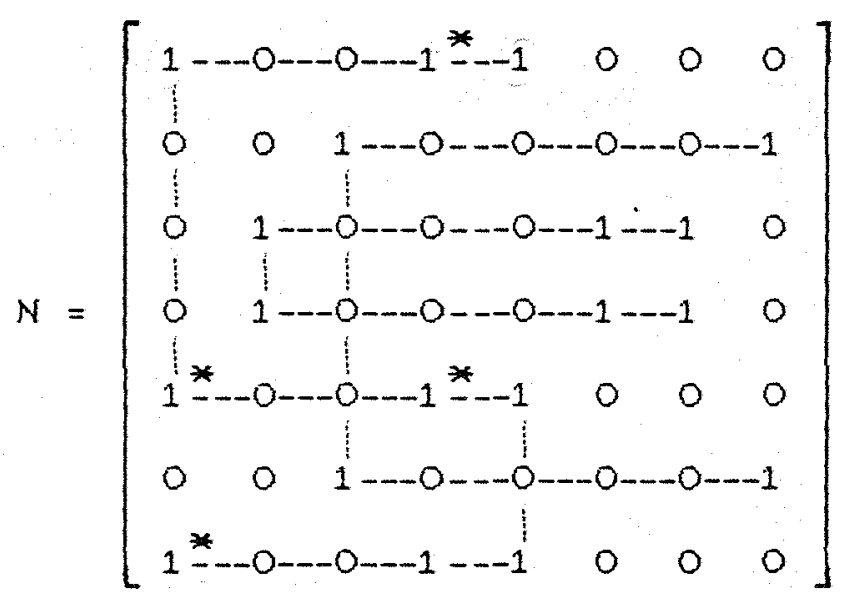


84.

Particão da matriz final $M$

Observa-se na primeira linha que os valores das colunas 1,4 e 5 são iguais a 1 , então

$$
J_{1}=\left\{\beta_{1}, \beta_{4}, \beta_{5}\right\}
$$

Essa mesma estrutura de linha repete-se nas

linhas $n^{9} 5 \in 7$, o que implica

$$
I_{1}=\left\{\alpha_{1}, \alpha_{5}, \alpha_{7}\right\}
$$

Escolhendo agor $a$ Iinha $i=\alpha_{2} \notin I_{1}$ o que nos

determina

$$
\begin{gathered}
I_{2}=\left\langle\beta_{3}, \beta_{a}\right\rangle \\
\text { Escolhendo } j_{2}=\beta_{3} \leq J_{2} \text { obtém-se } \\
I_{2}=\left\{\alpha_{2}, \alpha_{0}\right\}
\end{gathered}
$$

Seguidamente escolhem-se $i_{2}=a_{3} \neq I_{1} U I_{2}$

obtém-se

$$
\begin{gathered}
J_{3}=\left\{\beta_{2}, \beta_{\sigma}, \beta_{7}\right\} \\
\text { Finalmente escol he-se } j_{3}=\beta_{2} \text { obtem-se } \\
I_{3}=\left\{\alpha_{3}, \alpha_{4}\right\} \\
\text { Reunindo os subconjuntos } \\
I_{1} U I_{2} U I_{3}=\left\{\alpha_{1}, \alpha_{2}, \alpha_{3}, \alpha_{4}, \alpha_{5}, \alpha_{6}, \alpha_{7}\right\}= \\
J_{1} U J_{2} U J_{3}=\left\{\beta_{1}, \beta_{2}, \beta_{3}, \beta_{4}, \beta_{5}, \beta_{0}, \beta_{7}, \beta_{3}\right\}
\end{gathered}
$$

Fazendo um rearranjamento nas linhas e colunas na matriz final $M$ se tem:

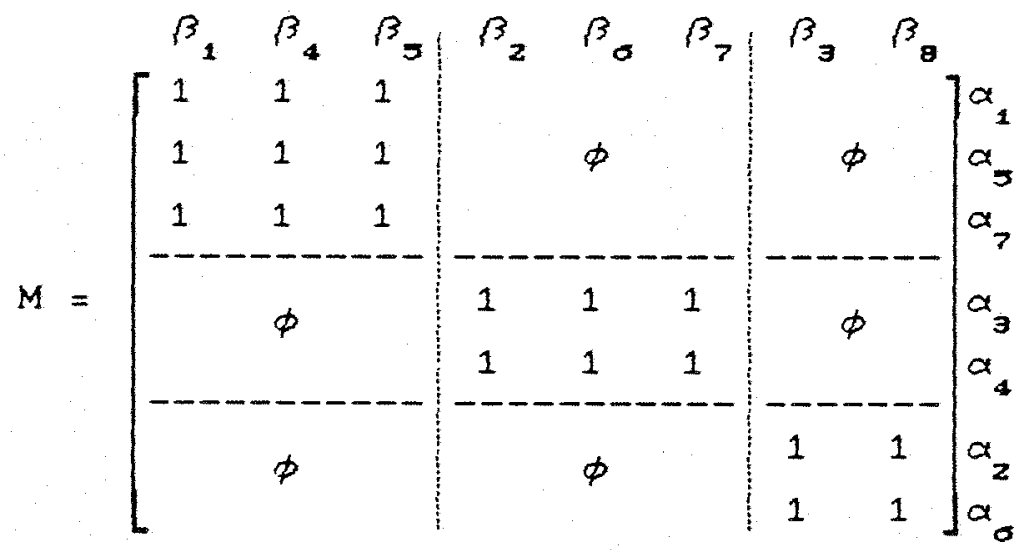


85.

Pode-se observar na matriz final $M$ os três subconjuntos conexos, cujos componentes são os parâmetros.

$$
\begin{gathered}
\left\{\alpha_{1}, \alpha_{5}, \alpha_{7}, \beta_{1}, \beta_{4}, \beta_{5} ;\right. \\
\left\{\alpha_{3}, \alpha_{4}, \beta_{2}, \beta_{6}, \beta_{7}\right\} ; \\
\left\{\alpha_{2}, \alpha_{5}, \beta_{3}, \beta_{8}\right\}
\end{gathered}
$$

obtencăo dos contrastes fara os dois fatores.

Multiplicando-se MM' e considerando-se somente os emponentes diferentes de zero da porano subdiagonal Irierior como iguais a 1 se tem o Iriangulo contador para as diferencas entre os níveis do fator $a$.

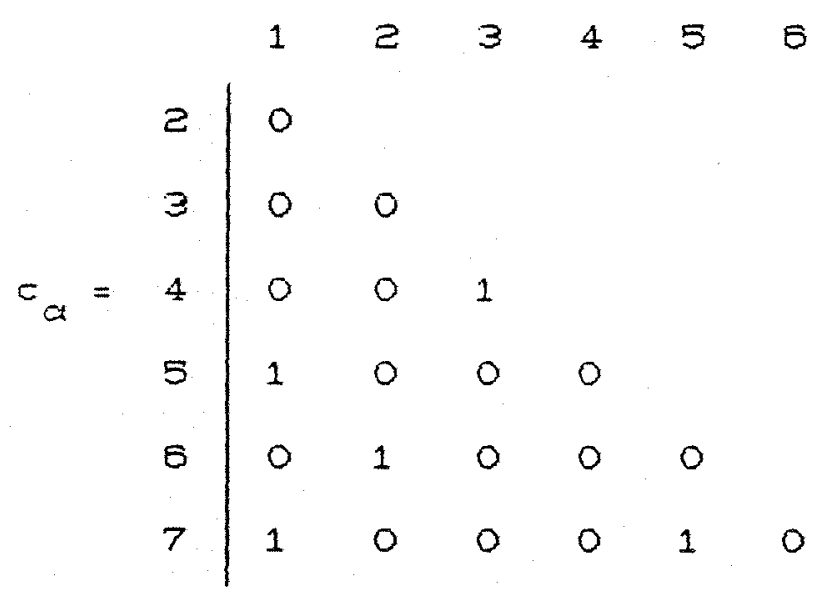

No Triângulo Contador $C_{a}$, observa-se que as linhas 4, 5, 8 e 7 tem pelo menos um componente que assume o valor 1 de modo que

$$
I_{\alpha}=\{4,5,6=7\}
$$

Portanto a dimensão do espaco vetorial dos contrastes estimáveis de a é:

$$
\left.f_{\alpha}=\not C I_{\alpha}\right)=4
$$

Uma base para $\bar{A}$ é:

$$
\left\{\alpha_{3}-\alpha_{4}, \alpha_{1}-\alpha_{5}, \alpha_{2}-\alpha_{0}, \alpha_{1}-\alpha_{7}\right\}
$$


86.

- mesmo critério é aplicado para se obter os contrastes para o fator $\beta$ ao multiplicar $M^{\prime} M$ e considerar somente os componentes diferentes de zero da porcăo subdiagonal inferior iguais a 1 .

$$
\begin{array}{l|lllllll}
2 & 0 & & & & & & \\
3 & 0 & 0 & & & & \\
4 & 0 & 1 & 0 & 0 & & & \\
0 & 1 & 0 & 0 & 1 & & \\
7 & 0 & 1 & 0 & 0 & 0 & & \\
8 & 0 & 0 & 1 & 0 & 0 & 0 & 1
\end{array}
$$

No Triangulo Contador $C_{\beta}$, observa-se que as Iinhas $4,5,6,7$ e tem pelo menos um componente que assume o valor 1 de modo que

$$
I_{\beta}=\{4,5,6,7 \in 8\}
$$

Portanto a dimensão de $f_{\beta}=\not\left(I_{\beta}\right)=5$

Uma base para $\vec{B}$ obtem-se dos contrastes se-

guintes:

$$
\beta_{1}-\beta_{4}, \beta_{1}-\beta_{5}, \beta_{2}-\beta_{0}, \beta_{2}-\beta_{7}, \beta_{3}-\beta_{3}
$$

pode-se também ter-se outra base.

$$
\begin{aligned}
& \left\{\beta_{1}-\beta_{4}, \beta_{4}-\beta_{5}, \beta_{2}-\beta_{6}, \beta_{6}-\beta_{7}, \beta_{7}-\beta_{8}\right\} \\
& \text { Sabe-se que } f_{c}=5=3(n \text { ) de grupos conexos); }
\end{aligned}
$$

uma base para $\bar{\varepsilon}$

$$
\left\{\mu+\alpha_{1}+\beta_{1} ; \alpha_{1}-\alpha_{2}+\beta_{1}-\beta_{3}\right\}
$$


Sendo que $f_{a}=v-s=7-3=4$, confirma-se sua dimensăo, ademais sabe-se que o posto $(x)-b=\hat{I}_{a}$

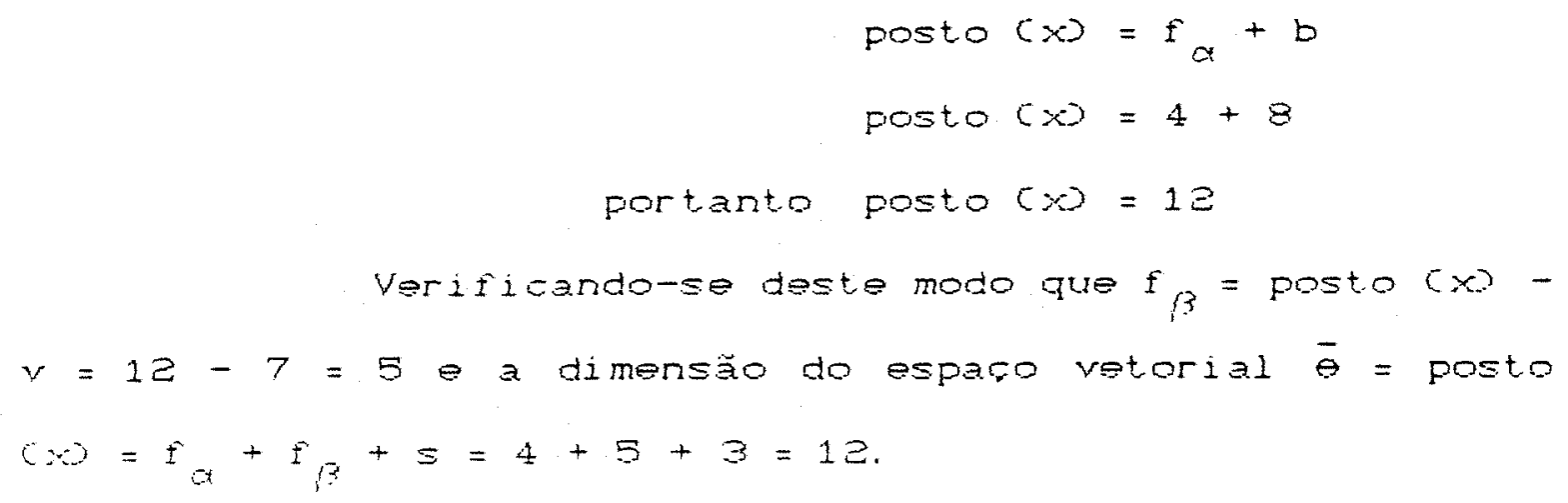

3. 3.5. Anâlise de variância

- quadro de análise de variância que resume as informações obtidas com respeito aos graus de liberdade é o seguinte:

CAUSAS DE VARI ACÄO E GRAUS DE LIBERDADE PARA O EX. 2

CY

Regressão

Ajuste para a média

Blocos não ajustados cajust. $p /$ a média $\beta / \mu$

Tratamentos $\tau / \mu, \beta$ cajust. $p /$ a média o blocos

Ajuste para a média

Tratamentos não ajustados (ajust. $p /$ a média $\tau / \beta$

Blocos $\beta / \mu, \tau$ (ajust. $p /$ a média e tratamentos)

Residuo

TOTAL
GL

12

20

32

Nota-se que o número total de 32 corresponde ao número de observaçóes do experimento. 
88.

3.3.6. Cálculo da soma de quadrados de regressão ajustados para as diferentes fontes de variaçăo

Apresenta-se a continuacao o método que nos permite obter algumas importantes somas de quadrados associados com o modelo considerado.

$$
\begin{aligned}
& \text { A anotacão da soma dos quadrados a considerar é: } \\
& \operatorname{soc} \alpha \beta=\operatorname{soc} \alpha \beta-\operatorname{soc} \beta \rho[3.3 .5 a] \\
& \operatorname{son} \alpha=\sec \alpha, \theta-\operatorname{son}
\end{aligned}
$$

onde SQCarb denota a soma de quadrados para os efeitos do fator $\alpha$, ajustado pelo fator $\beta$, ou seja, para os efeitos de a após ajustar os efeitos de $\beta$. A interpretacão da SQC $\beta / \infty$ é similar.

É de salientar que as somas de maior dificuldade apresentam na sua obtencão săo: $\operatorname{sQ}(\alpha, \beta), \quad S Q(\alpha / \beta)$ e SQC $\beta / \infty$, porém obtendo-se somente uma delas o cálculo das restantes é imediata.

A escolha de qual soma de quadrados deve ser obtida primeiro depende da soma de quadrados do fator cuja dimensão seja menor; sejam estes $f_{\alpha}$ ou $f_{\beta}$

Para encontrar uma solução única das E.N. em modelos de dois fatores com posto máximo da matriz $x$; posto $(\infty)=v+b-1, e$ aplicável às restricões:

$$
\sum_{i} \alpha_{1}=0 \text { e } \sum_{j} \beta_{j}=0
$$

No caso de delineamento desconexos este procedimento não é adequado. Assim deve-se optar por uma parametrizacão alternativa contida no seguinte teorema. 
89.

TEOREMA 3.3.6.1: suponhamos $f_{\beta}>0$ e seja $\wedge^{\prime} \beta$ um vetor de dimensăo $\hat{f}_{\beta} \times 1$ de funcöes paramétricas estimáveis que constitui uma base para o espaco de todos os contrastes estimá-

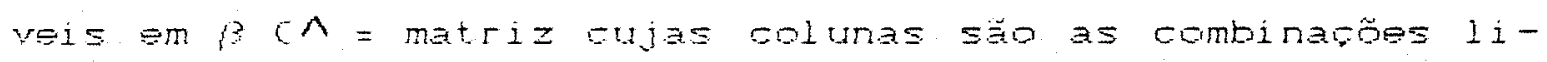
neares estimáveis do fator $\beta$, e ainda sendo $G=C I$ - PASB $M$, onde pa denota a projecăo ortogonal no espaco coluna de A. Enta uma parametrizacão irrestrita de posto coluna completa para o ceparo rotorial perado pelas colunas de $w$ é:

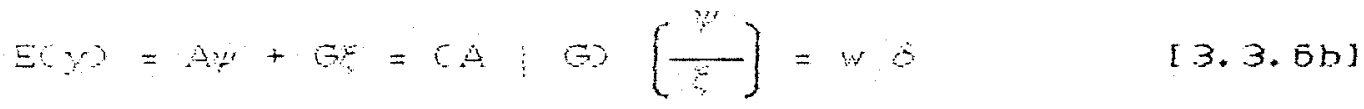

onde: $\psi \subseteq R^{v}, \xi \in R^{f \beta} e \delta \subseteq R^{m} C V=$ número de tratamentos; $f_{\beta}=$ dimensão do espaco vetorial gerado pelas funcóós paramétricas estimáveis do fator $\beta$ e $m=$ posto $(x)$. Sabemos que $w=(A G)$ e dada a parametrizaça irrestrita

$$
E(y)=1 \mu+A \alpha+B \beta=X \theta
$$

$\theta \in R^{p}$ onde $P=v+b+1$ e $E(y)=A \psi+G \xi=(A \mid G)\left(\frac{\psi}{\xi}\right)=W o$.

Esta parametrizacão nunca será de posto completo pois posto $(x)=m \leq(V+b-1<P)$.

Só serão de posto completo se:

a) se $m=p-k$

b) impusermos $k$ restricões 1 inearmente independentes e não estimáveis, entăo $E(y)=w \hat{b} \quad \delta \in R^{m}$

A parametrizacão será de posto completo se posto $(w)=m=$ posto $(x)=\operatorname{dim} \Omega$.

Da parametrizacão realizada no teorema [3.3.6.1] obtém-se as seguintes equacões normais $w^{\prime} w_{\hat{\delta}}=w^{\prime} y$, onde w'w e não singular, além disso as matrizes $A^{\prime} A$ e G'G 
90.

são também não singulares e $A^{\prime} G=0$, assim as equacõos normais para o teorema 3.3.6.1 pode reduzir-se a dois sistemas separzdos.

$$
\Delta^{\prime} \Delta \hat{y}=\Delta^{\prime} Y \odot G^{\prime} G \hat{\xi}=G^{\prime} Y
$$

A soma de quadrados so( $\beta / \alpha$ servirá para testar a nipótese $H_{0}: \Lambda^{\prime} \beta=0$; istóe, a hipóteses de que todas as funcöes in ineares estimáveis $y^{\prime}$ envol vem os parämetros R solguais a zero.

A correspondencia entre a soma de quadrados do modelo original $[E(y)=A \mu+A \alpha+B \beta=x \theta]$ e o parametrizado [3.3. Bb] segundo o TEOREMA [3.3.6.1] é o seguinte:

$$
\begin{gathered}
\operatorname{SQ}(\alpha)=\operatorname{SQ}(\psi) \\
\operatorname{SQ}(\alpha, \beta)=\operatorname{SQ}(\psi, \xi)=\operatorname{SQ}(\psi)+\operatorname{SQ}(\xi) \\
\text { Lembrando que } \operatorname{SQ}(\alpha, \beta)=\operatorname{SQ}(\alpha)+\operatorname{SQ}(\beta, \alpha),
\end{gathered}
$$

assim: $\operatorname{SQ}(\beta, \alpha)=\operatorname{SQ}(\xi)$.

A soma de quadrados $S Q(\xi)$ nos permite testar as hipóteses

$H_{0}: \xi=0$ e desta forma também permite testar as hipóteses $H_{0} E(y) \in R(A)$ espaco coluna de $x$, ou seja a hipótese de que $E\left(y_{i j k}\right)^{2}$ tem a forma $\mu+\alpha_{1} e f_{\beta}=0$, então $\operatorname{SQC} \beta / \alpha=\operatorname{SQ}(\xi)=0$.

\subsubsection{Exemplo 2}

A continuacão apresenta-se uma aplicação para obter as somas de quadrados segundo a parametrizacão proposta por DODGE (1985) (Equacões Normais Reduzidas). 
91.

Seja o caso do experimento fatorial $e^{2} \dot{\theta} 0$ seguinte:

\begin{tabular}{|c|c|c|}
\hline & 1 & $z$ \\
\hline$M=1$ & 1 & 0 \\
\hline 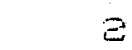 & $\Xi$ & 3 \\
\hline
\end{tabular}

$$
X=\left[\begin{array}{ccccc}
\text { fator } & \multicolumn{2}{c}{\text { fator }} \\
1 & 1 & 0 & 1 & 0 \\
1 & 0 & 1 & 1 & 0 \\
1 & 0 & 1 & 1 & 0 \\
1 & 0 & 1 & 0 & 0 \\
1 & 0 & 1 & 0 & 1 \\
1 & 0 & 1 & 0 & 1
\end{array}\right]
$$$$
y=\left[\begin{array}{l}
2 \\
3 \\
4 \\
3 \\
5 \\
4
\end{array}\right]
$$

$$
A=\left[\begin{array}{ll}
1 & 0 \\
0 & 1 \\
0 & 1 \\
0 & 1 \\
0 & 1 \\
0 & 1
\end{array}\right]
$$$$
B=\left[\begin{array}{ll}
1 & 0 \\
1 & 0 \\
1 & 0 \\
0 & 1 \\
0 & 1 \\
0 & 1
\end{array}\right]
$$

CÁLCULOS DAS SEGUINTES EXPRESSÖES

$$
\begin{array}{ll}
\left.P A=A C A^{\prime} A\right)^{-1} A & \text { Sabe-se que } \hat{\psi}_{i}=\frac{y_{i}}{n_{i}} \operatorname{para} \hat{\psi}_{1}=\frac{y_{1}}{n_{1}} \\
G=C I-P A D B & \\
\left.\hat{\psi}=C A^{\prime} A\right)^{-1} A^{\prime} Y & \hat{\psi}_{z}=\frac{y_{2}}{n_{z}} \\
\operatorname{SQC} \psi=\hat{\psi}^{\prime} A^{\prime} A \hat{\psi} & \\
\left.\hat{\zeta}=C G^{\prime} G\right)^{-1} G^{\prime} Y & \\
\text { SQC } \zeta=\hat{\zeta} G^{\prime} Y &
\end{array}
$$


92.

$$
\begin{aligned}
& \text { Assim tem-se as seguintes expressões: }
\end{aligned}
$$

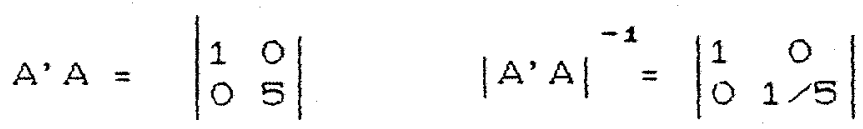

$$
\begin{aligned}
& \text { O projetor em } A \\
& P A=\left[\begin{array}{llllllll}
1.00 & 0.00 & 0.00 & 0.00 & 0.00 & 0.00 \\
0.00 & 0.20 & 0.20 & 0.20 & 0.20 & 0.20 \\
0.00 & 0.20 & 0.20 & 0.20 & 0.20 & 0.20 \\
0.00 & 0.20 & 0.20 & 0.20 & 0.20 & 0.20 \\
0.00 & 0.20 & 0.20 & 0.20 & 0.20 & 0.20 \\
0.00 & 0.20 & 0.20 & 0.20 & 0.20 & 0.20
\end{array}\right] \\
& \psi=\left[\begin{array}{l}
2.00 \\
3.80
\end{array}\right] \\
& \operatorname{SQ}(\psi)=70.20
\end{aligned}
$$

$$
I-P A=\left[\begin{array}{rrrrrr}
0.00 & 0.00 & 0.00 & 0.00 & 0.00 & 0.00 \\
0.00 & 0.80 & -0.20 & -0.20 & -0.20 & -0.20 \\
0.00 & -0.20 & 0.80 & -0.20 & -0.20 & -0.20 \\
0.00 & -0.20 & -0.20 & 0.80 & -0.20 & -0.20 \\
0.00 & -0.20 & -0.20 & -0.20 & 0.80 & -0.20 \\
0.00 & -0.20 & -0.20 & -0.20 & -0.20 & 0.80
\end{array}\right]
$$

$$
\begin{array}{rl}
G=\left[\begin{array}{r}
0.00 \\
1.20 \\
1.20 \\
-0.80 \\
-0.80 \\
0.80
\end{array}\right] & G \cdot G=48 \\
\hat{\zeta}=-0.25 & A=\left[\begin{array}{r}
1 \\
-1
\end{array}\right]
\end{array}
$$$$
\operatorname{SQ}(5)=0.30
$$

Por conseguinte o Quadro de Análise de Variância; pelo método original de Parametrização irrestrita $\theta$ 
93.

\begin{tabular}{|c|c|c|c|c|c|}
\hline FONTE DE VAR. & GL & $S Q$ & QM & $\begin{array}{c}\text { VALOR } \\
F\end{array}$ & $\begin{array}{c}P R O B \\
>F\end{array}$ \\
\hline Regressão & 3 & 76.50 & 25.50 & & \\
\hline Ajuste para $\mu$ & 1 & 73.50 & & & \\
\hline Ajuste para $C \beta, \beta$ & 1 & 1.50 & 1.50 & & \\
\hline Ajuste para $(\tau, \mu \beta)$ & 1 & 1.50 & 1.50 & 1.80 & 0.27 \\
\hline Ajuste para h & 1 & 73.50 & & & \\
\hline Ajuste para $(\tau / \mu)=S Q(\alpha) \beta)$ & 1 & 2.70 & e. 70 & & \\
\hline 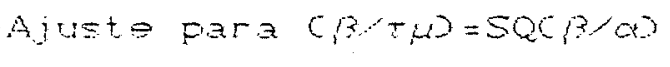 & 1 & 0.30 & 0.30 & & \\
\hline Pesiduo & 3 & 2.50 & 0.83 & & \\
\hline TOTAL & $\theta$ & 79.00 & & & \\
\hline
\end{tabular}

Das equivalências das somas de quadrados se tem

$$
\begin{aligned}
& \operatorname{SQ}(\psi)=\operatorname{SQ}(\alpha) \theta \\
& \operatorname{SQ}(\xi)=\operatorname{sQ}(\beta / \alpha)
\end{aligned}
$$

Substituindo pelos seus valores se tem

$76.2=73.50+270$

76. $2=76.2$

e

$0.30=0.30$

Isto nos confirma que são válidas as expressões, por conseguinte e viável a parametrizacão alternativa apresentada por DODGE (1980). 
94.

4. EXEMPLOS APLICATIVOS EM DELINEAMENTO DE DOIS FATORES

4.1. Delineamento em Blocos Incompletos

$$
\text { Est. tifo de delineamento } \Leftrightarrow \text { empregado na }
$$
aplicara do processo R CDODOE 1985 o modelo aditivo é dado por:

$$
y_{i j k}=\mu+\alpha_{i}+\beta_{j}+e_{i j k}
$$

Chamado também modelo superparametrizado cuja caracterizacăo é dada no item [3.2.1].

\section{2. Modelo de Médias}

$$
\mathbf{y}_{i j k}=\mu_{i j}+e_{i j k}
$$

o delineamento de dois fatores que descreve as parcelaś perdidas em termos das parcelas presentes é dado pelo modelo restrito já descrito no ponto 3.2.5.2.

CASO A: Um Exemplo em Blocos Incompletos

- presente experimento analisa o coeficiente de digestibilidade de nutrientes para CAITETUS CTayassu Tayacw, consumido a níveis crescentes de alimentos volumosos. 
95.

o tipo de delineamento inicial foi planejado para blocos casualizados, balanceados envolvendo 4 tratamentos; os tratamentos $A, B, C=D$, constituem niveis volumosos

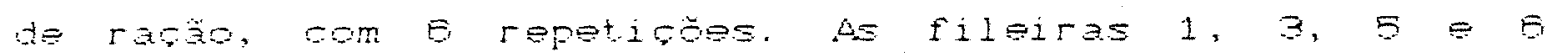
constituem machos $\theta$ as fileiras $\geq \theta 4$ săo femeas.

Por razöes próprias do manejo experimental ferderam-se 4 parcelas, como se encontra na Tabela 4.2.1, a sua eflócia de digestibilidade é medida por

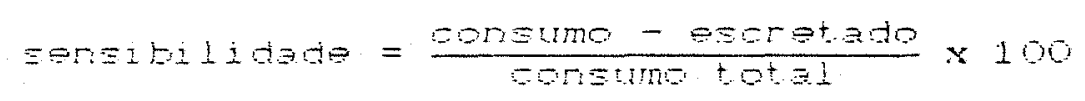

Tabela 4.2.1.

\begin{tabular}{|cccccc|}
\hline \multicolumn{5}{c}{ TRATAMENTOS } \\
\cline { 2 - 6 } BLocos & A & B & C & D \\
\hline 1 & 75,68 & - & - & 50,38 \\
2 & 78,13 & 69,85 & 71,73 & 63,73 \\
3 & 77,84 & 77,54 & 74,03 & - \\
4 & 78,51 & 77,45 & 66,24 & 50,95 \\
5 & - & 70,70 & 74,09 & 65,91 \\
6 & 78,70 & 73,19 & 70,05 & 68,79 \\
\hline
\end{tabular}

A perda de parcelas determina que o delineamento seja de Blocos Incompletos năo Balanceados.

- modelo aditivo superparametrizado de DODGE (1985). 
Delineamento em blocos incompletos

o modelo aditivo vem dado por

$$
y_{i, j k}=\mu+\alpha_{1}+\beta_{j}+\theta_{i, j k}
$$

A matriz de delineamento para este experimento no modelo irrestrito sobreparametrizado é

$$
\mathbb{R}=\left[\begin{array}{lllllllllll}
\mu_{1} & \alpha_{2} & \alpha_{3} & 0 & \beta_{1} & \beta & \beta_{3} & \beta_{4} & \beta & \beta \\
1 & 1 & 0 & 0 & 0 & 1 & 0 & 0 & 0 & 0 & 0 \\
1 & 1 & 0 & 0 & 0 & 0 & 1 & 0 & 0 & 0 & 0 \\
1 & 0 & 1 & 0 & 0 & 0 & 1 & 0 & 0 & 0 & 0 \\
1 & 0 & 0 & 1 & 0 & 0 & 1 & 0 & 0 & 0 & 0 \\
1 & 0 & 0 & 0 & 1 & 0 & 1 & 0 & 0 & 0 & 0 \\
1 & 1 & 0 & 0 & 0 & 0 & 0 & 1 & 0 & 0 & 0 \\
1 & 0 & 1 & 0 & 0 & 0 & 0 & 1 & 0 & 0 & 0 \\
1 & 0 & 0 & 1 & 0 & 0 & 0 & 1 & 0 & 0 & 0 \\
1 & 1 & 0 & 1 & 0 & 0 & 0 & 0 & 1 & 0 & 0 \\
1 & 0 & 1 & 0 & 0 & 0 & 0 & 0 & 1 & 0 & 0 \\
1 & 0 & 0 & 0 & 1 & 0 & 0 & 0 & 1 & 0 & 0 \\
1 & 0 & 1 & 0 & 0 & 0 & 0 & 0 & 0 & 1 & 0 \\
1 & 0 & 0 & 1 & 0 & 0 & 0 & 0 & 0 & 1 & 0 \\
1 & 0 & 0 & 0 & 1 & 0 & 0 & 0 & 0 & 1 & 0 \\
1 & 1 & 0 & 0 & 0 & 0 & 0 & 0 & 0 & 0 & 1 \\
1 & 0 & 1 & 0 & 0 & 0 & 0 & 0 & 0 & 0 & 1 \\
1 & 0 & 0 & 1 & 0 & 0 & 0 & 0 & 0 & 0 & 1 \\
1 & 0 & 0 & 0 & 1 & 0 & 0 & 0 & 0 & 0 & 1
\end{array}\right]
$$

cuja matriz de incidência fica da seguinte forma 
BLOCOS

IFATANENTOS $13\left[\begin{array}{llllll}1 & 2 & 3 & 4 & 5 & 0 \\ 1 & 1 & 1 & 1 & 0 & 1 \\ 0 & 1 & 1 & 1 & 1 & 1 \\ 0 & 1 & 1 & 1 & 1 & 1 \\ 1 & 1 & 0 & 1 & 1 & 1\end{array}\right]$

Pode-se observar que apesar da perda das parcelas $(1,5),(2,1),(3,1)=(4,3)$ o delineamento é conectado. Easta apilcar o procedimerto geométriop obterido-se uma cadeia que une as observaces presentes.

A continuacăo por um processo aleatório progressivo de tirar parcelas perdem-se as seguintes parcelas: $(1,2),(1,3),(1,5),(2,1)(2,2),(2,3),(2,5),(3,1)$, $(3,2),(3,3),(3,4),(3,6),(4,1)$ e $(4,5)$, ficando ao final:

\section{BLOCOS}

IRATAMENTOS $13\left[\begin{array}{llllll}1 & 2 & 3 & 4 & 5 & 0 \\ 1 & 0 & 0 & 1 & 0 & 1 \\ 0 & 0 & 0 & 1 & 0 & 1 \\ 0 & 0 & 0 & 0 & 1 & 0 \\ 0 & 1 & 1 & 1 & 0 & 1\end{array}\right]$

Aplicando o Processo $R$ se tem

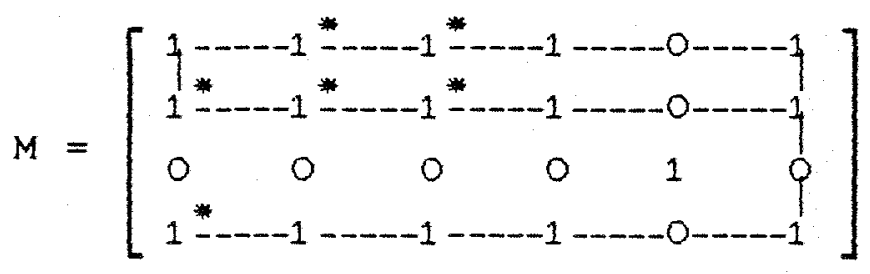


Determinando-se um delineamento desconectado, ao ter-se dois grupos de conexăo, o primeiro constitui o grupo ligado pela cadeia, e o segundo o constitui a parcela (3,5); a matriz de delineamento fica

$$
\mathbb{R}=\left[\begin{array}{lllllllllll}
\mu_{1} & \alpha_{2} & \beta_{3} & \beta_{4} & \beta_{1} & \beta_{2} & \beta_{3} & \beta_{3} & \beta_{3} \\
1 & 1 & 0 & 0 & 0 & 1 & 0 & 0 & 0 & 0 & 0 \\
1 & 1 & 0 & 0 & 0 & 0 & 0 & 1 & 0 & 0 & 0 \\
1 & 1 & 0 & 0 & 0 & 0 & 0 & 0 & 1 & 0 & 0 \\
1 & 1 & 0 & 0 & 0 & 0 & 0 & 0 & 0 & 0 & 1 \\
1 & 0 & 1 & 0 & 0 & 1 & 0 & 0 & 0 & 0 & 0 \\
1 & 0 & 1 & 0 & 0 & 0 & 1 & 0 & 0 & 0 & 0 \\
1 & 0 & 1 & 0 & 0 & 0 & 0 & 1 & 0 & 0 & 0 \\
1 & 0 & 1 & 0 & 0 & 0 & 0 & 0 & 1 & 0 & 0 \\
1 & 0 & 1 & 0 & 0 & 0 & 0 & 0 & 0 & 0 & 1 \\
1 & 0 & 0 & 1 & 0 & 0 & 0 & 0 & 0 & 1 & 0 \\
1 & 0 & 0 & 0 & 1 & 1 & 0 & 0 & 0 & 0 & 0 \\
1 & 0 & 0 & 0 & 1 & 0 & 1 & 0 & 0 & 0 & 0 \\
1 & 0 & 0 & 0 & 1 & 0 & 0 & 1 & 0 & 0 & 0 \\
1 & 0 & 0 & 0 & 1 & 0 & 0 & 0 & 1 & 0 & 0 \\
1 & 0 & 0 & 0 & 1 & 0 & 0 & 0 & 0 & 0 & 1
\end{array}\right]
$$

A parcela $(3,5)$ não pode ser estimada, pois o tratamento 3 não ocorre com nenhum dos outros tratamentos no mesmo bloco. Deste modo o efeito do tratamento 3 é confundido com o bloco 5 .

O grupo de contrastes dos tratamentos é determinado pela matriz diagonal inferior do produto da matriz final MM'dado por $C_{\alpha}$, onde 
99

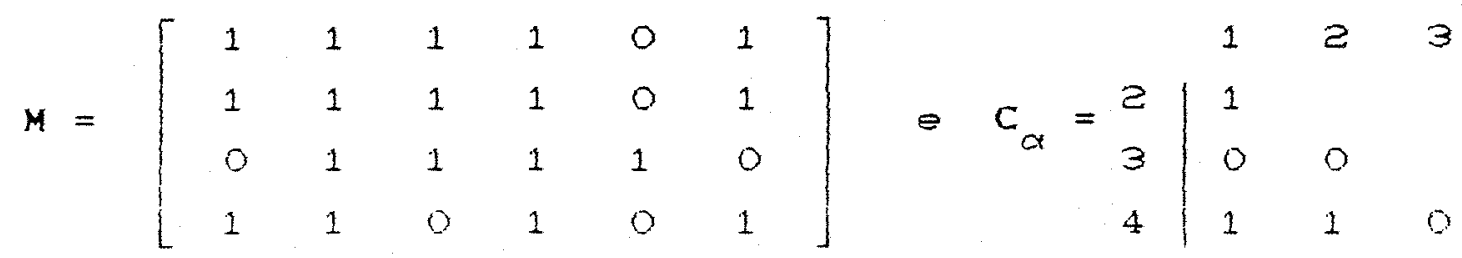

$$
\begin{aligned}
& \text { os contrastes que formam uma base sao: } \\
& \bar{A}=\left\{\alpha_{1}-\alpha_{2}, \alpha_{1}-\alpha_{4}\right\} o u\left\{\alpha_{1}-\alpha_{2}, \alpha_{2}-\alpha_{4}\right\rangle \\
& \text { com o objetivo de conferir a validades dos re- } \\
& \text { sultedos da anjise exposta neste exemplo, utiliza-se o } \\
& \text { Maralo Etetivo de Médias. }
\end{aligned}
$$

a) No caso de Conexăo

1) Conforme HOCKING (1985), no modelo reduzido a forma particionada da matriz $W$ será $W={ }_{24}{ }_{4} \mathbf{z 4}_{20}^{W} \theta$ $\mu=\left[\mu_{m}: \mu_{0}\right]=$

$=\left[\begin{array}{c:c}\mu_{12}, \mu_{13}, \mu_{34}, \mu_{51} & \mu_{11}, \mu_{14}, \mu_{21}, \mu_{22}, \mu_{23}, \mu_{24}, \mu_{31}, \mu_{32}, \mu_{33}, \mu_{41}, \\ & \mu_{42}, \mu_{43}, \mu_{44}, \mu_{52}, \mu_{53}, \mu_{54}, \mu_{61}, \mu_{03}, \mu_{64}, \mu_{64}\end{array}\right]$

No processo de estabelecer as combinacões possiveis das parcelas, com o objetivo de se conferir a validade da matriz G, é conveniente considerar o seguinte:

- Estabelecer contrastes das parcelas perdidas em funcão das parcelas presentes.

- Estabelecer contrastes com o menor número de parcelas presentes.

Assim as parcelas perdidas em funcão das parcelas presentes são 


$$
\begin{aligned}
& \mu_{12}+\mu_{21}-\mu_{11}-\mu_{22} \\
& \mu_{13}+\mu_{24}-\mu_{23}-\mu_{14} \\
& \mu_{34}+\mu_{43}-\mu_{44}-\mu_{33} \\
& \mu_{31}+\mu_{62}-\mu_{61}-\mu_{52}
\end{aligned}
$$

o total de combinacóes \& dado por $n-a-b+1$, o que determina $24-6-4+1=15$ combinacoes, o resto é escolhido dos contrastes de tratamentos dado pela combinacáo $C_{6}^{2}=15$ contrastes, completando-se com

$$
\begin{aligned}
& \mu_{11}+\mu_{21}-\mu_{21}-\mu_{14} \\
& \mu_{11}+\mu_{34}-\mu_{31}-\mu_{14} \\
& \mu_{11}+\mu_{44}-\mu_{41}-\mu_{14} \\
& \mu_{11}+\mu_{54}-\mu_{51}-\mu_{14} \\
& \mu_{11}+\mu_{04}-\mu_{01}-\mu_{14} \\
& \mu_{21}+\mu_{32}-\mu_{31}-\mu_{22} \\
& \mu_{21}+\mu_{43}-\mu_{41}-\mu_{23} \\
& \mu_{22}+\mu_{53}-\mu_{52}-\mu_{23} \\
& \mu_{21}+\mu_{02}-\mu_{01}-\mu_{22} \\
& \mu_{31}+\mu_{42}-\mu_{41}-\mu_{32} \\
& \mu_{52}+\mu_{03}-\mu_{53}-\mu_{02}
\end{aligned}
$$

A matriz $G$ assume a estrutura do seguinte modo: 


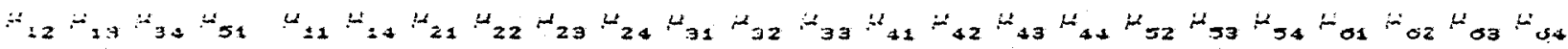

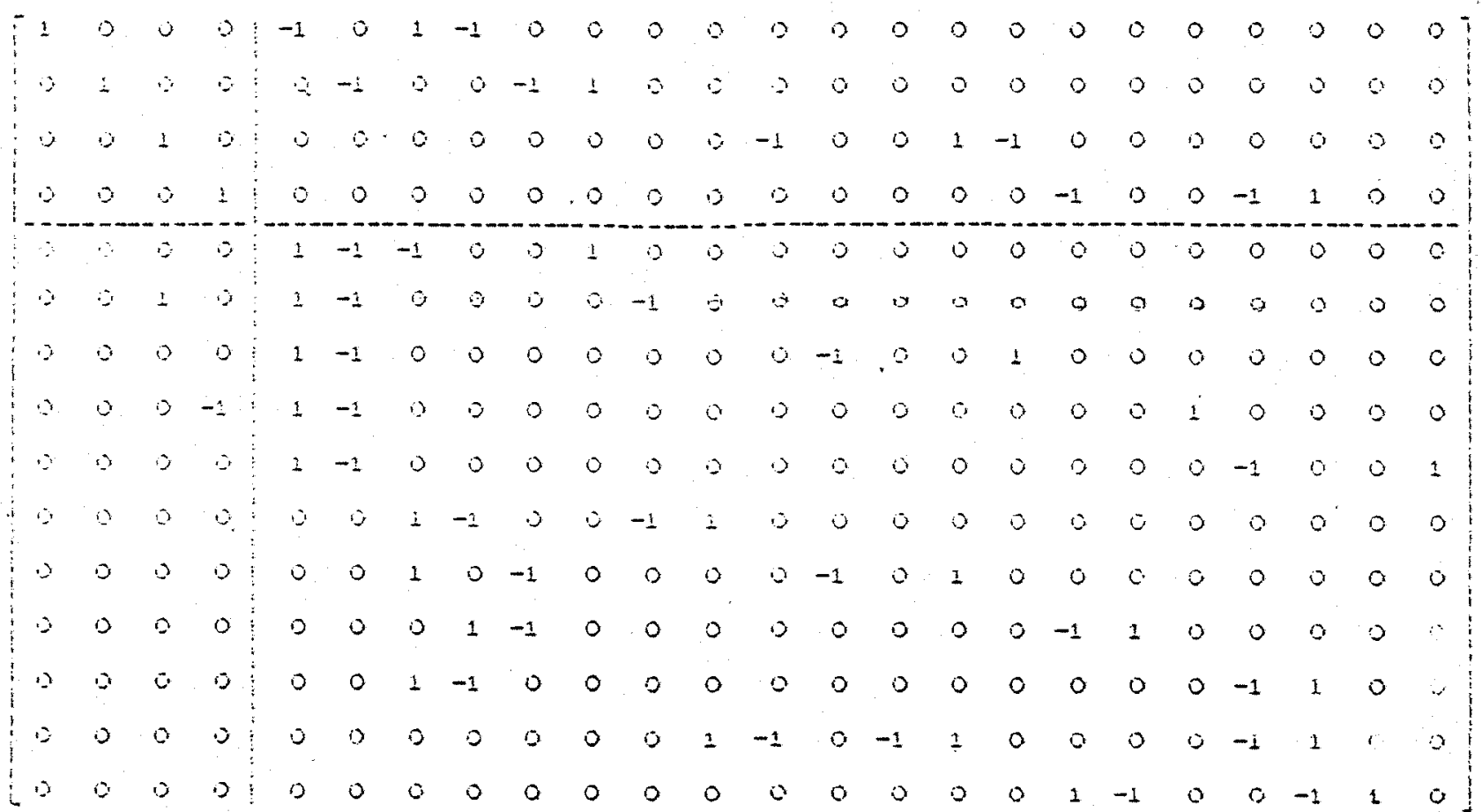

Fazendo arranjos nas linhas $\theta$ simplificando, tem-se a parti qão da matriz G.

$$
G=\left[\begin{array}{c|c}
G_{m m} & G_{0} \\
\hdashline \sigma & G_{\mathbf{E}}
\end{array}\right]
$$




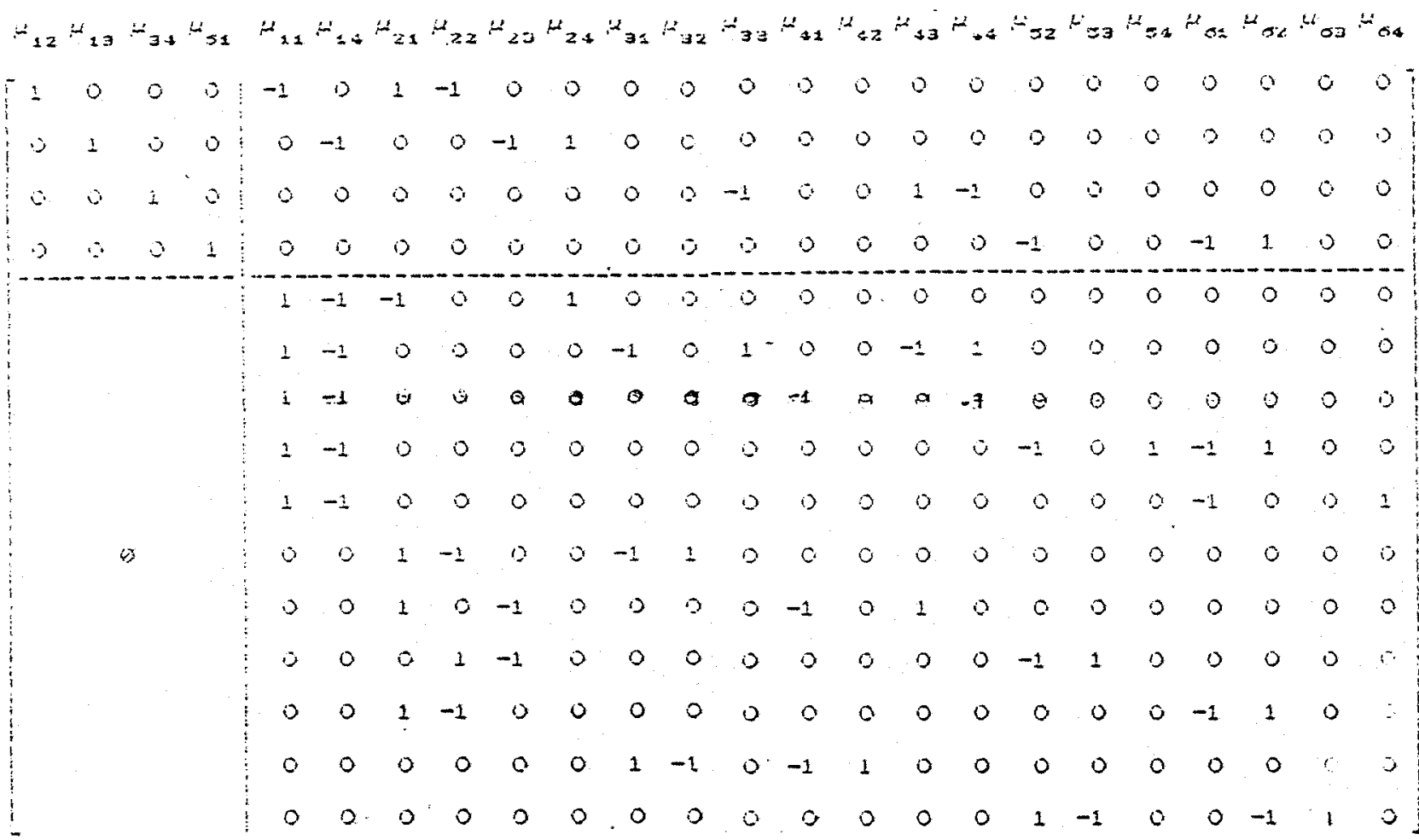

Nota-se que a matriz $\mathbf{G}_{m m}$ é não singular de posto linha completo, a que a restricão efetiva está integrada por $m-a-b+1$ combinacões possiveis dos contrastes dos tratamentos em termos das parcelas presentes, ou seja, 20-8-4+1=11, onde $m$ é o número de observaqões presentes.

Pelo modelo efetivo de médias, de acordo com Hocking o delineamento é conexo. Deste modo confirma-se o já demonstrado pelo processo R.

\section{b) No caso desconexo}

Considere-se agora o caso de perda de parcelas do delineamento desconexo apresentado anteriormente, onde sua matriz de incidência é dada por: 
FATOR B

\begin{tabular}{|c|c|c|c|c|c|c|c|}
\hline & & 1 & 2 & 3 & 4 & 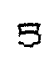 & $\theta$ \\
\hline \multirow{4}{*}{ FATOR A } & 1 & 1 & 0 & 0 & 1 & 0 & 1 \\
\hline & 2 & 0 & 0 & 0 & 1 & 0 & 1 \\
\hline & 3 & 0 & 0 & 0 & 0 & 1 & 0 \\
\hline & 4 & 0 & 1 & 1 & 1 & 0 & 1 \\
\hline
\end{tabular}

onde O representa perda de parcela.

Conforme já estabelecido, as combinacóes possiveis das médias das parcelas perdidas com respeito as parbelas presente săo:

$$
\begin{aligned}
& \mu_{12}+\mu_{41}-\mu_{11}-\mu_{42} \\
& \mu_{13}+\mu_{41}-\mu_{11}-\mu_{42} \\
& \mu_{21}+\mu_{14}-\mu_{11}-\mu_{24} \\
& \mu_{22}+\mu_{44}-\mu_{42}-\mu_{24} \\
& \mu_{23}+\mu_{44}-\mu_{43}-\mu_{24} \\
& \mu_{31}+\mu_{16}-\mu_{11}-\mu_{30} \\
& \mu_{32}+\mu_{43}-\mu_{42}-\mu_{33} \\
& \mu_{33}+\mu_{44}-\mu_{43}-\mu_{34} \\
& \mu_{15}+\mu_{24}-\mu_{12}-\mu_{25} \\
& \mu_{25}+\mu_{30}-\mu_{35}-\mu_{20} \\
& \mu_{45}+\mu_{30}-\mu_{35}-\mu_{4 \sigma} \\
& \mu_{14}+\mu_{20}-\mu_{24}-\mu_{16} \\
& \mu_{24}+\mu_{46}-\mu_{44}-\mu_{20} \\
& \mu_{34}+\mu_{45}-\mu_{44}-\mu_{35} \\
& \mu_{41}+\mu_{10}-\mu_{11}-\mu_{40}
\end{aligned}
$$

A matriz $G$ fica estruturada como segue: 


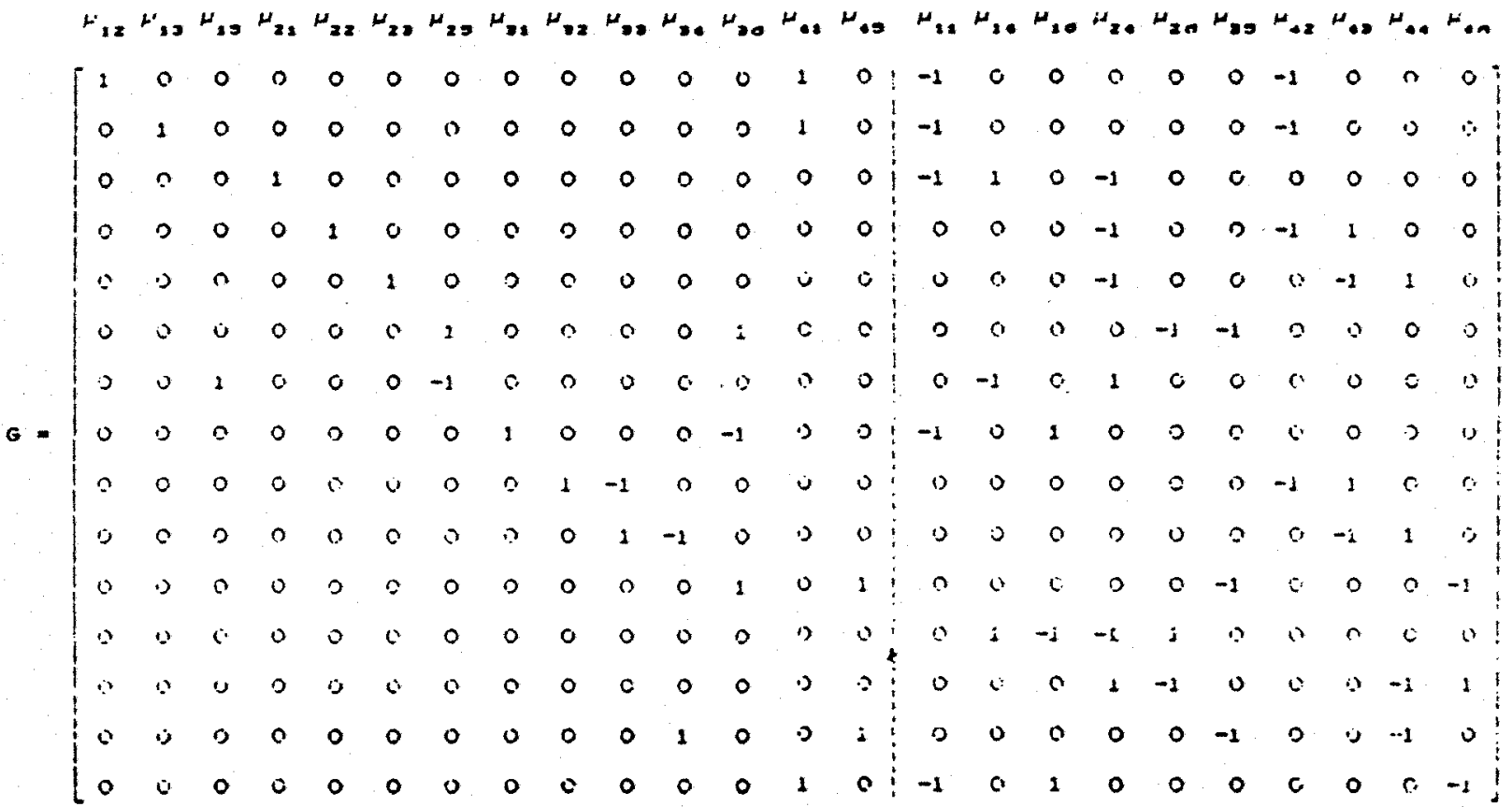

fazendo os arranjos respectivos nas linhas tem-se:

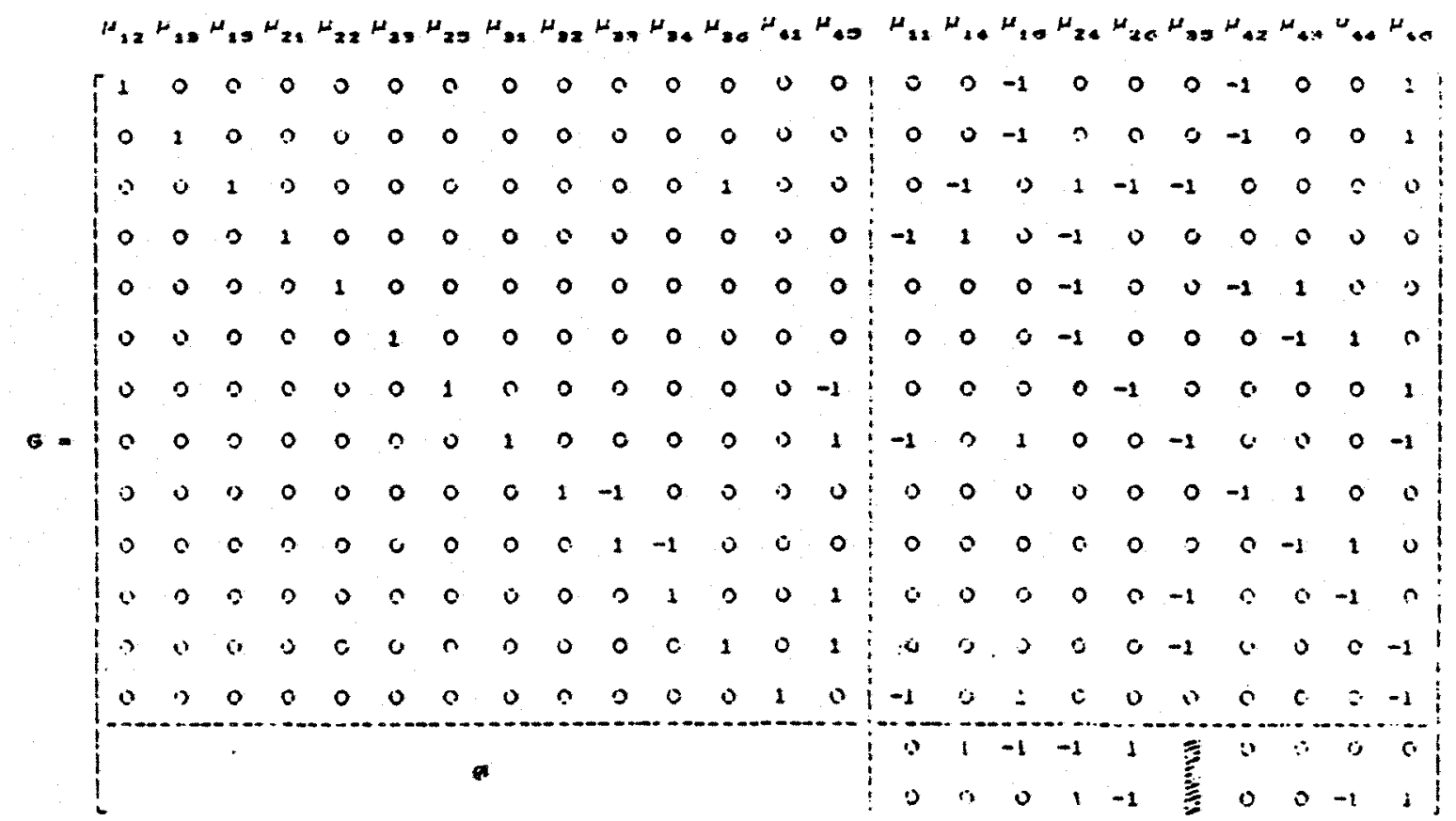


105.

Observa-se que na $G_{E}$ só se dăo os contrastes do fator A para $a_{1}-a_{2} e a_{1}-a_{4}$ confirmando-se os contrastes obtidos pelo processo R. Portando é válido o procedimento do Modelo Efetivo.

Discussăo

Nota-se no exemplo apresentado nessa secăo, que a matrie $G_{\mathrm{mm}}$ ś singular, sendo de posto incompleto igual a 13 o que indica que o delineamento é desconexo.

Na matriz dos contrastes efetivos, pode-se observar que a coluna correspondente à parcela mas é formada exclusivamente por zeros, o que indica que a média dessa parcela não é estimável e, portanto, não poderão ser efetuados os contrastes entre o nivel 3 do fator A com os demais níveis, nem poderão ser efetuados contrastes entre o nível 5 do fator $B$ com os demais niveis deste fator. Os contrastes observados para o fator A săo $\alpha_{1}-\alpha_{2} \theta \alpha_{1}-\alpha_{4}$ confirmando os já obtidos pelo método de DODGE (1985).

\section{CASO B: Um Exemplo em PBIB}

\section{Caracterizaça}

Trata-se de um látice $6 \times 6$ com 4 repeticões, cuja matriz tem a seguinte estrutura: 
FATOR B

$$
\text { FATOR A } 12\left[\begin{array}{llllll}
1 & 2 & 3 & 4 & 5 & 6 \\
1 & 0 & 1 & 1 & 0 & 1 \\
1 & 1 & 0 & 1 & 1 & 0 \\
0 & 1 & 1 & 0 & 1 & 1 \\
1 & 0 & 1 & 1 & 0 & 1 \\
1 & 1 & 0 & 1 & 1 & 0 \\
0 & 1 & 1 & 0 & 1 & 1
\end{array}\right]
$$

Considere-se perdidas as seguintes parcelas:

$(1,4),(2,2),(3,3),(3,5),(3,6),(5,2),(6,2)$, configurando a seguinte estrutura:

FATOR B

$$
\text { FATOR A } 1 .\left[\begin{array}{llllll}
1 & 2 & 3 & 4 & 5 & 6 \\
1 & 0 & 1 & 0 & 0 & 1 \\
1 & 0 & 0 & 1 & 1 & 1 \\
0 & 1 & 0 & 0 & 0 & 0 \\
1 & 0 & 1 & 1 & 0 & 1 \\
1 & 0 & 0 & 1 & 1 & 0 \\
0 & 0 & 1 & 0 & 1 & 1
\end{array}\right]
$$

\section{1) Aplicaçăo do Processo R}

Aplicando-se o Processo $R$ nesta matriz, obtémse a matriz final $M$

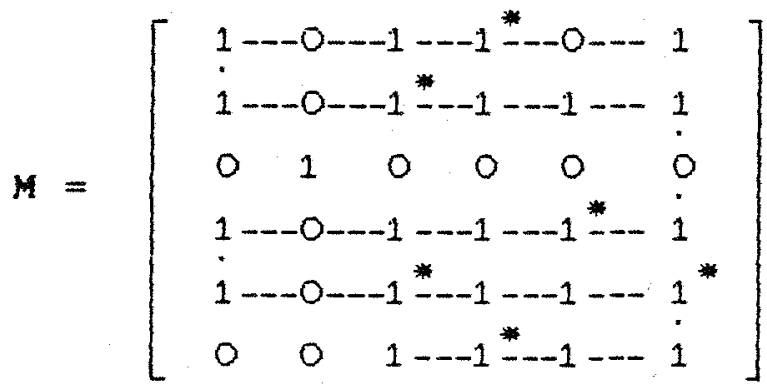


Tem-se dois grupos conexos, o que determina que o delineamento é desconexo. Assim, o primeiro grupo é formado pelas parcelas unidas pela cadeia, o segundo formado exclusi vamente pela parcela ( 3,2$)$.

Os contrastes do fator a é dado pelo triangulo contador em $\mathrm{C}_{a}$ :

$$
c_{a}=\begin{array}{l|lllll}
2 & 1 & 2 & 3 & 4 & 5 \\
3 & 0 & 0 & & & \\
1 & 1 & 1 & 0 & & \\
5 & 1 & 1 & 0 & 1 & \\
0 & 1 & 1 & 0 & 1 & 1
\end{array}
$$

Assim, um grupo de contrastes estimáveis para o fator $\alpha$ é dado por $\bar{A}=\left\{a_{1}-a_{2}, \alpha_{1}-\alpha_{4}, a_{4}-a_{5}, \alpha_{4}-a_{5}\right\rangle$ ou $\left\{\alpha_{1}-\alpha_{2}, \alpha_{2}-\alpha_{4}, \alpha_{4}-\alpha_{5}, \alpha_{5}-\alpha_{0}\right\}$

\section{2) Aplicaçăo do Modelo Efetivo de Médias}

A seguir aplica-se o Modelo Efetivo de Médias, obtendo-se o conveniente número de combinacões das médias das parcelas em funcão do número de parcelas presentes no número máximo.

Assim, se $n=38, a=6$ e $b=6$, tem-se $36-6-6+1=25$ combinacões, como segue:

$$
\begin{aligned}
& \mu_{12}+\mu_{21}-\mu_{11}-\mu_{22} \\
& \mu_{15}+\mu_{24}-\mu_{14}-\mu_{25} \\
& \mu_{22}+\mu_{05}-\mu_{02}-\mu_{20} \\
& \mu_{23}+\mu_{14}-\mu_{13}-\mu_{24}
\end{aligned}
$$


:epe Inbtjuos utsse edtJ

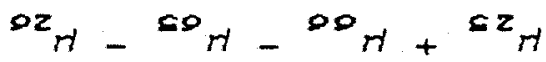

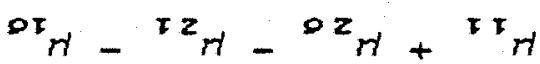

$$
\begin{aligned}
& s z_{H-t} H-\varepsilon \varepsilon_{H}+* z_{H}
\end{aligned}
$$

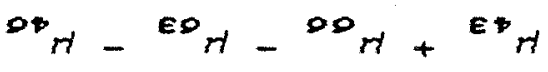

$$
\begin{aligned}
& * H-r \varepsilon_{H}-* \varepsilon_{H}+r \\
& \Delta H-H H+D H
\end{aligned}
$$

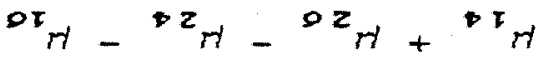

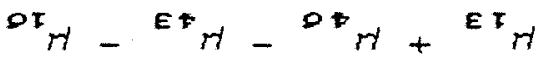

$$
\begin{aligned}
& \infty y-2 h-\infty e^{4}+\infty
\end{aligned}
$$

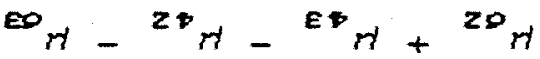

$$
\begin{aligned}
& \infty_{H-H} H-e^{H}+P_{H}
\end{aligned}
$$

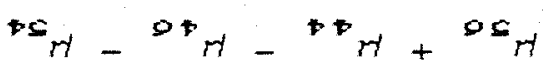

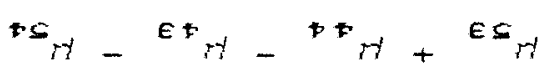

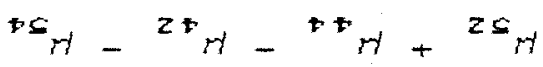

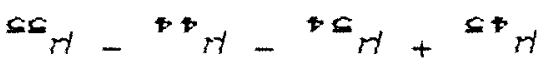

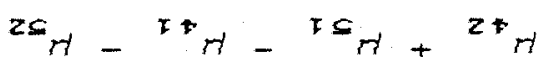

$$
\begin{aligned}
& D z_{H}-s e_{H}-s z_{H}+o e_{H} \\
& s z_{H}-\Delta \varepsilon_{H}-c z_{H}+s \varepsilon_{H} \\
& \Delta e^{H}-t_{H} H-\Delta t^{H}+E_{H}
\end{aligned}
$$

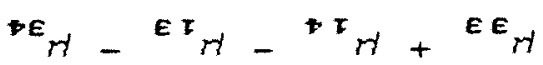

$$
\begin{aligned}
& F E_{H}-t r_{H}-t h+t_{H}
\end{aligned}
$$


109.

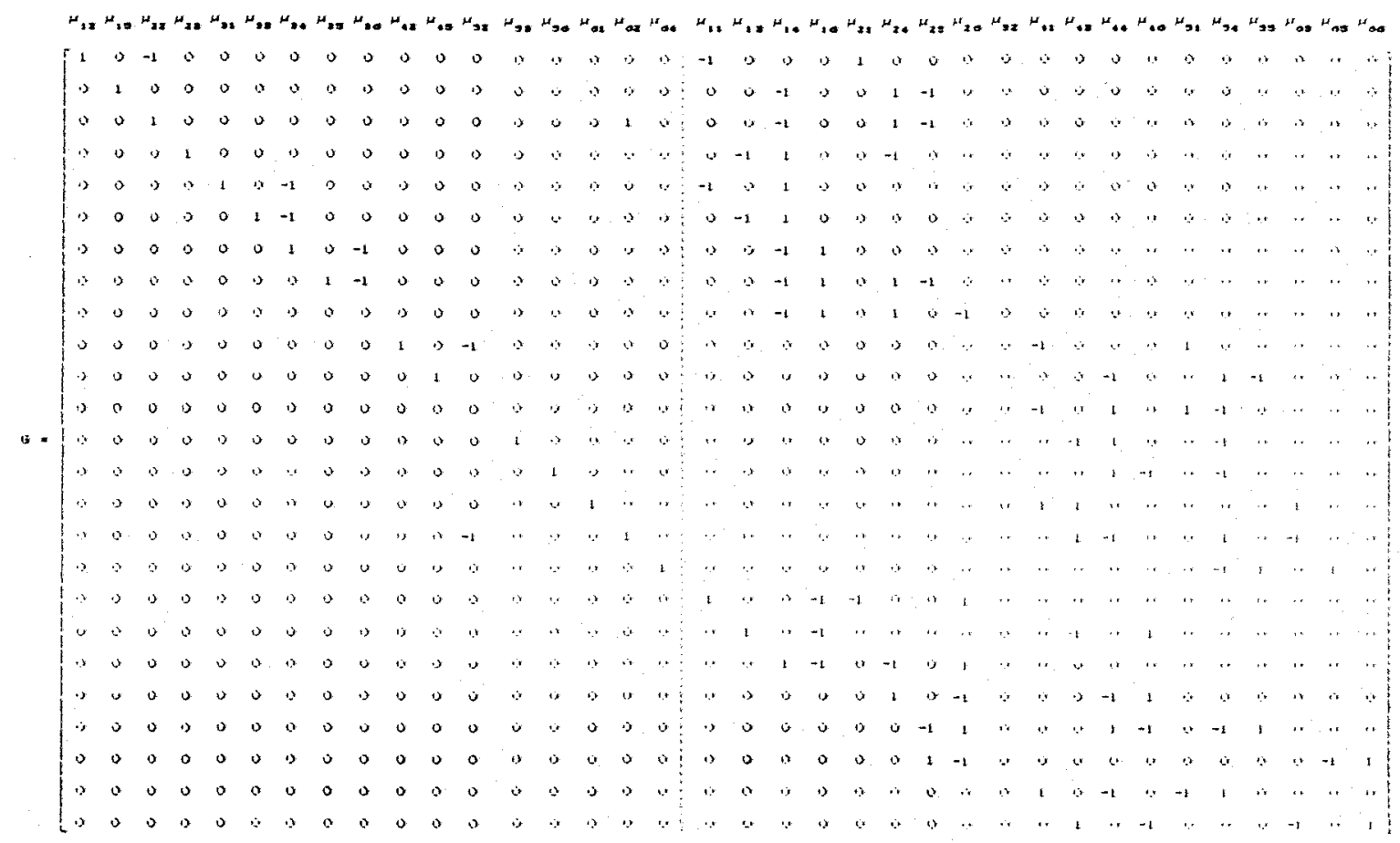

Fazendo o conveniente arrranjo nas linhas, fica: 


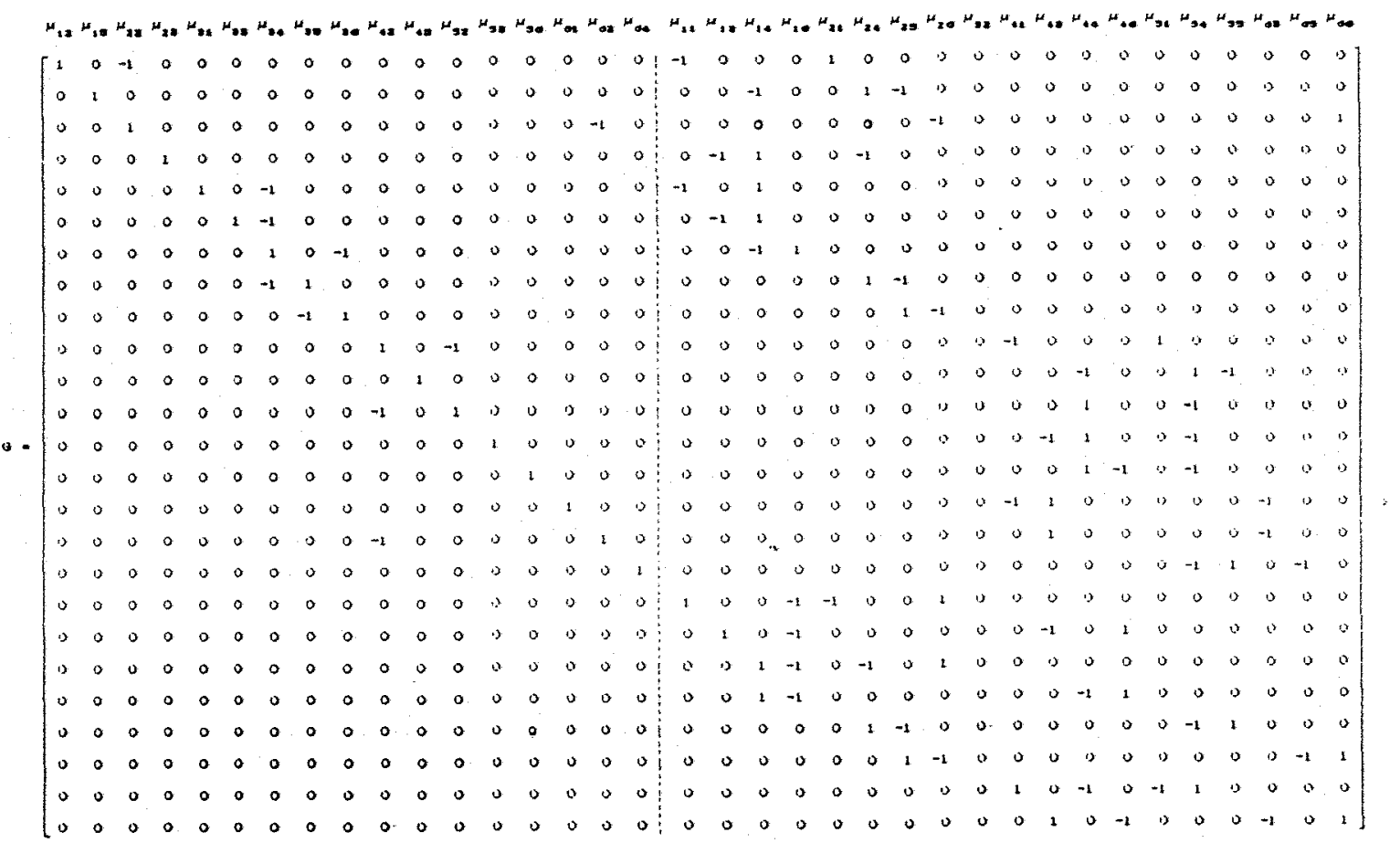

Finalmente, a matriz $G$ particionada fica como

segue:

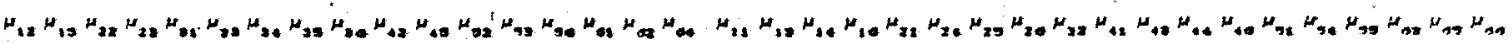

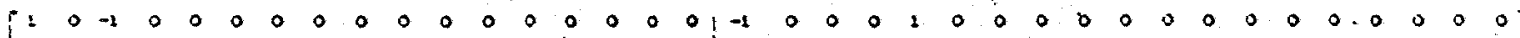

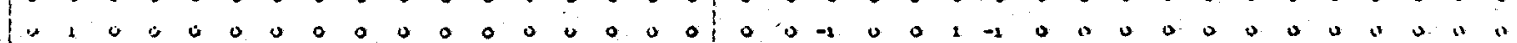

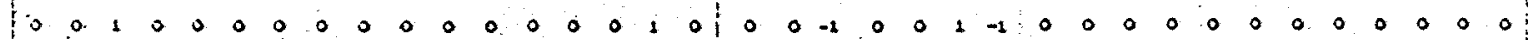

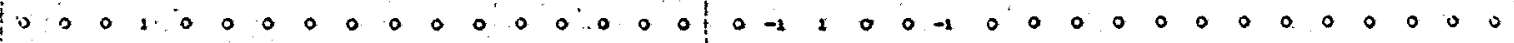

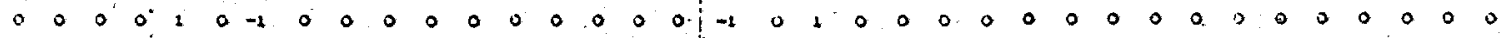

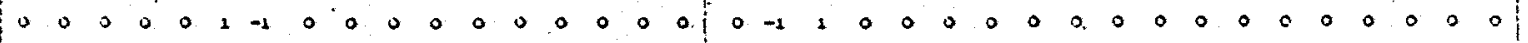

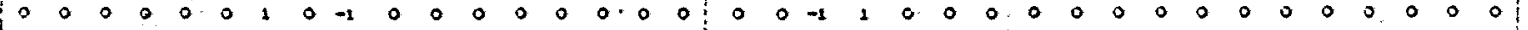

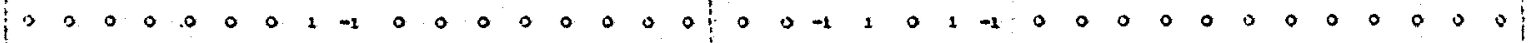

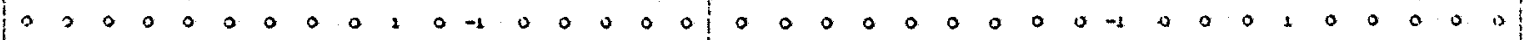

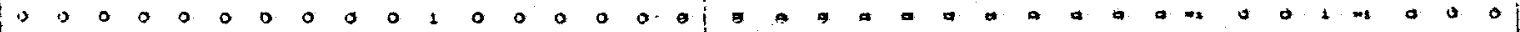

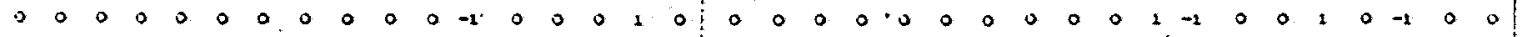

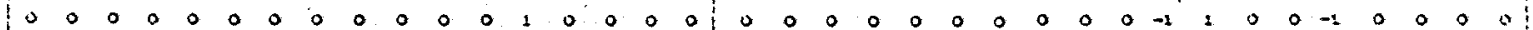


111.

Di scussão

No exemplo apresentado nesta secão, numa primeira análise, ao aplicar-se o Processo $R$ obteve-se, através do triângulo contador, os seguintes contrastes estimáveis $\alpha_{1}-\alpha_{2}, \alpha_{1}-\alpha_{4}, \alpha_{4}-\alpha_{5}$ e $\alpha_{4}-\alpha_{0}$ não podendo-se estabeler contrastes unicamente com o nivel 3 do fator $\alpha$, determinando-se que estes contrastes não são estimáveis.

Da aplicacão do Modelo Efetivo de Médias, neste exemplo, na correspondente submatriz de restricão efetiva $\mathbf{E}_{\text {' }}$ observa-se que a coluna correspondente à média da parcela $\mu_{3 z}$ é vazia, o que implica que o nivel 3 da média desta parcela não está relacionado com outros niveis das médias do fator $\alpha$. 
112.

Esta situacăo determina que o delineamento é desconexo, pois a estrutura da submatriz $G_{m m}$ não tem posto I inha completo, confirmando-se a validade dos resultados obtidos pelo Processo. R. 
113.

5. CONCLUSOES

1) A perda de parcelas determina o grau de estimabilidade dos parametros, condicionando a formulacå de testes de hipóteses que envol vem os paràmetros mencionados.

2) Uma propriedade de dados desconexos é que eles ao serem separados em dois ou mais conjuntos conexos podem ser analisados separadamente.

3) Nos delineamentos de blocos incompletos com dois fatores, uma alternativa muito eficiente de se estimar perda de parcelas consiste noestabelecimento de contrastes ortogonais entre os niveis de cada fator, prestando um valiosa contribuicão na análise de variância proporcionando os graus de liberdade para cada efeito.

4) Na situação em que a matriz de delineamento no modelo de médias seja de posto coluna completo e justificável - uso do modelo restrito para detectar estimabilidade. 
114

5) Nos casos de desconexão no modelo efetivo de médias é possivel determinar funcões paramétricas estimáveis mediante os contrastes das médias não observadas em função das médias observadas.

6) modelo efetivo de médias permite obter a est.rutura de conexăo do delineamento de forma transparente contribuindo na compreensăo dos problemas de conexao estimabilidade de funcöes estimáveis, essa metodologia poderá ser utilizada com finalidade didática.

7) No modelo aditivo de dois fatores ou modelo de DODGE (1985) a obtencão da matriz final $M$ permite obter quais das esperancas das parcelas perdidas săo estimáveis. Do mesmo modo, é possivel obter os grupos conexos da matriz $Y R$ de delineamento.

8) A determinacão do triângulo contador de cada um dos fatores gera os contrastes entre os diferentes níveis do fator $\alpha$ do fator $\beta$, que constituem uma base para - espaco vetorial de $\alpha$ e $\beta$, respectivamente. A dimensão do espaço vetorial de $\alpha$ e $\beta$, é dada pela adicão de suas bases e permite obter o posto da matriz de delineamento $\mathcal{K}$.

9) O processo $R$ é mais operativo e funcional, o que permite atuar com sucesso nos casos de grande quantidade 
115.

de dados o que não acontece com o modelo efetivo de médias, pois este algoritmo emprega maior número de passos e tempo de operacão. 
REFERENCIAS BIBLIOGRAFICAS

AITKEN, A. On least squares and linear combination of observations. Proc. Roy. Soc., Edimburgo, Série A, 55: $42-48,1935$.

ARTHANARI, T. \& DODGE, Y. Mathematical Programming in Statistical, New York, John Wiley, 1981.

BARTLEIT, M.S. Some examples of Statistical Methods of Research in Agriculture and applied biology. Journal of the Royal Statistics Society, London, 4: 137-83, 1937.

BIRKES, D. DODGE \& SEELY, J. Spanning Sets for Stimable Contrasts. The Annals of Statistics, Hayward, 4(1): 86-107, 1976.

BOSE, R. \& NAIR, K. Partially balanced incomplete block designs. Sankhyã, Calcutta, 4: 337-72, 1939.

BOSE, R. Least square aspects of the analysis of variance, Nort Carolina, Chapel Hil1, 1949. Série 9, 120p.

BOSE, R.C. Combinatorial properties of parcially balanced designs and association schemes. Sankhyã, Calcutta, Serie A, 25(2). 1963.

CHAKRABARTI, M.C. Mathematics of Design and Analysis of Experiments. London. ASIA PUBLISHNG HOUSE. 1962. 120 p. 
CHAKRABARTI, $M$. On the $C$ Matrix design of Experiments. Sankhyã, Calcutta, 1: 8-23, 1963.

COCHRAN, W. G. \& COX, G.M. Experimental Designs, New York, John Wiley \& Sons. 1957. 661p.

CORNISH, E. The estimation of missing values in incomplete randomized block experiments. Annals of Eugenees, London 10: $112-18.1940$.

COPMISH, E. The estimation of missing values in quase-fatorial designs. Annals of Eugenies, London, 10 : $137-143$, 1940 .

CRAIG RIDELL, W. M. Predition in Generalized Least. Squares. The American Statistician, Washington, $31(2)$ : 88-90, 1977 .

DAS, M. N. \& GHOSH, D.K. Balancing Incomplet Block Designs Sankhyã. Calcutta. 47: 67-77. 1985.

DODGE, $Y$. On the Connectedness of Designs. Sankhyã, Calcutta, p. 284-287. 1977.

DODGE, $Y$. Analysis of Experiments whit Missing Data. New York, John wiley, 1985. 499p.

ECCLESTON, J. \& HEDAYAT, A. On the Theory of Concepts Designs Characterization and Optimaty. American of Statistcs. Alexandria, 2: 1238-1255, 1974.

ECCLESTON. J. \& RUSSEL, K. Connectedness and Ortogonality in Multifactor Designs. Biometrika, London, 6ZC 1975. 
FEDERER, H. Experimental Design Theory and Aplication. Canada, Macmilian, 1955. 544p.

FERREIRA de CARVALHo, J. Modelos lineares e sua Avaliacăo. 1982. 95p. CTese de Livre Docencia - Instituto de ciencias Matemáticas de Săo Carlos.USP).

FISHER, R. On the mathematical foundations of theorical statistic Philophical. Transactions of the Royal Society, London, 222: 309. 1922.

FISHER, R. An examination of the different possible solution ot a problem in. Incomplete Blocks. Annals of Eugenics, London, p. 5e-75, 1940.

FOX, J. Linear Statistical Models and Related Methods with aplications to social research, New York, John Wiley \& Sons, 1984 .

FRASSER, D. Fundamentos y Tecnicas de la Inferencia Estatística, Mexico, Edit. Limusa, 1970. 404p.

GOODNIGHT, J. The sweep operator: Its importance in statistical compoting SAS IECNICAL report R-106 Raleigh: SAS INSTI TUTE, 1978 . 40p.

GRAYBILL, F. An Introduction to Linear Statistics Models. New York, Mc Graw-Hill Book Company, 1961. vol. 1, 463p.

GRAYBILL, F. Theory and Application of the Linear Models. California. Duxbury Press. 1976. 704p.

GUPTA, S.C. A basic lemma and the analysis of block and kronecker product designs. Journal of Statistical Planning and Inference, Amsterdam, 7: 407-416, 1983. 
HARTLEY, H. A plan for programming analysis of variance for general purpose computers. Biometrics, Alexandria, 12: $110-122,1956$.

HASEMAN, J. \& GAYLOR, D. An Algorithm for non-iterative estimation of multiple missing values for crossed classifications. Technometrics, Alexandria, 15: 631-636. 1973.

HEALY, M. \& WETSMACOT, M. Missing values in experiments analysed on automatic computers. Appl. Statistics, London, 5: 203-206, 1956.

HOCKING, R.R. The Analysis of Linear Models. Monterey. California Brooks/Cole Publishing. 1985. 384p.

HOCKING, R.R.; SPEED, F.M. \& COLEMAN, A. T. Hipotheses to be tested Whit Unbalanced Data. Communications An Statistcs Theory and Madison, A9(2): 117-129. 1980.

HOFFMANN, R. \& VIEIRA, S. Análise de Regressão: Uma Introducão à Econometria. $2^{a}$ edicăo, São Paulo, Ed. Hucitec, 1983. $379 p$.

IEMMA, A.F. Modelos Lineares: uma Introducão para Profissionais da Pesquisa Agropecuária. Londrina. FUEL/Depto. de Matemática Aplicada. 1987. 263p.

IEMMA. A.F. Uma introdução algebra de Matrizes. Piracicaba, ESALQ USP, $1989.118 p$.

JOHN, J.A. \& QUENOUILLE, M. H. Experiments: Designs and Analysis. 2 ed. London. Charles Griffin \& Company. 1977. $296 p$.

JOHN, P.W. Statistics Designs and Analysis of Experiments. Mac Millan. 1971. 355p. 
JOHN, P.W. Incomplete Block Designs. New York, Marcel Deckker Inc. $1980.101 \mathrm{p}$.

KAGEYAMA, S. Connectedness of two Associate PBIB Designs. Journal of Statistical Planning and Inference, dmsterdam, $7: 77-8 \mathrm{Z}, 1982$.

KAGEYAMA, S. A Note on A Efficiency of Connected designs. Journal of Statistical PIanning and Inference, Amsterdam, 20: $221-224,1988$.

KEMPTHORNE, o. The eficiency factor of an incomplete block design. Annals of Mathematic Statistic, Baltimore, 27 : $846-849,1956$.

KSHIRSAGAR, A. Linear Models. New York. Marcel Dekker. 1983. $421 \mathrm{p}$.

LI, C.C. Analysis of unbalanced data. A Pre-Program Introduction, New York, Cambridge University Press, 1982.

MEDINA, V.M. \& IEMMA, A.F. Estimabilidade de contrastes em delineamentos desconexos. In: Simpósio de Estatistica Aplicada a Experimentação Agronômica, 3.; Reunião Anual da Região brasileira da Sociedade Interniafional de Biometria, 34 Lavtas, 1989. Resumos. Lavras, ESAL, 1989. p. 31 .

MILLIKEN, G. \& JOHNSON, D. Analysis Missing Data. New York, Van Nostrand Reinhold Company. 1984. 472p.

MURRAY, L. \& SMITH, D. Estimability. Testability and Connectedness in the Cell Means Models. Comm. Static. Theory Methods, New York, 1468): 1899-1917. 1985. 
MURRAY, L. Missing Cell Estimate in the Randomized Block Designs with Randon Effects. American Statistical Association, Washington, 42(2): 134-136. 1988.

MURRAY, L. A Note on Connectedness in Fixed Effects Manova and $G$ Manova Models with Missing Cells. Comm. Estatist. Theory Meth., New York, 18(7): 2527-31, 1989.

NAIR, K. \& RAO, C. A note unparcially balanced incomplete block designs science and culture calcutta, 7: 568-69, 1942 .

MELDER, I. A. A note on missing plot values. Biometrics, Raleigh, 10: 400-401, 1954.

NETER, J. \& WASSERMAN, W. Applied Linear Statistical Models. Richard $v$. Irwin Inc. 1974. $481 \mathrm{p}$.

NEYMAN, J. \& DAVID, F. Extension of the markof theorem on least squares. Statistical Research Memoin, London, 2 : $105-116,1938$.

NORTON, H. A further note on missing data. Biometrics, Raleigh, 11: 110. 1955.

PARZEN, E. An approach to time series analysis. Ann. Math. Statistics An Arbor, 32: $951-989.1961$.

PLACKETI, R.L. A historical note on the method of least squares. Biometrika, London, 36: 458-60, 1949.

PLACKETI, R.L. Some theorems in least squares. Biometrics, London, 37: 149-157, 1950.

RAGHAVARAO, D. Construction and Combinatorial Problems in Designs of Experiments. New York, John Wiley. 1971. 386p. 
RAGHAVARAO, D. \& FEDERER, $W$. On connectedness in two way elimination of Heterogeneity Designs. The Annais of Statistical. vol. $3 n^{2} 3.1975$. p. $730-735$.

RAO, G.R. Markof's theorem with linear restructions on parameters. Sankhỹa, Calcutta, 7: 16-19, 1945.

RAO, C.R. Generalization of markof:'s theorem and tests of linear hipothesis. Sankhỹa, Calcutta, 7: 9-16, 1945.

Roo, C.R. On the linear combination of observations and the general theory of least squares. Sankhÿi, calcutta, $7630: 237-249,1940$.

RAO, C.R. A note on a generalized inverse of a matrix with applications to problems in mathematical statistic. J. Royal Statist. Soc., 24: 152-158, 1962.

RAO, C.R. Linear Statistical Inference and its Applications. $2^{\circ}$ ed., New York, John Wiley \& Sons. 1973. 6e5p.

RAO, C.R. A note on Bal anced Designs. Annals of Mathematical of Estatistic, Hayward, 29: 290-294, 1958.

RIBOLDI, J. A Decomposicão da Soma de Quadrados de Iratamentos nos Delineamentos de Blocos Incompletos Parcialmente Balanceados. Piracicaba, 1988. 165p. CDoutorado Escola Superior de Agricultura "Luiz de Queiroz"/USP).

RUBIN, D. A non iterative algorithm for least squares estimation of missing values in any analysis of variance design. Applied Statistic, London, 21: 136-141. 1972.

SARRIES, G. A. Sistema SABI: Manual do Usuário. Piracicaba, USP/PGP/CIAGRI , $1988 \mathrm{a}$. 
SCHEFFÉ, $H$. The analysis of variance. New York, Wiley Publication in Statistic, 1959. 477p.

SEARLE, S.R. Linear Models. New York, John Wiley. 1971. 532p.

SEARLE, S.R. Matrix Algebra Useful for Statistcs. New York, John Wiley \& Sons. 1982. 438 p.

SEARLE, S.R. Linear Models for Unbalanced Data. New York, John Wiley, 1987 . 536p.

SEELEY, I. \& EIRKES, D. Estimability in Fartitioned Linear Models. The Annais of Statistics, 8C25: 399-400. 1980.

SHAH, K.R. \& DODGE, Y. On Connectedness of Designs. Sankhyă, Calcutta, 39: 284, 1977.

SHRIKHANDE, S. \& RAGHAVARAO, D. A method of construction of Incomplete block designs. Sankhyã, Calcutta, 25: 399-40e, 1963.

SIA, L. Some Properties of Connectedness in two-ways Designs. Comm. Statistics. Theory Methods. 6(12): 1165-1169. 1977 .

SPEED, F.; HOCKING, R. \& HACKEY, P. Method of Analise on Balanced dates the Models Lineares. Journal of the American Statistical Association, Boston, 736361$)$ Sec. Teory and Methods: $105-111.1978$.

STEMBERG, D.M. \& HUNTER, H.G. Blocks of Designs. Technometrics, Alexandria, 26(2): 84-85. may, 1984.

TAYLOR, J. Errors of treatment comparisons when observations are missing. Nature, London, 62: 262-263, 1948. 
THEIL, H. Principles of Ecometrics. New York, John Wiley \& Sons, 1971 . 736p.

THOMPSON, H. Extensions to missing plot techniques. Biometrics, Raleigh, 12: 241-249, 1956.

TOCHER, K.D. The desingn and analysis of block experiments. Journal of the Royal Statistics Society, 14(1): 45-100, 1952.

MEEKS, D.L. \& WILLIAMS D.R. A note on the determination of connechedness in an n-way cross classification. Technometrics, Raleigh, 7: 281, 1904.

WILKINSON G. Estimation of missing values for the analysis of incomplete data Biometrics. Raleigh $14: 257,286.1958$.

WISHART, J. \& SANDERS, M. Principles and practice of field: Experimentation. Commonweath Agricultural Bureaux, Cambridge Engl and, 125p. 1958.

YATES, F. The analysis of replicated experiments when the field results are incomplete. Empire Journal Experiments Agriculture, London, 1: $129-142,1933$.

YATES, $F$. The analysis of multiple classifications with unequal number in the diferent classes. American Statistical Association, Washington, 2: 51-66, 1934.

YATES, $F$. A new method of arranging variety trials involving a large number of varieties. Journal Agricultural Science, Cambridge, 26: 424-455, 1936.

YATES, F. Experimental Design: Selected Papers of yates. Edit. Charles Greffin. 1970. 
125.

ZYSKIND, G. \& MARTIN, F. On Best Linear estimation and a general Gauss Markov Theorem in Linear models with arbitrary non negative covariance structure. SIAM $J$. Appl. Math. 17(6): 1190-1202. 1969. 